\title{
₹USGS
}

science for a changing world

Methods of Analysis by the U.S. Geological Survey National Water Quality Laboratory-Determination of Polycyclic Aromatic Hydrocarbon Compounds in Sediment by Gas Chromatography/Mass Spectrometry

Water-Resources Investigations Report 03-4318
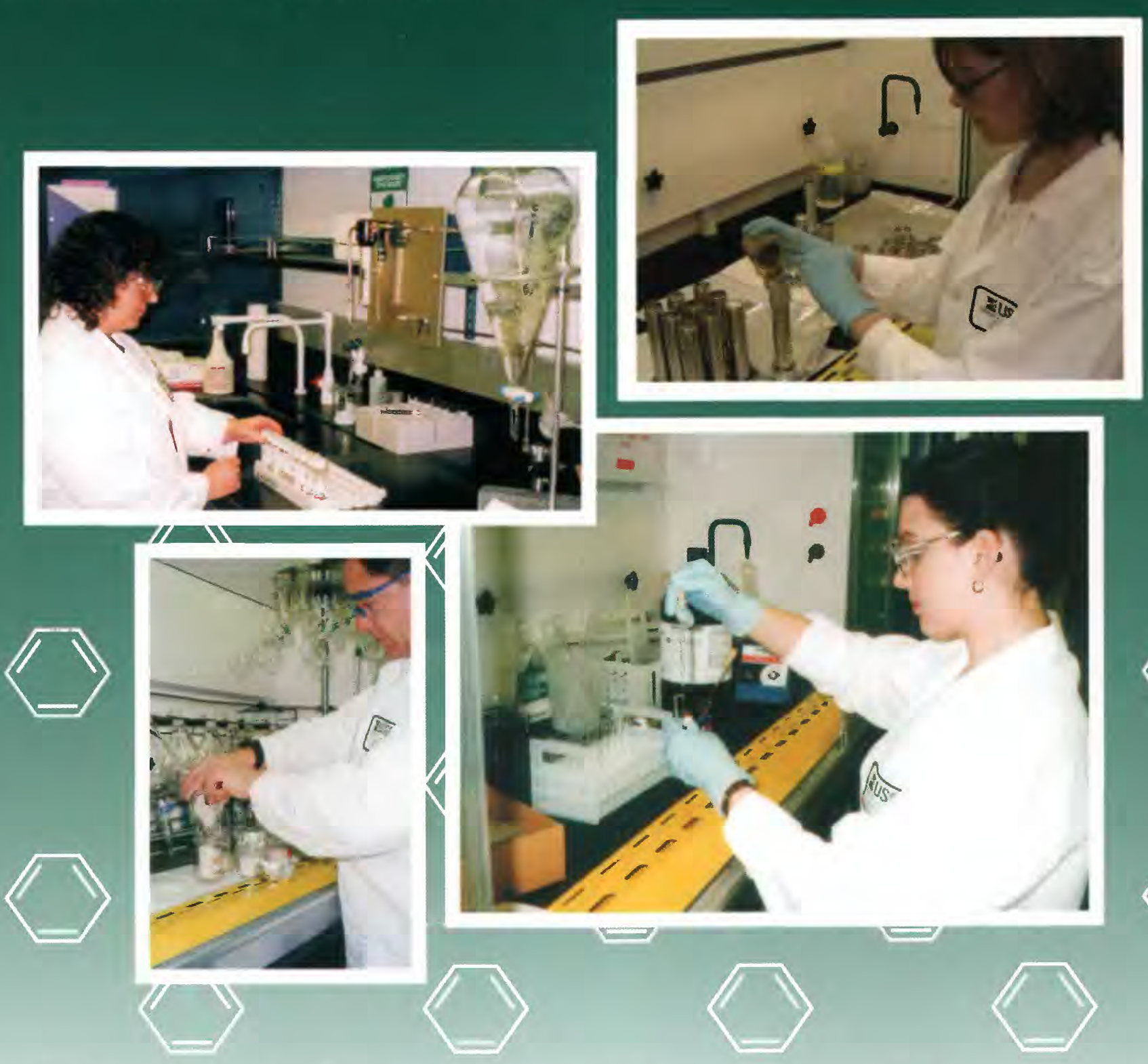

\}
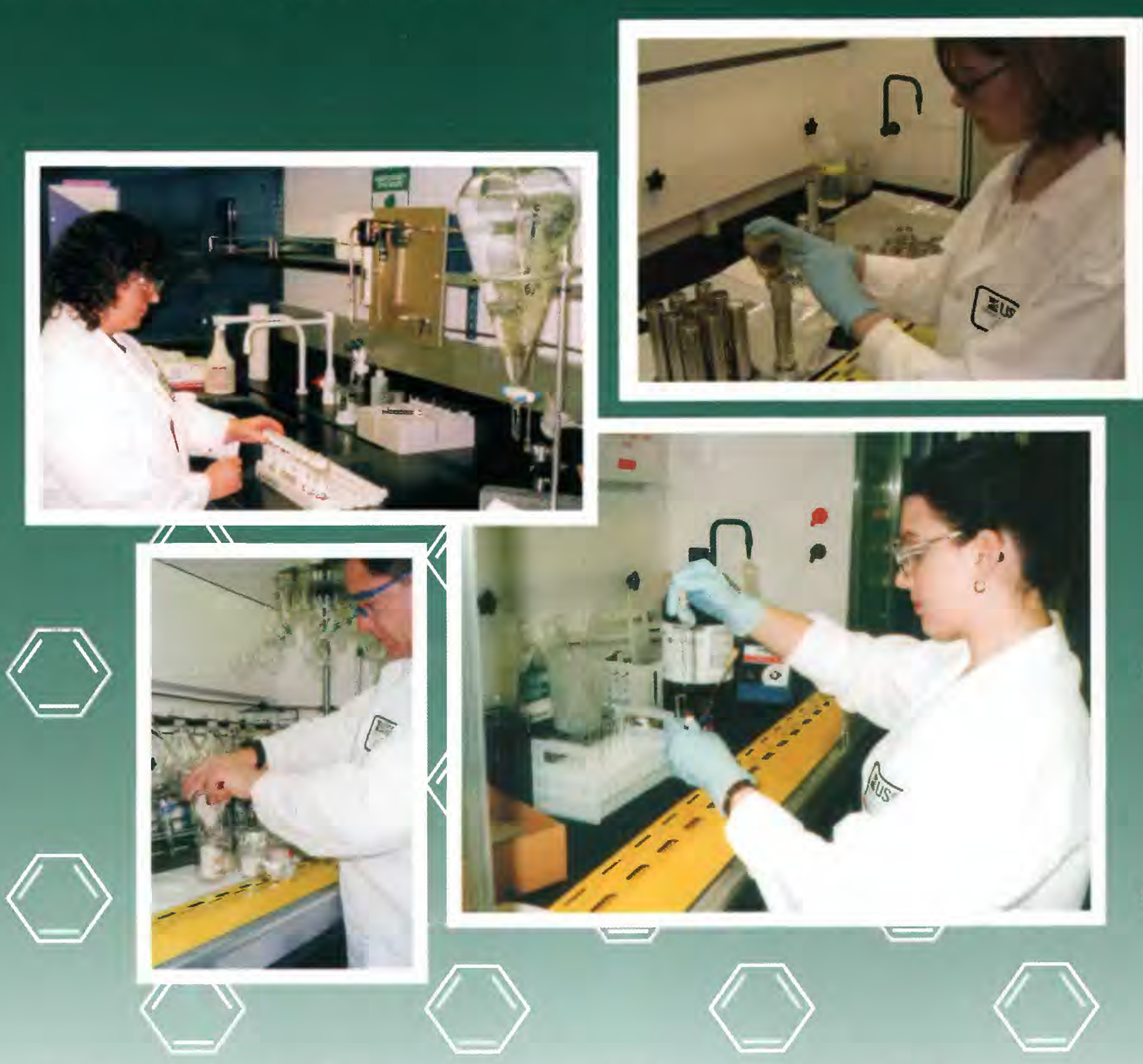

.
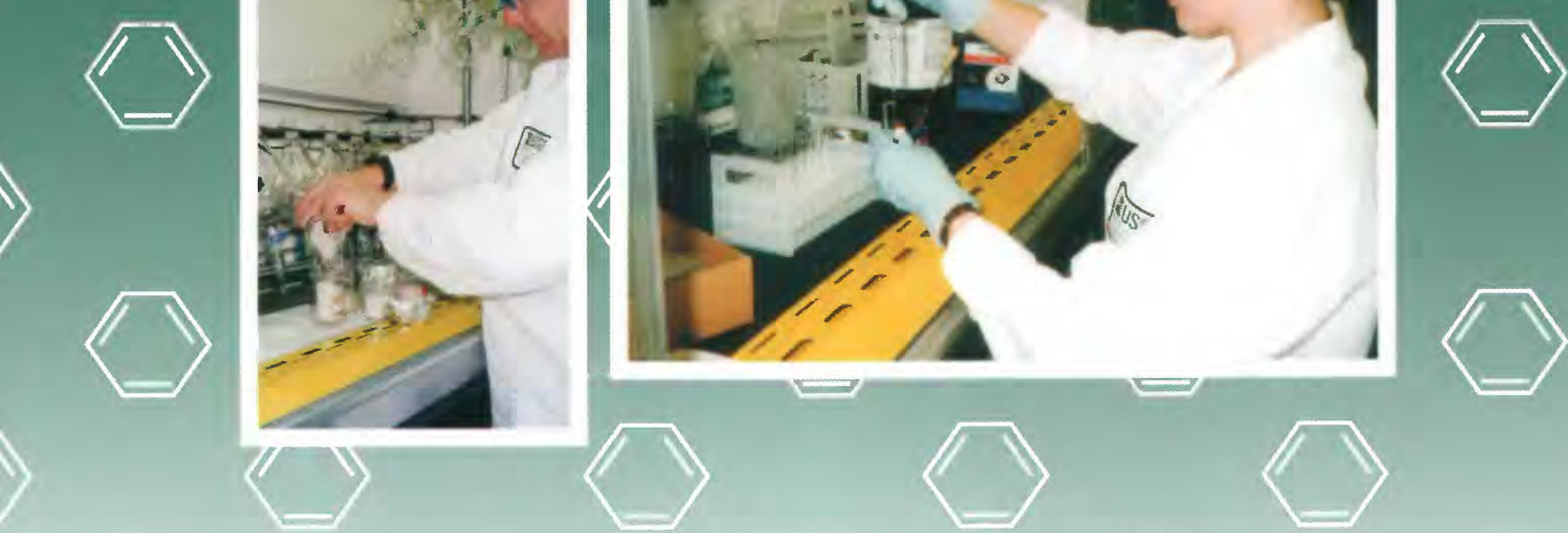

U.S. Department of the Interior U.S. Geological Survey 


\section{Methods of Analysis by the U.S. Geological Survey \\ National Water Quality Laboratory-Determination of Polycyclic Aromatic Hydrocarbon Compounds in Sediment by Gas Chromatography/Mass Spectrometry}

By Mary C. Olson, Jana L. Iverson, Edward T. Furlong, and Michael P. Schroeder

Water-Resources Investigations Report 03-4318

U.S. Department of the Interior

U.S. Geological Survey 


\title{
U.S. Department of the Interior
}

Gale A. Norton, Secretary

\author{
U.S. Geological Survey \\ Charles G. Groat, Director
}

U.S. Geological Survey, Denver, Colorado: 2004

For sale by U.S. Geological Survey, Information Services

Box 25286, Denver Federal Center

Denver, CO 80225

For more information about the USGS and its products:

Telephone: 1-888-ASK-USGS

World Wide Web: http://www.usgs.gov/

Any use of trade, product, or firm names in this publication is for descriptive purposes only and does not imply endorsement by the U.S. Government.

Although this report is in the public domain, permission must be secured from the individual copyright owners to reproduce any copyrighted materials contained within this report. 


\section{Contents}

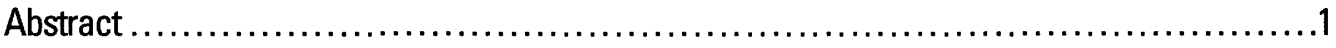

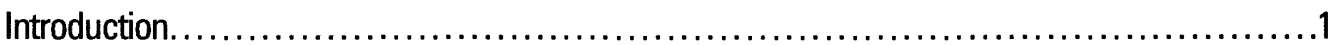

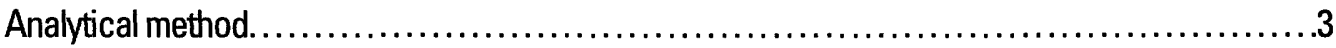

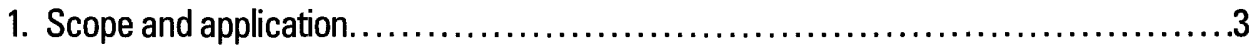

2. Summary of method.................................................... 4

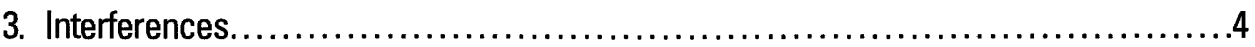

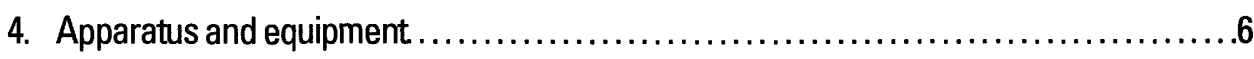

5. Reagents and consumable materials ........................................ 7

6. Safety precautions ......................................................

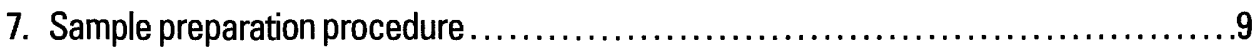

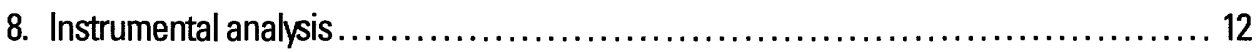

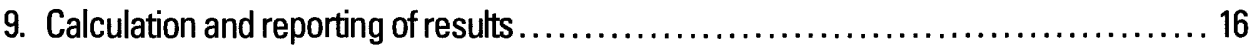

10. Quality assurance and quality control.................................... 17

11. Method performance. ................................................. 20

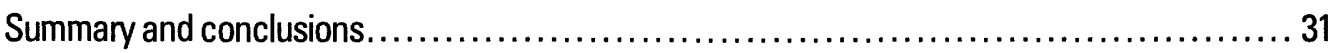

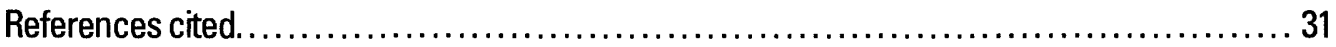

Attachment 1: Determination of polycyclic aromatic hydrocarbons in sediment by

gas chromatography/mass spectrometry using selected-ion monitoring ............ 33

\section{Figures}

1. Flowchart showing polycyclic aromatic hydrocarbons, organophosphate pesticides, and organochlorine pesticides

2. Graphs showing quantitation and monitor ions in the homolog series for the isomeric parent polycyclic aromatic hydrocarbons phenanthrene/anthracene in a sample ....

\section{Tables}

1. Individual polycyclic aromatic hydrocarbon compounds determined using this method ...3

2. Alkylated polycyclic aromatic hydrocarbon homolog groups determined using this method and reported permanently as estimated...

3. Suggested gel permeation chromatography processing sequence $\ldots \ldots \ldots \ldots \ldots \ldots 12$

4. Retention times, relative retention times, gas chromatography/mass spectrometry quantitation ions, confirmation ions, and percent relative abundance of confirmation ions for individual polycyclic aromatic hydrocarbons (PAHs) and alkylated PAH homolog groups.

5. Gas chromatography/mass spectrometry analytical sequence suggested for use in this method.

6. Relative response factors used for the quantitation of alkylated polycyclic aromatic hydrocarbon homolog series

7. Bias and precision data of polycyclic aromatic hydrocarbon spike recoveries for seven replicates using full-scan acquisition with compound concentrations of 4.8, 12.0 , and 24.0 micrograms per kilogram in three matrices 
8. Polycyclic aromatic hydrocarbon matrix background concentrations in full-scan acquisition.

9. Recovery of semivolatile organic compounds from Evergreen Lake sediment samples spiked at 800 micrograms per kilogram ........................26

10. Recovery of semivolatile organic compounds from Evergreen Lake sediment samples spiked at 2,000 micrograms per kilogram

11. Recovery of semivolatile organic compounds from Mississippi River sediment samples spiked at 400 micrograms per kilogram ........................28

12. Polycyclic aromatic hydrocarbon concentrations certified by the National Institute of Standards and Technology for Standard Reference Material $1941 \mathrm{~b}$ and determined using this method.

13. Alkylated polycyclic aromatic hydrocarbon homolog group concentrations detected in Standard Reference Material 1941b not reported by the National Institute of Standards and Technology and determined using this method

14. Polycyclic aromatic hydrocarbon concentrations certified by the National Institute of Standards and Technology for Standard Reference Material 1944 and determined using this method

15. Alkylated polycyclic aromatic hydrocarbon homolog group concentrations detected in Standard Reference Material 1944 not reported by the National Institute of Standards and Technology and determined using this method

16. Bias and precision data of polycyclic aromatic hydrocarbon spike recovenies for seven replicates using selected-ion monitoring acquisition with compound concentrations of 4.8, 12.0, and 24.0 micrograms per kilogram in three matrices

17. Polycyclic aromatic hydrocarbon matrix background concentrations in selected-ion monitoning.

18. Polycyclic aromatic hydrocarbon method spike recoveries using selected-ion monitoring at a concentration of 24 micrograms per kilogram for year 2000

19. Polycyclic aromatic hydrocarbon concentrations certified by the National Institute of Standards and Technology for Standard Reference Material 1941b and determined using selected-ion monitoring .....

20. Alkylated polycyclic aromatic hydrocarbon homolog groups detected in Standard Reference Material $1941 \mathrm{~b}$ not reported by the National Institute of Standards and Technology and determined using selected-ion monitoring

21. Polycyclic aromatic hydrocarbon concentrations certified by the National Institute of Standards and Technology for Standard Reference Material 1944 and determined using selected-ion monitoring

22. Alkylated polycyclic aromatic hydrocarbon homolog groups detected in Standard Reference Material 1944 not reported by the National Institute of Standards and Technology and determined using selected-ion monitoring ...........43

23. Polycyclic aromatic hydrocarbon concentrations detected in Certified Reference Material 354 using selected-ion monitoring for year 2001

24. Statistics for selected-ion monitoring and full-scan acquisition data fortified at 12.0 micrograms per kilogram 


\section{Conversion Factors}

\begin{tabular}{lcl}
\hline \multicolumn{1}{c}{ Multiply } & By & \multicolumn{1}{c}{ To obtain } \\
\hline centimeter $(\mathrm{cm})$ & Length & \\
meter $(\mathrm{m})$ & $3.94 \times 10^{-1}$ & inch \\
micrometer $(\mu \mathrm{m})$ & $3.28 \times 10^{-0}$ & foot \\
millimeter $(\mathrm{mm})$ & $3.94 \times 10^{-5}$ & inch \\
nanometer $(\mathrm{nm})$ & $3.94 \times 10^{-2}$ & inch \\
\hline & $3.94 \times 10^{-8}$ & inch \\
\hline gram $(\mathrm{g})$ & Mass & \\
microgram $(\mu \mathrm{g})$ & $3.53 \times 10^{-2}$ & ounce, avoirdupois \\
nanogram $(\mathrm{ng})$ & $3.53 \times 10^{-8}$ & ounce, avoirdupois \\
picogram $(\mathrm{pg})$ & $3.53 \times 10^{-11}$ & ounce, avoirdupois \\
\hline & $3.53 \times 10^{-14}$ & ounce, avoirdupois \\
\hline liter $(\mathrm{L})$ & Volume & \\
microliter $(\mu \mathrm{L})$ & $3.38 \times 10^{-1}$ & ounce, fluid \\
milliliter $(\mathrm{mL})$ & $3.38 \times 10^{-5}$ & ounce, fluid \\
\hline & $3.38 \times 10^{-2}$ & ounce, fluid \\
\hline kilopascal $(\mathrm{kPa})$ & Pressure & \\
\hline
\end{tabular}

Temperature in degrees Celsius $\left({ }^{\circ} \mathrm{C}\right)$ may be converted to degrees Fahrenheit $\left({ }^{\circ} \mathrm{F}\right)$ as follows:

$$
{ }^{\circ} \mathrm{F}=\left(1.8 \times{ }^{\circ} \mathrm{C}\right)+32
$$

\section{ABBREVIATED WATER-QUALITY UNITS}

${ }^{\circ} \mathrm{C}$ degree Celsius

${ }^{\circ} \mathrm{C} / \mathrm{min}$ degree Celsius per minute

$\mathrm{g} /$ mole gram per mole

$\mu \mathrm{g} / \mathrm{kg} \quad$ microgram per kilogram (parts per billion)

$\mathrm{mg} / \mathrm{kg} \quad$ milligram per kilogram

$\mathrm{mg} / \mathrm{L} \quad$ milligram per liter

$\mathrm{mL} / \mathrm{min}$ milliliter per minute

$\mathrm{ng} / \mu \mathrm{L} \quad$ nanogram per microliter

$\mathrm{pg} / \mathrm{\mu L} \quad$ picogram per microliter

\section{ABBREVIATIONS AND ACRONYMS}

ACS American Chemical Society

amu atomic mass unit

ASMB Alberta Sweet Mix Blend

CAS Chemical Abstracts Service

CRM Certified Reference Material

CCV continuing calibration verification solution

DFTPP decafluorotriphenylphosphine

dPAH perdeuterated polycyclic aromatic hydracarbon

dPAHIS perdeuterated polycyclic aromatic hydrocarbon internal standard 
ERL

eV

FEP

FS

GC

GC/MS

GC/MS/MS

GPC

HPLC

ID

IDL

IS

K-D

LRB

LRS

MDL

MRL

MS

MSD

MSDS

$\mathrm{m} / \mathrm{z}$

NAWQA

N-Evap

NIST

no.

NWIS

NWOL

OC

OP

$\mathrm{PAH}$

PCBs

PTFE

QA/OC

OC

rpm

RRF

RRT estimated reporting limit

electron volts

fluorinated ethylene propylene

full-scan ion monitoring

gas chromatographic (or gas chromatograph)

gas chromatography/mass spectrometry

gas chromatography/mass spectrometry/mass spectrometry

gel permeation chromatography

high-performance liquid chromatography

internal diameter

instrument detection limit

internal standard

Kuderna-Danish

laboratory reagent blank

laboratory reagent spike

method detection limit

minimum reporting level

mass spectrometric (or mass spectrometer)

mass selective detector

Material Safety Data Sheets

mass-to-charge ratio

National Water-Quality Assessment Program

nitrogen gas evaporator

National Institute of Standards and Technology

number

National Water Information System

National Water Quality Laboratory

organochlorine

organophosphate

polycyclic aromatic hydrocarbon

polychlorinated biphenyls

polytetrafluoroethylene

quality assurance/quality control

quality control

revolutions per minute

relative retention factor

relative retention time 


$\begin{array}{ll}\text { RSD } & \text { relative standard deviation } \\ \text { SIM } & \text { selective-ion monitoring } \\ \text { SRM } & \text { Standard Reference Material } \\ \text { TPC } & \text { third-party check solution } \\ \text { USEPA } & \text { U.S. Environmental Protection Agency } \\ \text { USGS } & \text { U.S. Geological Survey } \\ \text { UV } & \text { ultraviolet } \\ \text { Wt. } & \text { weight } \\ \pm & \text { plus or minus } \\ < & \text { less than } \\ \leq & \text { less than or equal to } \\ \text { percent RSD } & \text { percent relative standard deviation }\end{array}$





\title{
Methods of Analysis by the U.S. Geological Survey National Water Quality Laboratory-Determination of Polycyclic Aromatic Hydrocarbon Compounds in Sedimen* by Gas Chromatography/Mass Spectrometry
}

\author{
By Mary C. Olson, Jana L. Iverson, Edward T. Furlong, and Michael P. Schroeder
}

\section{Abstract}

A method for the determination of 28 polycyclic aromatic hydrocarbons (PAHs) and 25 alkylated $\mathrm{PAH}$ homolog groups in sediment samples is described. The compounds are extracted from sediment by solvent extraction, followed by partial isolation using high-performance gel permeation chromatography. The compounds are identified and quantitated using capillary-column gas chromatography/mass spectrometry. The report presents performance data for full-scan ion monitoring. Method detection limits in laboratory reagent matrix samples range from 1.3 to 5.1 $\mu \mathrm{g} / \mathrm{kg}$ for the $28 \mathrm{PAHs}$. The 25 groups of alkylated PAHs are homologs of five groups of isomeric parent PAHs. Because of the lack of authentic standards, these homologs are reported semiquantitatively using a response factor from a parent $\mathrm{PAH}$ or a specific alkylated PAH. Precision data for the alkylated PAH homologs are presented using two different standard reference materials produced by the National Institute of Standards and Technology: SRM 1941b and SRM 1944. The percent relative standard deviations for identified alkylated PAH homolog groups ranged from 1.55 to 6.98 for SRM $1941 \mathrm{~b}$ and from 6.11 to 12.0 for SRM 1944. Homolog group concentrations reported under this method include the concentrations of individually identified compounds that are members of the group.

Organochlorine (OC) pesticides-including toxaphene, polychlorinated biphenyls (PCBs), and organophosphate (OP) pesticides-can be isolated simultaneously using this method.

In brief, sediment samples are centrifuged to remove excess water and extracted overnight with dichloromethane ( 95 percent) and methanol ( 5 percent). The extract is concentrated and then filtered through a 0.2-micrometer polytetrafluoroethylene syringe filter. The PAH fraction is isolated by quantitatively injecting an aliquot of sample onto two polystyrene-divinylbenzene gel-permeation chromatographic columns connected in series. The compounds are eluted with dichloromethane, a PAH fraction is collected, and a portion of t 1 ? coextracted interferences, including elemental sulfur, is separated and discarded. The extract is solvent exchanged, the volume is reduced, and internal standard is added. Sample analysis is completed using a gas chromatograph/mass spectrometer and full-scan acquisition.

\section{Introduction}

Polycyclic aromatic hydrocarbons (PAHs) are hydrophobic compounds composed of two or more fused conjugated benzene rings. They are commonly associated with fossil fuels, combustion of fossil fuels, and other complex carbon sources. They are found in air, water, and sediment and many are considered to be toxic and carcinogenic (Nauss, 1995), thus indicating that long-term exposure pose a risk to aquatic and terrestrial organisms.

The PAHs can be loosely divided into unsubstituted or parent PAHs and alkyl-substituted PAHs or alkylated PAHs. Alkylated PAHs are defined as PAHs with attached alkyl substituent(s). The alkylated PAHs are grouped by the number of carbon atoms present in the alkyl substituent(s). A particular homolog group includes all the isomers with the same number of carbc $n$ atoms in the substituents and the same parent PAH. Various combinations can occur depending on the alkyl substituent(s) involved. For example, the possible substitutions for a $\mathrm{C}_{3}-\mathrm{PAH}$ could include 


\section{Determination of Polycyclic Aromatic Hydrocarbon Compounds in Sediment}

propyl-( $n$-propyl-, isopropyl), trimethyl- and ethylmethyl. An alkylated $\mathrm{PAH}$ homolog series is $\mathrm{C}_{1}$ through $\mathrm{C}_{5}$ substituent(s) for the same parent PAH. For example, an alkylated PAH homolog series for naphthalene follows: $\mathrm{C}_{1}$-alkylated naphthalene, $\mathrm{C}_{2}$-alkylated naphthalene, $\mathrm{C}_{3}$-alkylated naphthalene, $\mathrm{C}_{4}$-alkylated naphthalene, and $\mathrm{C}_{5}$-alkylated naphthalene.

In the processes that result in the production of alkylated PAHs, not all isomers within a homolog group are produced in equal amounts. Isomers within a homolog group have common physical properties, such as the same molecular weight and fragmentation patterns in a mass spectrometer. The fragment ions produced for each isomer within the same homolog group typically are identical, although the abundance ratios can be different. This results in a complex chromatographic pattern of partially resolved components.

If the parent PAH also is an isomer of another $\mathrm{PAH}$, their homolog groups are combined. For example, phenanthrene and anthracene are isomers of each other. Their $C_{1}$-alkyl substituent homolog group includes the $C_{1}$ substituent attached to phenanthrene and those attached to anthracene. This homolog group is called $\mathrm{C}_{1}$-alkylated phenanthrene/anthracene.

Analytical methods are needed to quantitate low concentrations of PAH compounds and homolog groups in sediment. The U.S. Geological Survey (USGS) National Water Quality Laboratory (NWQL) developed a new method to quantitate these compounds in sediment by gas chromatography/mass spectrometry (GC/MS) at low method detection limits with greater confidence compared to commonly used methods. Improved instrumentation allowed a selected-ion monitoring custom method to be updated to GC/MS in full-scan mode. See Attachment 1 for a discussion of the custom method and differences between full-scan and selected-ion monitoring.

The purpose of this report is to describe method performance for the determination of $28 \mathrm{PAHs}$ and the semiquantitation of 25 alkylated $\mathrm{PAH}$ homolog groups for five parent PAHs, four of which are groups of isomers. Bias and precision data for three matrices and three fortification levels are presented and define the low end of detection $(10 \mu \mathrm{g} / \mathrm{kg})$. These performance data are supplemented by bias and precision data from Furlong and others (1996), which are included in this report because the same methodology is used, identical parent PAHs are described, and sediment matrices are similar.

Bias and precision data also are included in the attachment for selected-ion monitoring (SIM) acquisition for the three matrices and three fortification levels presented in this report. The method describet in this report (O-5505-03) was originally designed using SIM methodology. With the advances of instrumentation providing full-scan acquisition rivaling SIM in detection limits and the need for better qualitative identification of the alkylated PAH homolog groups, full-scan acquisition is preferred. The additional SIM data are prorided for historical and comparison purposes.

This method was approved by USGS in November 2003 and implemented at the NWQL in January 2004. It uses elements outlined in the method by Furlong and others (1996), which was implemented at the National Water Quality Laboratory (NWQL) in January 1993 and supplements other USGS methods for detern ination of organic substances in bottom sediment described by Fishman (1993) and by Wershaw and others (1987).

This method was designed so that selecteorganochlorine (OC) pesticides, polychlorinated biphenyls (PCBs), and organophosphate pest: $\mathrm{cides}(\mathrm{OP})$ can be determined from the same sediment sample extraction as the PAHs, although only the PA Hs are described in this report. The OC method is described by Noriega and others (in press), and the OP method is described by Jha and others (2002). Use of a common extraction provides the advantage of reduced analytical cost, especially valuable when the amount of sample is small or difficult to collect.

This report provides a detailed description of all aspects of the method, from sample preparation through calculation and reporting of results. This method is applicable for samples of soil and bottom seciment. Matrices described in this report include a laboratory reagent matrix and bottom sediment from two separate sources. Recovery data and method detectior limits (MDLs) for 28 PAHs are presented. Although no recovery data are presented for the 25 alkylated PAH homolog groups, precision data using standard referen?e material are provided.

The following parent PAHs are discussed: naphthalene, isomeric parents phenanthrene/anthracene, fluoranthene/pyrene, benzo $[a]$ anthracene/chrysene, and benzopyrene/perylene. Increasing the number of fused rings in the parent $\mathrm{PAH}$ results in a greater number of sites for alkyl-substitution, increasing the number of possible isomers and the complexity of the observed homolog groups. For example, there are greater numbers of isomers within the $\mathrm{C}_{3}$-phenanthrene/anthracene ( 3 fused rings) group compared to the $\mathrm{C}_{3}$-alkylated naphthalene ( 2 fused rings) group.

In the method described herein, 25 groups of alkylated $\mathrm{PAH}$ homologs can be qualitatively identifie $\mathrm{l}$ and 
semiquantitated using the response factor and calibration curve from a selected compound within its homolog series or the appropriate parent $\mathrm{PAH}$. These homolog groups are semiquantitated as the summed $\mathrm{C}_{1^{-}}, \mathrm{C}_{2^{-}}, \mathrm{C}_{3^{-}}, \mathrm{C}_{4^{-}}$, $\mathrm{C}_{5}$-alkylated homolog groups of the parent $\mathrm{PAH}(\mathrm{s})$.

Reference mass spectra agreement and pattern recognition are used to qualitatively identify the alkylated PAH homolog groups.

Because a particular group is composed of more than one isomer, the responses of each isomer are added together for a total response. The concentration of the alkylated PAH homolog group is calculated using this total response and a relative response factor (RRF) from a related compound calibration curve. The RRF, although from a related compound, may or may not reflect each individual isomer's response. Wang and others (1994) found that by using the RRF produced from the parent naphthalene standard's calibration curve, an error of 30 to 150 percent was introduced when quantitating alkylated naphthalene homolog groups. For this reason and because authentic standards are not available for every isomer, the concentration of a particular homolog group is reported as an estimate calculated from the sum of all its measured isomers. The alkylated PAH homolog groups are reported with an "E" qualifier, thus indicating an estimated value. The PAH compounds whose concentrations are defined are listed in table 1, and the alkylated PAH homolog groups whose concentrations are estimated are listed in table 2 .

\section{Analytical Method}

\section{Organic Compounds and Parameter Codes: Polycyclic aromatic hydrocarbons, sediment, high-performance gel permeation chromatography, capillary-column gas chromatography/mass spectrometry, 0-5505-03 (see table 1)}

\section{Scope and Application}

This method is suitable for the determination of polycyclic aromatic hydrocarbons in soil and sediment samples containing at least $10 \mu \mathrm{g} / \mathrm{kg}$ of each PAH compound. This method is applicable to compounds that are (1) efficiently extracted from sediment by a dichloromethane/methanol azeotrope, (2) adequately separated from natural coextracted compounds by gel permeation chromatography (GPC), and (3) sufficiently volatile and thermally stable for determination by gas chromatography/mass spectrometry (GC/MS). The
Table 1. Individual polycyclic aromatic hydrocarbon compounds determined using this method.

[NWIS, National Water Information System; CAS, Chemical Abstracts Service registry number]

\begin{tabular}{|c|c|c|}
\hline Compound & $\begin{array}{c}\text { NWIS } \\
\text { parameter } \\
\text { code }\end{array}$ & CAS number \\
\hline Acenaphthene & 62549 & $83-32-9$ \\
\hline Acenaphthylene & 62550 & $208-96-8$ \\
\hline Anthracene & 62551 & $120-12-7$ \\
\hline Benz $[a]$ anthracene & 62552 & $56-55-3$ \\
\hline Benzo $[b]$ fluoranthene & 62554 & $205-99-2$ \\
\hline Benzo $[k]$ fluoranthene & 62557 & $207-08-9$ \\
\hline Benzo $[g, h, i]$ perylene & 62556 & $191-24-2$ \\
\hline Benzo $[a]$ pyrene & 62553 & $50-32-8$ \\
\hline Benzo $[e]$ pyrene & 62555 & $192-97-2$ \\
\hline Chrysene & 62558 & $218-01-9$ \\
\hline Dibenz $[a, h]$ anthracene & 62560 & $53-70-3$ \\
\hline 1,2-Dimethylnaphthalene & 62538 & $573-98-8$ \\
\hline 1,6-Dimethylnaphthalene & 62539 & $575-43-9$ \\
\hline 2,6-Dimethylnaphthalene & 62544 & $581-42-0$ \\
\hline 2-Ethylnaphthalene & 62545 & $939-27-5$ \\
\hline Fluoranthene & 62561 & $206-44-0$ \\
\hline 9H-Fluorene & 62548 & $86-73-7$ \\
\hline Indeno $[1,2,3-c d]$ pyrene & 62562 & $193-39-5$ \\
\hline 2-Methylanthracene & 62546 & $613-12-7$ \\
\hline 1-Methyl-9H-fluorene & 62540 & $1730-37-6$ \\
\hline 1-Methylphenanthrene & 62541 & $832-69-9$ \\
\hline 1-Methylpyrene & 62542 & $2.381-21-7$ \\
\hline 4,5-Methylenephenanthrene & 62547 & $203-64-5$ \\
\hline Naphthalene & 62563 & $91-20-3$ \\
\hline Perylene & 62565 & $198-55-0$ \\
\hline Phenanthrene & 62566 & $85-01-8$ \\
\hline Pyrene & 62568 & $129-00-0$ \\
\hline 2,3,6-Trimethylnaphthalene & 62543 & $829-26-5$ \\
\hline $\begin{array}{l}\text { 2-Fluorobiphenyl (method } \\
\text { surrogate) }\end{array}$ & 62594 & $321-60-8$ \\
\hline $\begin{array}{l}\text { Nitrobenzene- } d_{5} \text { (method } \\
\text { surrogate) }\end{array}$ & 62595 & $4165-60-0$ \\
\hline $\begin{array}{l}\text { Terphenyl- } d_{14} \text { (method } \\
\text { surrogate) }\end{array}$ & 62596 & $1718-51-0$ \\
\hline
\end{tabular}

individual PAH compounds determined using this method, the National Water Information System parameter code, and Chemical Abstracts Service number for each compound are listed in table 1 . The alkylated PAH homolog groups determined and their National Water Information System parameter codes are listed in table 2 . 


\section{Determination of Polycyclic Aromatic Hydrocarbon Compounds in Sediment}

Table 2. Alkylated polycyclic aromatic hydrocarbon homolog groups determined using this method and reported permanently as estimated.

[NWIS, National Water Information System]

\begin{tabular}{|c|c|}
\hline Compound & $\begin{array}{c}\text { NWIS parameter } \\
\text { code }\end{array}$ \\
\hline $\mathrm{C}_{1}$-alkylated naphthalene & 62569 \\
\hline $\mathrm{C}_{2}$-alkylated naphthalene & 62574 \\
\hline $\mathrm{C}_{3}$-alkylated naphthalene & 62579 \\
\hline $\mathrm{C}_{4}$-alkylated naphthalene & 62584 \\
\hline $\mathrm{C}_{5}$-alkylated naphthalene & 62589 \\
\hline $\mathrm{C}_{1}$-alkylated phenanthrene/anthracene & 62570 \\
\hline $\mathrm{C}_{2}$-alkylated phenanthrene/anthracene & 62575 \\
\hline $\mathrm{C}_{3}$-alkylated phenanthrene/anthracene & 62580 \\
\hline $\mathrm{C}_{4}$-alkylated phenanthrene/anthracene & 62585 \\
\hline $\mathrm{C}_{5}$-alkylated phenanthrene/anthracene & 62590 \\
\hline $\mathrm{C}_{1}$-alkylated fluoranthene/pyrene & 62571 \\
\hline $\mathrm{C}_{2}$-alkylated fluoranthene/pyrene & 62576 \\
\hline $\mathrm{C}_{3}$-alkylated fluoranthene/pyrene & 62581 \\
\hline $\mathrm{C}_{4}$-alkylated fluoranthene/pyrene & 62586 \\
\hline $\mathrm{C}_{5}$-alkylated fluoranthene/pyrene & 62591 \\
\hline $\mathrm{C}_{1}$-alkylated benz $[a]$ anthracene/chrysene & 62572 \\
\hline $\mathrm{C}_{2}$-alkylated benz $[a]$ anthracene/chrysene & 62577 \\
\hline $\mathrm{C}_{3}$-alkylated benz $[a]$ anthracene/chrysene & 62582 \\
\hline $\mathrm{C}_{4}$-alkylated benz $[a]$ anthracene/chrysene & 62587 \\
\hline $\mathrm{C}_{5}$-alkylated benz $[a]$ anthracene/chrysene & 62592 \\
\hline $\mathrm{C}_{1}$-alkylated benzopyrene/perylene & 62573 \\
\hline $\mathrm{C}_{2}$-alkylated benzopyrene/perylene & 62578 \\
\hline $\mathrm{C}_{3}$-alkylated benzopyrene/perylene & 62583 \\
\hline $\mathrm{C}_{4}$-alkylated benzopyrene/perylene & 62588 \\
\hline $\mathrm{C}_{5}$-alkylated benzopyrene/perylene & 62593 \\
\hline
\end{tabular}

\section{Summary of Method}

A flowchart of the analytical method described in this report is shown in figure 1 , and the method is summarized as follows.

Wet-sediment samples are homogenized and centrifuged, if necessary, to remove water, and water content is determined. Each sample is mixed with anhydrous sodium sulfate and placed into a glass Soxhlet thimble. After adding the method surrogate compounds and $25 \mathrm{~mL}$ of methanol to remove water not bound by sodium sulfate, wait 30 minutes. Extract the sample with $350 \mathrm{~mL}$ of dichloromethane plus the methanol in a Soxhlet apparatus for at least 12 hours, typically overnight. The extract is dried with sodium sulfate and reduced to $3 \mathrm{~mL}$ by Kuderna-Danish concentration and filtered with a polytetrafluoroethylene (PTFE) membrane. A method gel permeation chromatography (GPC) surrogate compound is added and the volume is increased to $4 \mathrm{~mL}$. A $1,400-\mu \mathrm{L}$ aliquot of the sample extract is injected quantitatively onto two polystyrenedivinylbenzene GPC columns, connected in series and eluted with dichloromethane. The PAH compounds are isolated from coextracted chemical interferennes and collected in an 8.6-mL fraction. This GPC frection is exchanged into ethyl acetate and reduced to $C .5 \mathrm{~mL}$. A perdeuterated polycyclic aromatic hydrocarbon internal standard (dPAHIS) solution is added to each extract. The extract-containing vial then is sealed and held at $<5^{\circ} \mathrm{C}$ until analysis for PAHs. Organophosphate pesticides (OP) also can be determined using this extract (Jha and others, 2003). A second aliquot $(1,100 \mu \mathrm{L})$ of the sample extract is injected onto the GPC if OCs are requested and taken through separate steps (Noriega and others, 2704).

The instrumental analysis consists of a gas chromatographic (GC) separation of the compounds followed by mass spectrometric (MS) identification and quantitation. The compounds are separated within the GC using a fused-silica capillary column with temperature programming to optimize compound separation. The compounds are identified by comparison to a library of reference mass spectra. The internal standard method is used to quantitate the compounds using a multiple-point calibration curve.

\section{Interferences}

3.1 Organic compounds that are coextracted, collected in the GPC fraction, and have GC retention times and characteristic ions with masses identical to those of the selected PAHs of interest might interfere. In particular, hydrocarbons and hydrocarbon degradation products can cause substantial interferences. Diluting the sample extract before analysis can minimize the interferences.

Analyses of laboratory reagent blanks provide information about the presence of contaminants and are used to determine if an interference exists. If irterferences are identified, cleaning or replacement of parts may be required to remove the interference(s).

3.2 Contaminants might interfere when a sample containing low (micrograms per kilogram) correntrations of compounds is analyzed immediately after a sample containing high (milligrams per kilogram) corsentrations of compounds. Syringes and splitless injection port liners need to be cleaned carefully or replaced as ne?ded. The GPC system needs to be monitored continuously to ensure that it is not a source of sample cross-contamination. 
Homogenize wet sediment; centrifuge a portion to remove excess water; determine percent moisture (separate aliquot)

Weigh centrifuged sediment into beaker:

(25-gram equivalent dry weight)

Mix with anhydrous sodium sulfate to form loose mixture<smiles>[AlH]</smiles>

Transfer to extraction thimble and add method surrogate compounds<smiles>[AlH2]</smiles>

Add 25 milliliters $(\mathrm{mL})$ methanol; wait 30 minutes: extract sample for 12 hours in Soxhlet apparatus with $350 \mathrm{~mL}$ dichloromethane; cool; dry extract with sodium sulfate

$\downarrow$

Reduce sample volume to $3.0 \mathrm{~mL}$ using Kuderna-Danish apparatus; filter extract; add method gel permeation chromatography (GPC) surrogate (benzo[ $e]$ pyrene- $d_{12}$ ) compound; increase volume to $4.0 \mathrm{~mL}$.

GPC using dichloromethane; collect time-window fraction for polycyclic aromatic hydrocarbons (PAHs) and organophosphate (OP) pesticides, 1,400 microliters $(\mu \mathrm{L})$ injected, and a second injection for organochlorine (OC) pesticides, $1,100 \mu \mathrm{L}$ injected

Reduce each collected fraction using micro-Kuderna-Danish apparatus and nitrogen evaporation

\section{PAHs and OPs}

Solvent exchange to ethyl acetate; reduce fraction to $0.5-\mathrm{mL}$ final volume; add perdeuterated PAH internal standard; (Single extract for PAHs and OPs)

\section{PAHs}

Gas chromatography/mass spectrometry in full-scan; identify and quantify or semiquantify selected compounds

\section{OPs}

Capillary gas chromatography with flame photometric detection and dual column confirmation
Solvent exchange to hexane; reduce fraction to $1.0 \mathrm{~mL}$

Alumina/silica combined column adsorption chromatography with hexane and hexane:acetone; collect two fractions $\downarrow$

Reduce fraction 1 to $0.5-\mathrm{mL}$ final volume; $\downarrow$

Reduce fraction 2 to $1.0 \mathrm{~mL}$;

Florisil column clean-up of fraction 2;

Reduce fraction 2 to $0.5-\mathrm{mL}$ final volume; add retention time standards to fractions

1 and 2

Capillary gas chromatography with electron-capture detection and dual column confirmation

Figure 1. Flowchart for polycyclic aromatic hydrocarbons, organophosphate pesticides, and organochlorine pesticides. 


\section{Apparatus and Equipment}

The equipment required, along with specific models and sources that were used to develop this method, are listed as follows.

4.1 Sample storage, dewatering, and percent moisture determination

4.1.1 Freezer-upright, capable of storing 100 or more $1,000-\mathrm{mL}$ wide-mouthed jars at $-15^{\circ} \mathrm{C}$ for up to 1 year.

4.1.2 Centrifuge-with four-place rotor, capable of 5,000 relative centrifugal force, International Equipment Co. Model EXD or equivalent.

4.1.3 Centrifuge bottles-250-mL Teflon (FEP) with sealing-cap assemblies and centrifuge bottle adapter.

4.1.4 Analytical balance - top loading, capable of weighing $250 \mathrm{~g} \pm 0.1 \mathrm{~g}$.

4.1.5 Moisture determination balancecapable of moisture determination on a $1.8-$ to $2.2-\mathrm{g}$ aliquot of sediment sample to \pm 0.1 percent moisture, Sartorius Corp. Thermo Control Balance Model YTC O1L or equivalent. volume.

4.1.6 Glass beakers-borosilicate, $400-\mathrm{mL}$

\subsection{Sediment extraction}

4.2.1 Soxhlet apparatus - 85-mL extractor capacity, with $45 / 50$ standard taper top joint and $24 / 40$ standard taper bottom joint; fitted with a $500-\mathrm{mL}$ roundor flat-bottom flask with a $24 / 40$ standard taper joint and a water-cooled extractor condenser with $45 / 50$ bottom joint.

\subsubsection{Soxhlet extraction sample thimble-} borosilicate glass, 35 by $90 \mathrm{~mm}$, Kontes, Inc. Model K-586500-0022EC or equivalent.

\subsubsection{Soxhlet extraction combined steam} bath/condenser unit - Organomation Associates, Inc. Model 13055 ROT-X-TRACT or equivalent.

4.2.4 Fixed volume micropipet-50- and $100-\mu \mathrm{L}$ sizes, Drummond micropipetor-microdispenser or equivalent.

\subsection{Sediment extract concentration}

4.3.1 Kuderna-Danish $(K-D)$ evaporative concentrator-500-mL flask, three-ball Snyder column, and a custom-designed $10-\mathrm{mL}$ centrifuge receiver tube (see 4.3.2), all with 19/22 standard taper joints.

4.3.2 Centrifuge receiver tube $-10 \mathrm{~mL}$, made using the top of a 10-mL K-D receiver tube, with 19/22 standard female taper joint, fused to an $8-\mathrm{cm}$ long by 1.6- $\mathrm{cm}$ outer diameter centrifuge tube, volume graduated at 2, 3, and $5 \mathrm{~mL}$; Allen Scientific Glassblc 'vers, Inc. ASG-215-01 or equivalent.

\subsubsection{Kuderna-Danish combinea' steam} bath/condenser unit - Organomation Associates, Inc. Model 120 S-Evap or equivalent.

\subsubsection{Nitrogen manifold sample} concentrator - Organomation Associates, Inc. Model 124 $\mathrm{N}$-Evap or equivalent.

\subsection{Sediment extract filtration}

4.4.1 Syringe filter - Gelman Acrodisc, 25-mm syringe filter with $0.2-\mu \mathrm{m}$ PTFE membrane or equivalent.

4.4.2 Syringe $-5-\mathrm{mL}$ gas-tight or ground-glass syringe equipped with Luer-Lok ${ }^{\mathrm{TM}}$ fitting.

\subsection{Gel permeation chromatography,}

\subsubsection{Gel permeation chromatography} system-an automated GPC system consisting of the following components from Waters Corporation or equivalent.

4.5.1.1 High-performance liquid chromatography (HPLC) pump - model 5C 1.

4.5.1.2 Autosampler-model 717 with 2.4-mL injection loop capacity with tray storage region maintained at $20^{\circ} \mathrm{C}$.

4.5.1.3 Absorbance detector-model 441 with excitation wavelength set at $254 \mathrm{rm}$.

\subsubsection{Data module and integrator-}

model 746.

4.5.1.5 Fraction collector-no model number, fitted with in-house-built tube holder capable of holding 36, 25-mL K-D receiver tubes.

4.5.1.6 HPLC in-line precolumn filter unit-model WATO84560 with replaceable $0.2-\mu \mathrm{m}$ filters.

4.5.1.7 Column heater-set at $27.0^{\circ} \mathrm{C}$; Jones Chromatography Ltd. or equivalent.

\subsubsection{Nitrogen pressurization}

system - consisting of a regulated grade 5 nitrogen source, PTFE tubing, a 23-gage needle, and associated metal fittings and ferrules for connecting the needle to the nitrogen source by the tubing.

4.5.1.9 Helium sparging system-used for deoxygenating the dichloromethane sol"ent prior to GPC.

4.5.1.10 HPLC pump priming syringe$25 \mathrm{~mL}$, Hamilton Gas-Tight 1,000 Series, Model 82520 or equivalent.

4.5.1.11 Balance-capable of weighing to $200 \pm 0.001 \mathrm{~g}$; Mettler-Toledo Model AT 200 or equivalent.

4.5.1.12 K-D receiver tube-calibrated 25-mL volume, with 19/22 ground-glass stopper. 
4.5.1.13 HPLC syringe assembly for

Waters 717 autosampler-2,500 $\mu \mathrm{L}$, Waters

Chromatography Model 077342.

\subsection{GPC fraction concentration and solvent} exchange

4.6.1 Water bath-Precision Scientific Co. Model 82 or equivalent, fitted with a rack capable of holding at least eighteen $25-\mathrm{mL}$ receiver tubes.

4.6.2 Micro-Snyder column-three-ball.

\subsection{Fraction concentration}

4.7.1 Micropipet-50- $\mu \mathrm{L}$ volume; Hamilton Co. Model 80366 or equivalent; for addition of internal standard solution.

\subsection{Gas chromatography/mass spectrometry} analysis

\subsubsection{Gas chromatograph/mass}

spectrometer-Agilent Technologies 5973B MSD

coupled to an Agilent Technologies 6890 gas chromatograph and equipped with an autosampler, a split/splitless injector, and a computer controller

(ChemStation instrument control and Target data review software) or equivalent. The GC system must be suitable for use with capillary column GC analysis. Full-scan and SIM mass-spectral data are acquired using this system.

4.8.2 Syringe-10- $\mu \mathrm{L}$; Hamilton Co. Model 80377 for GC autosampler or equivalent.

\subsection{Instrument calibration and spike standards} solution preparation

4.9.1 Analytical balance-capable of accurately weighing to $0.0001 \mathrm{~g}$.

4.9.2 Volumetric flasks - varied volumes from 1 to $50 \mathrm{~mL}$.

4.9.3 Micropipets-fixed- and variablevolume pipets from 25 to $250 \mu \mathrm{L}$.

4.9.4 Syringes - variable volumes from 10 to $2,500 \mu \mathrm{L}$

\section{Reagents and Consumable Materials}

The following reagents and consumable materials required for this method are grouped by the specific preparation or analysis step but are not repeated if used in more than one step of the method. Specific models and sources that were used to develop or implement this method also are listed, as appropriate.

\subsection{Sample storage, dewatering, and percent} moisture determination

5.1.1 Sample containers - wide-mouth, 1,000 $\mathrm{mL}$, with PTFE-lined lids.

5.1.2 Weighing boats — disposable, aluminum, $5.1-\mathrm{cm}$ diameter.
5.1.3 Sodium sulfate-anhydrous, granular, reagent grade, bake at $450^{\circ} \mathrm{C}$ for 8 hours and store in a ground-glass stoppered flask in a desiccator until used.

\subsection{Sediment extraction}

5.2.1 Solvents-dichloromethane and methanol, pesticide grade, or higher purity.

5.2.2 Boiling chips - amphoteric alındum, Hengar granules from Hengar Co., Thorofare, New Jersey. Pre-extract with dichloromethane and bake at $450^{\circ} \mathrm{C}$ for 8 hours.

5.2.3 Disposable glass capillaries--to fit the 50 - and $100-\mu \mathrm{L}$ fixed-volume micropipets described in sections 4.2.4 and 4.9.3. Clean the glass capillaries by baking at $450^{\circ} \mathrm{C}$ for 8 hours.

\subsubsection{Surrogate solution}

\subsubsection{PAH surrogate solution-} containing nitrobenzene- $d_{5}$, 2-fluorobiphenyl, and terphenyl- $d_{14}$ obtained as a mixed solution at 1,000 $\mu \mathrm{g} / \mathrm{mL}$ per component from Supelco, Inc. (Be'lefonte, Pennsylvania). Dilute purchased intermediate concentration solutions to a final mixed solution concentration of $40 \mathrm{ng} / \mu \mathrm{L}$ in methanol. Other a эpropriate surrogate compounds and levels can be added or substituted after demonstrating acceptable method performance.

\subsubsection{Individual spike solutions}

5.2.5.1 PAH spike solution - c ontains the individual PAH compounds listed in table 1. Four solutions were obtained from Absolute Standards, Inc. (Hamden, Connecticut), each containing a subset of the semivolatile compounds. Individual compounds in each solution are at concentrations of $2,000 \mathrm{ng} / \mu \mathrm{L}$. Dilute an aliquot of each solution into a single final spike solution. The final selected concentration of each component is $150.0 \mathrm{ng} / \mu \mathrm{L}$ in ethyl acetate.

5.2.6 Standard reference materials (SRMs), certified reference material (CRM) or other quality-control $(Q C)$ reference materials - any SRM/CRM or other sediment or soil reference material available to test the method for recovery of some or all of the selected compounds may be an appropriate QC material. SRM 1941b and SRM 1944 were produced by the National Institute of Standards and Technology (NIST) and consist of natural sediment certified for specific compounds with additional uncertified values also reported. No single SRM currently (2003) available contains all of the compounds determined usirg this method. The CRM used in this report was obtained from Environmental Resource Associates (Arvada, Colorado) catalog no. PPS-45, lot no. 354. 


\subsection{Sediment extract concentration}

5.3.1 Nitrogen gas - for solvent evaporation, grade 5 or equivalent.

\subsection{Sample extract filtration}

5.4.1 Filter- $0.2-\mu \mathrm{m}$ pore size, $25-\mathrm{mm}$ diameter disposable PTFE membrane syringe filter, Gelman Sciences Acrodisc ${ }^{\mathrm{TM}} \mathrm{CR}$ or equivalent.

5.4.2 Pasteur pipet-14.6- and 22.9-cm-long disposable borosilicate pipets with rubber bulbs.

5.4.3 GPC vial, 4- $m L$-with open-top screw cap and PTFE-faced silicone rubber septum. Supelco, Inc. part numbers $2-3219 \mathrm{M}, 2-3261 \mathrm{M}$, and $3-3185 \mathrm{M}$ or equivalent.

5.4.4 GPC-PAH surrogate solution - contains benzo[ $e]$ pyrene- $d_{12}$ at a concentration of $100 \mathrm{ng} / \mu \mathrm{L}$ in dichloromethane. Make solution from a neat standard, Cambridge Isotope Laboratories or equivalent.

\subsection{Gel permeation chromatography}

5.5.1 Helium gas - grade 5 or equivalent.

5.5.2 Gel permeation chromatographic columns - two $30-\mathrm{cm}$-long by $7.5-\mathrm{mm}$ inside diameter (ID) columns packed with $5-\mu \mathrm{m}$ diameter styrenedivinylbenzene resin particles using 50-angstrom pore size; Polymer Laboratories, Ltd. PL Gel ${ }^{\mathrm{TM}}$ or equivalent. Connect the columns in series with a low dead-volume union.

\subsubsection{GPC-PAH fraction calibration}

solution - contains di- $n$-octylphthalate, benzo $[g, h, i]$ perylene, and elemental sulfur, each at a maximum concentration of $250 \mathrm{pg} / \mu \mathrm{L}$ in dichloromethane.

\section{exchange \\ 5.6 GPC fraction concentration and solvent}

5.6.1 Ethyl acetate-pesticide-residue grade, or higher purity.

\subsection{Fraction concentration}

5.7.1 Vial-1.5- or 2-mL, amber glass, with plastic caps that have dual PTFE-faced silicone rubber septa.

\subsubsection{Perdeuterated PAH internal standard} (dPAHIS) solution - contains the following: 1,4 dichlorobenzene- $d_{4}$, naphthalene- $d_{8}$, phenanthrene- $d_{10}$, perylene- $d_{12}$, acenaphthene- $d_{10}$, and chrysene- $d_{12}$, all at $100 \mathrm{ng} / \mu \mathrm{L}$ in ethyl acetate. This standard solution was obtained from NSI Solutions, Inc. (Raleigh, North Carolina) and diluted in ethyl acetate.

\section{analysis}

\subsection{Gas chromatography/mass spectrometry}

5.8.1 Capillary GC column-fused-silica, $25-\mathrm{m}$ long by $0.20-\mathrm{mm}$ ID, internally coated with a 5-percent diphenyl and 95-percent dimethyl polysiloxane stationary phase with a $0.33-\mu \mathrm{m}$ film thickness; J\&W Scientific Columns from Agilent Technologies Ultra $2^{\mathrm{TM}}$ or equivalent.

5.8.2 GC injection-port glass liner-use any instrument-specific splitless or direct injection-port liner that provides acceptable peak shape and detertor response.

\subsection{Instrument calibration and quality-control} solution preparation

5.9.1 GC/MS PAH calibration solution 5.9.1.1 Prepare working solutions of the entire suite of individual PAH compounds listed in table 1 at $0.1,0.2,0.5,1.0,2.5,5.0,8.0,10.0$, and $20.0 \mathrm{ng} / \mu \mathrm{L}$ per component in ethyl acetate using mixed stock solutions, including PAH surrogate solution (section 5.2.4.1) and GPC-PAH surrogate solution (section 5.4.4). Obtain stock solutions from Absolute Standards, Inc., Supelco, Inc. or equivalent. Aliquots of the dPAHIS solution (section 5.7.2) are added to each of the calibration solutions to produce individual dPAHIS compound concentrations of $10 \mathrm{ng} / \mu \mathrm{L}$

\subsubsection{Alkylated PAH homolog retertion time} source material - any crude-oil-containing sample can be used to test $\mathrm{GC}$ retention times for alkylated PAH homolog groups and create reference mass spectra. The original material used was a sediment sample from the Powell River near Knoxville, Tennessee. It was submitted to the NWQL for the National Water-Quality Assessment Program (Station 03532000; sampled on Dec?mber 13, 1995). Optionally, use Alberta Sweet Mix Blend (ASMB). ASMB crude is the standard oil used for dispersant-treating tests in the Emergencies Science Division of Environment Canada (Wang and others, 1994).

5.10 GC/MS quality control/quality asstrance solutions - concentrations of selected PAHs in these solutions are measured at periodic intervals within the analytical sequence to monitor instrument performance.

5.10.1 Continuing calibration verification $(\mathrm{CCV})$ solution - $\mathrm{a} \mathrm{CCV}$ solution, having individual compound concentrations of $2.5 \mathrm{ng} / \mu \mathrm{L}$, is analyzed after every 10 environmental and laboratory QC samples, verifying that the initial quantitation calibration is maintained.

\subsubsection{Instrument detection limit (IDL)} solution - an IDL solution, having individual compound concentrations of $0.2 \mathrm{ng} / \mu \mathrm{L}$, is analyzed (1) at the beginning and (2) at the end of the analytical sequence. This analysis is used to verify instrument performance near the lowest concentrations of the calibration curve during the entire analytical sequence. 


\subsubsection{Mass spectrometer calibration-a} solution of decafluorotriphenylphosphine (DFTPP) is analyzed before the first CCV analysis. This analysis verifies the initial mass spectrometer axis calibration and the relative abundance of ions formed over the mass range of the analysis. Prepare this solution from commercially available neat standards, Ultra Scientific or equivalent.

5.10.4 Third-party check (TPC) - a solution of all compounds or selected compounds to be analyzed. The TPC is analyzed after the initial calibration sequence to independently verify the instrument calibration. This solution is prepared from a source other than that used for preparing calibration standards. Currently (2003), a $0.4-\mathrm{ng} / \mu \mathrm{L}$ standard (stock solution from Supelco, Inc.) is being used at the NWQL.

\section{Safety Precautions}

It is important to observe proper laboratory safety procedures. Several of the compounds and materials in this method are known or suspected human carcinogens. A well-vented fume hood needs to be used for all steps involving organic solvents and compounds. Eye protection and the appropriate type of gloves needs to be worn. It is important to read the Material Safety Data Sheets (MSDS) on each compound and solvent prior to using this method. Disposal of all organic solvents, sediment samples, standards and rinse wastes needs to be performed in accordance with NWQL hazardous waste disposal rules and regulations.

\section{Sample Preparation Procedure}

Samples are grouped into sets of 16 , including QC samples. A typical sample set consists of 13 field samples, a set reagent blank, a set reagent spike, and a QC reference material sample.

\subsection{Sample dewatering and percent moisture determination}

7.1.1 Retrieve samples from the freezer and allow to thaw overnight in refrigerator.

7.1.2 Thoroughly homogenize each sample with spatula or scoopula.

7.1.3 Remove about 20 -g wet weight aliquot to an appropriate container for separate determination of total carbon and total inorganic carbon if requested (Wershaw and others, 1987). Total organic carbon is obtained by the difference.

7.1.4 If necessary, weigh about $150 \mathrm{~g}$ of homogenized sample into a tared $250-\mathrm{mL}^{\text {Teflon }}{ }^{\mathrm{TM}}$ centrifuge bottle. Repeat with a second sample, identically weighing to $\pm 0.1 \mathrm{~g}$ of the first sample for balanced centrifuge operation. Repeat for two more samples and centrifuge the two pairs of four individual samples for 20 minutes at $2,000 \mathrm{rpm}$. Carefully decant the clear supernatant water; remove the supernatant using a Pasteur pipet if the sediment pellet is too soft for decantation. If the supernatant is not clear, repeat centrifugation before decanting.

7.1.5 Thoroughly rehomogenize the sediment sample in the centrifuge bottle. Remove a 1.8- to 2.2-g aliquot of sediment and determine the moisture content of the centrifuged sediment to \pm 0.1 percent using the moisture determination balance (4.1.5).

7.1.6 Based on determinations in section 7.1.5, calculate the weight of wet, centrifuged sedim?nt needed to produce a 25 -g equivalent dry-weight sample (sample weight required for extraction equals $25-\mathrm{g}$ /fraction dry weight). From this result, calculate the total weight of water, in grams, present in this sample of wet, centrifuged sediment. Then determine the amount of anhydrous sodium sulfate required to adequately absorb the weight of water present in the sample, as follows: the amount of sodium sulfate required is equivalent to about four times the weight of water. If the sum of the weights of wet, centrifuged sediment and anhydrous sodium sulfate is less than $160 \mathrm{~g}$, combine these two weights in a tar?d $400-\mathrm{mL}$ beaker. If the combined calculated weights are greater than $160 \mathrm{~g}$, reduce the specified dry weight required by 20 percent to 20 -g equivalent dry weight. Recalculate the required weights of wet sediment and anhydrous sodium sulfate and determine if the sum of these two weights is less than $160 \mathrm{~g}$. If it is, combine these new recalculated weights in a tared $400-\mathrm{mL}$ beaker. If not, repeat the equivalent dry-weight reduction and recalculation procedure until the combined calculated weight is less than $160 \mathrm{~g}$. Record the combined weight to $\pm 0.1 \mathrm{~g}$. Mix thoroughly, and, if necessary, add additional anhydrous sodium sulfate to ensure that the mixture is dry and loose, always remaining less than a net combined weight of 160 $\mathrm{g}$ of wet, centrifuged sediment and anhydrous sodium sulfate. Method detection limits and laborator:' reporting levels are determined on a 25-g dry-weight basis. If smaller quantities of sediment are used in the method, laboratory reporting levels are adjusted propontionately.

\subsection{Sediment extraction}

7.2.1 Add the sediment-sodium sulfate mixture to a Soxhlet extraction thimble with spatula. Repeat for all samples.

7.2.2 Prepare the following QC samples as required, depending on types of analyses to be performed. 


\subsubsection{Laboratory reagent blank (set} blank) - Weigh and place $125 \mathrm{~g}$ of sodium sulfate into an extraction thimble.

\subsubsection{Set laboratory reagent spike} (PAH spike) - Weigh and place $125 \mathrm{~g}$ sodium sulfate into an extraction thimble, place thimble into Soxhlet, and spike sodium sulfate with $100 \mu \mathrm{L}$ of individual PAH spike solution (5.2.5.1) using a $100-\mu \mathrm{L}$ fixed-volume micropipet.

\subsubsection{A quality-control reference} material sample-Place 1 to $25 \mathrm{~g}$ of appropriate dry SRM/CRM (see 5.2.6) into an extraction thimble; the amount extracted will depend on SRM/CRM availability, compound concentrations relative to the reporting level, and cost. Mix in $100 \mathrm{~g}$ of sodium sulfate to simulate step 7.1.6. (SRM/CRMs usually do not contain appreciable water.) The previously described QC samples (sections 5.2.5 and 5.2.6) are extracted and processed through the remainder of the method exactly as for the field samples.

7.2.3 Place each extraction thimble into a Soxhlet apparatus connected to a $500-\mathrm{mL}$ flask containing $350 \mathrm{~mL}$ dichloromethane and 5 to 10 boiling chips.

7.2.4 Using a micropipet, add $100 \mu \mathrm{L}$ of PAH surrogate solution (5.2.4.1) on top of each sample contained in a thimble.

7.2.5 Carefully add $25 \mathrm{~mL}$ methanol to the top of the sample and allow 30 minutes for it to percolate through sample and the thimble frit. This step helps to remove any residual moisture not bound by the sodium sulfate.

Note 1. Do not use more than $25 \mathrm{~mL}$ of methanol during this step. The amount of methanol added must not exceed 7 percent of the total volume of dichloromethane plus methanol used during the extraction.

7.2.6 Attach the Soxhlet apparatus to the condenser and extract the sample at $70^{\circ} \mathrm{C}$ for at least 12 hours. Carefully monitor Soxhlet extraction to ensure that the siphoning mechanism works correctly and the fresh solvent cycles through each sample at least once each hour.

7.2.7 Following extraction, add about $50 \mathrm{~g}$ of sodium sulfate to the flask and swirl to remove residual water. Add additional sodium sulfate as needed to ensure water removal. Excessive amounts of water might require separation using a 1-L separatory funnel. Seal with a ground-glass stopper and store sodium sulfate-containing extract in a refrigerator for at least 4 hours.

\subsection{Sediment extract concentration}

7.3.1 Decant the extract (but not the sodium sulfate) from the flask to a K-D concentrator (4.3.1) fitted with a $10-\mathrm{mL}$ centrifuge receiver tube (4.3.2) containing boiling chips. Rinse the flask three times using 5- to $10-\mathrm{mL}$ aliquots of dichloromethane and transfer these rinses to the K-D concentrator.

7.3.2 Concentrate the extract to about $3 \mathrm{~mL}$ at $70^{\circ} \mathrm{C}$.

Note 2. The methanol used in the extraction step needs to be removed during this K-D concentration step, otherwise it will interfere with the GPC cleanup (7.5). Methanol is completely removed only by the formation of an azeotrope having a 92.7 percent dichloromethane and 7.3 percent methanol composition that boils at $37.8^{\circ} \mathrm{C}$ (at $101.3 \mathrm{kPa}$ ). Therefore, the amount of methannl must not exceed 7 percent of the total extract volume of dichloromethane plus methanol in the Soxhlet extract (7.2.6); otherwise, the desired azeotrope comrosition will not occur during the K-D concentration.

7.3.3 Store extract in a refrigerator or freezer until step 7.4 .

\subsection{Sediment extract filtration}

7.4.1 Tare a labeled, 4-mL GPC vial with cap and septum attached (5.4.3) to $\pm 0.0001 \mathrm{~g}$.

7.4.2 Attach a 0.2- $\mu \mathrm{m}$ PTFE filter (4.4.1) to a 5-mL Luer-Lok syringe (4.4.2). Remove syringe plunger and place a tared GPC vial under filter-tip outlet.

7.4.3 Transfer the extract to the syringe barrel using a Pasteur pipet.

7.4.4 Carefully insert the plunger into the syringe and pass the extract through the filter into the GPC vial. After expelling sample, push air through the filter to remove residual extract from the filter.

7.4.5 Rinse the centrifuge receiver tube with $500 \mu \mathrm{L}$ dichloromethane, washing down the tube walls using the Pasteur pipet. Transfer the rinse to the syringe barrel using the Pasteur pipet. Filter this rinse into the GPC vial as in 7.4.4.

7.4.6 Repeat step 7.4.5.

7.4.7 Add $50 \mu \mathrm{L}$ of the GPC-PAH surrogate solution (5.4.4) to the extract in the GPC vial if determining PAHs by GC/MS.

7.4.8 Bring extract volume up to $4 \mathrm{~mL}$ with dichloromethane and cap GPC vial. Store extract in a refrigerator or freezer at $\leq 5^{\circ} \mathrm{C}$ until step 7.5.

\subsection{Gel permeation chromatography}

Complete details of GPC operation are reyond the scope of this report. Instead, the following procedure outlines the steps necessary for GPC instrument fraction calibration and subsequent cleanup of sample extracts. Consult the appropriate instrument manuals for additional details regarding general GPC system operation.

7.5.1 The GPC data system needs to be turned on continuously. Other system components, including the 
pump, autosampler, detector, fraction collector, and column heater, need to be turned on at least 2 hours in advance of fraction calibration.

7.5.2 Degas the dichloromethane mobile phase with helium for 15 to 30 minutes prior to use.

7.5.3 Pump degassed dichloromethane through the GPC columns at the mobile phase flow rate of $1 \mathrm{~mL} / \mathrm{min}$ for at least 2 hours prior to fraction calibration (7.5.8).

Note 3. Slowly ramp up the flow rate from 0.1 to 1 $\mathrm{mL} / \mathrm{min}$ for 1 minute to minimize pressure shock to the GPC columns.

7.5.4 Bring the GPC vial containing the sample to room temperature.

7.5.5 Prior to vial pressurization (7.5.6), weigh the extract in the tared GPC vial with cap and septum (7.4.8) to $\pm 0.001 \mathrm{~g}$ and record weight.

7.5.6 For all samples, the GPC vial headspace is pressurized with nitrogen gas, just prior to beginning a GPC fractionation sequence. Pierce the vial septum with the pressurization needle, and pressurize with $207 \mathrm{kPa}$ nitrogen for about 1 minute. Make sure the end of the needle is not placed into the liquid. Rinse the needle with clean dichloromethane after pressurizing each vial.

7.5.7 Verify GPC system cleanliness and baseline stability by injecting a $1,400-\mu \mathrm{L}$ aliquot of fresh pesticide-grade dichloromethane (system blank) and monitoring detector response at low attenuation (usually at attenuation 8, depending upon the collector). Fractions typically are not collected for GPC system blank analyses.

7.5.8 GPC fraction calibration-PAH elution times might vary between analyses of sample sets because of GPC column aging, the presence of residual methanol from sample extraction, and other factors. Therefore, prior to beginning automated analysis, the fraction collection beginning and ending times are established for the PAHs to allow final configuration of the fraction collector.

\subsubsection{Establish PAH fraction}

collection times by injecting $1,400 \mu \mathrm{L}$ of the GPC-PAH fraction calibration solution (5.5.3) and monitoring the elution times of the peaks at attenuation 8 for 30 minutes. Repeat injections of the GPC-PAH fraction calibration solution to ensure chromatographic reproducibility. The retention times should be within \pm 12 seconds of each other. Fractions are not collected for the GPC-PAH fraction calibration test analyses.
7.5.8.2 The beginning time is determined by processing the chromatogram resulting from the injection of the GPC-PAH fraction calibration solution at attenuation 8 and graphically determining when the baseline begins to rise, thus indicating the first peak. Set the "beginning time" on the fraction collector at the time just before the detector baseline begins to rise for the first peak (di- $n$-octylphthalate). Set the "end time" on the fraction collector for the GPC-PAH fraction at the valley between the benzo[ $g, h, i]$ perylene and sulfur paaks, the second and third peaks.

7.5.8.3 Fraction cutoffs origirally are determined by injecting a solvent blank spiked with the suite of analytes into the GPC system. Fractions are collected in 2-minute intervals for the 30-minute analysis. The 15 extracts are concentrated and analyzed on the GC/MS. This exercise identifies the first peak (di- $n$-octylphthalate) and the last well-chromatographed peak (benzo $[g, h, i]$ perylene) to elute and their retention times. The remaining compounds elute between these two. This step is taken at the initial setup of a GPC system for this analysis. GPC fraction calibration subsequently is validated with the PAH fraction calibration solution. This step must be repeated if new types of GPC co'umns or instruments are used.

Note 4. The GPC window used for the PAHs complements the organophosphate pesticides (Jha and others, 2003), and one extract can be used for both analyses. Different GPC fraction collection window start and end times are used when an aliquot of the sample extract is processed by GPC for OC pesticides and PCBs described in Noriega and others (2004).

7.5.9 Perform a GPC automated separation. Inject $1,400 \mu \mathrm{L}$ of the sample extract and collact the GPC-PAH fraction in a $25-\mathrm{mL} \mathrm{K}-\mathrm{D}$ receiver tube. Process each sample for 30 minutes. A suggested processing sequence, using the sample types contained in a normal sample set at the NWQL (one set blank, set PAH spike, quality-control reference material, and 13 field samples), is listed in table 3. Repeated $1,400-\mu \mathrm{L}$ injections of the GPC-PAH fraction test solution along with system blanks help to ensure continued calibration and system cleanliness. The PAH elution times are reproducible from sequence to sequence.

7.5.10 Reweigh the GPC sample vial with original cap and septum to $\pm 0.001 \mathrm{~g}$ as soon as possible after injection of the sample and record weight. 
Table 3. Suggested gel permeation chromatography processing sequence.

[PAH, polyclcylic aromatic hydrocarbon compound; GPC, gel permeation chromatography]

\begin{aligned} & \hline $\begin{array}{c}\text { Analytical } \\ \text { sequence }\end{array} \\ &$\hline 1 Sample type \\ & 2 System blank \\ & 3 Set blank \\ & 4 Set PAH spike (or set spike options) \\ & 5 Quality-control reference material sample \\ & 6 Sample 1 \\ & 7 Sample 3 \\ & 8 Sample 4 \\ & 9 Sample 5 \\ & 10 Sample 6 \\ & 11 Sample 7 \\ & 12 GPC-PAH fraction test solution \\ & 13 System blank \\ & 14 Sample 8 \\ & 15 Sample 9 \\ & 16 Sample 10 \\ & 17 Sample 11 \\ & 18 Sample 12 \\ & 19 Sample 13 \\ & 20 GPC-PAH fraction test solution \\ & 21 System blank \\ & \hline\end{aligned}

7.5.11 Cap K-D receiver tube containing the GPC-PAH fraction with a ground-glass stopper and store in a refrigerator until the concentration step (7.6).

7.5.12 Replace the septum on the GPC sample vial and store the remaining extract at $\leq 5^{\circ} \mathrm{C}$.

7.6 GPC-PAH fraction concentration and solvent exchange

7.6.1 Add $4 \mathrm{~mL}$ of ethyl acetate and two to three small boiling chips to the extract and attach a three-ball micro-Snyder column to the top of the K-D receiver tube.

7.6.2 Slowly introduce the $\mathrm{K}-\mathrm{D}$ receiver tube to a water bath (4.6.1) maintained at $70^{\circ} \mathrm{C} \pm 2^{\circ}$ and reduce the solvent volume to about $4 \mathrm{~mL}$ or until solvent evaporation dramatically decreases. Remove the tube from the bath and cool.

7.6.3 Raise bath temperature to $85^{\circ} \mathrm{C} \pm 2^{\circ}$. Add two to three fresh boiling chips and $1 \mathrm{~mL}$ ethyl acetate to the K-D receiver tube, vortex, and replace into water bath for no longer than 20 minutes. Do not reduce solvent volume to less than $1 \mathrm{~mL}$.

7.6.4 Remove tube from water bath and reduce the extract to $0.5 \mathrm{~mL}$ by using a gentle stream of nitrogen (4.3.4).
7.6.5 Transfer the fraction to a $1.8-\mathrm{mL}$ amber autosampler vial using a Pasteur pipet. Add $50 \mu \mathrm{L}$ of the PAH internal standard (dPAHIS, 5.7.2) solution, cap the vial, and mix. Store in a freezer at $\leq 5^{\circ} \mathrm{C}$ until analysis by GC/MS.

\section{Instrumental Analysis}

Samples are analyzed by GC/MS using full-scan monitoring. A capillary column GC system is equipped with an autosampler and a split/splitless injection port operated in the splitless mode, and is directly connected to a quadrupole mass spectrometer. A computer system is used to allow complete control of the autosampler, GC and MS operations, and to acquire, process, and store signals from the GC/MS. Complete details of GC/MS operation are beyond the scope of this report. Instead, the suggested GC/MS operating conditions and sample sequence used in this method are outlined in the following procedure. Users should consult the appropriate instrument manuals for additional details regarding general GC/MS system operation. Note that $\mathrm{t} \cdot \mathrm{GC} / \mathrm{MS}$ operating conditions are provided for guidanc: only. Different GC/MS systems will require differert operating conditions to achieve acceptable instrument performance. Use those operating conditions that result in anceptable instrument performance for the available GC/MS system.

\subsection{Instrumental conditions and setup}

8.1.1 Suggested GC-operating conditions for

$P A H s$. Begin with the oven temperature at $65^{\circ} \mathrm{C}$ (hold for 3 minutes), then ramp at $6^{\circ} \mathrm{C} / \mathrm{min}$ to $320^{\circ} \mathrm{C}$, and hold for 20 minutes to allow for sufficient column bake-out; injection port temperature, $285^{\circ} \mathrm{C}$ with electronic pressure control set for constant flow of helium gas of $0.7 \mathrm{~mL} / \mathrm{min}$, $1 \mu \mathrm{L}$, splitless injection.

\subsubsection{Determine compound retention times.}

Following GC/MS setup, establish compound retention times with calibration standards. Peak identifinations, retention times, mass-to-charge ratios and abundances relative to the quantitation ion for $\mathrm{PAHs}$, using the GC/MS operating conditions described in section 8.1.1 with a J\&W Scientific Ultra $2^{\text {TM }}$ Column from Agilent Technologies, are listed in table 4 . The relative ion abundances are not provided for the alkylated PAH homolog groups because the ratios are different among isomers. The determination of retention times for the alkylated PAH homolog groups is described in 8.1.3.

CAUTION: Because of differences in GC columns, even from the same manufacturer, and operational characteristics between instruments, the elutic n profiles will vary. Therefore, it is critical to verify instrument-specific compound retention times. Use 
Table 4. Retention times, relative retention times, gas chromatography/mass spectrometry quantitation ions, confirmation ions, an-1 percent relative abundance of confirmation ions for individual polycyclic aromatic hydrocarbons (PAHs) and alkylated PAH homolog groups.

[Compounds are reported in chromatographic elution order; min, minute; compounds followed by $\mathbf{R} \mathbf{R}$ are method internal standards and are followed by a designation (RR-1, RR-2,..), which indicates their order as a retention reference; $\mathrm{min}$, minutes; $\mathrm{m} / \mathrm{z}$, mass-to-charge ratio]

\begin{tabular}{|c|c|c|c|c|c|c|}
\hline Compound & $\begin{array}{l}\text { Retention } \\
\text { time } \\
\text { (min) }\end{array}$ & $\begin{array}{l}\text { Relative } \\
\text { retention } \\
\text { time }\end{array}$ & $\begin{array}{l}\text { Retention } \\
\text { reference } \\
\text { compound }\end{array}$ & $\begin{array}{c}\text { Quantitation } \\
\text { ion } \\
(\mathrm{m} / \mathrm{z})\end{array}$ & $\begin{array}{c}\text { Confirmation } \\
\text { ions }(\mathrm{m} / \mathrm{z})\end{array}$ & $\begin{array}{l}\text { Percent relative } \\
\text { to c'rantitation } \\
\text { ion abundance }\end{array}$ \\
\hline 1,4-Dichlorobenzene- $d_{4}(\mathbf{R R}-1)$ & 6.8 & 1.000 & 1 & 152 & 150,115 & 150,60 \\
\hline Nitrobenzene- $d_{5}$ & 8.6 & 1.265 & 1 & 128 & 82,98 & 280,40 \\
\hline Naphthalene- $d_{8}$ (RR-2) & 11.0 & 1.000 & 2 & 136 & none & none \\
\hline Naphthalene & 11.1 & 1.009 & 2 & 128 & 129,102 & 10,10 \\
\hline $\mathrm{C}_{1}$-alkylated naphthalene & 14.0 & 1.272 & 2 & 141 & 142,127 & variable \\
\hline 2-Fluorobiphenyl & 15.3 & 1.391 & 2 & 172 & 171,85 & 30,10 \\
\hline 2-Ethylnaphthalene & 15.9 & 1.445 & 2 & 141 & 156,115 & 45,25 \\
\hline 2,6-Dimethylnaphthalene & 16.1 & 1.464 & 2 & 141 & 156,115 & 140,25 \\
\hline $\mathrm{C}_{2}$-alkylated naphthalene & 16.1 & 1.464 & 2 & 141 & 156,115 & variable \\
\hline 1,6-Dimethylnaphthalene & 16.5 & 1.500 & 2 & 141 & 156,115 & 125,25 \\
\hline Acenapthylene & 16.6 & .937 & 3 & 152 & 151,76 & 20,30 \\
\hline 1,2-Dimethylnaphthalene & 17.2 & 1.564 & 2 & 151 & 156,115 & 70,25 \\
\hline Acenaphthene- $d_{10}$ (RR-3) & 17.7 & 1.000 & 3 & 162 & 164,80 & 100,40 \\
\hline Acenaphthene & 17.8 & 1.006 & 3 & 153 & 154,152 & 95,50 \\
\hline 2,3,6-Trimethylnaphthalene & 19.1 & 1.079 & 3 & 170 & 155,153 & 100,25 \\
\hline $\mathrm{C}_{3}$-alkylated naphthalene & 19.5 & 1.102 & 3 & 170 & 155,153 & variable \\
\hline 9H-Fluorene & 19.8 & 1.186 & 3 & 166 & 165,82 & 95,15 \\
\hline 1-Methyl-9H-fluorene & 22.0 & 1.243 & 3 & 180 & 165,89 & 130,30 \\
\hline $\mathrm{C}_{4}$-alkylated naphthalene & 23.0 & 1.300 & 3 & 184 & 169,141 & variable \\
\hline Phenanthrene- $d_{10}(\mathbf{R R}-4)$ & 23.3 & 1.000 & 4 & 188 & 189,94 & 15,20 \\
\hline Phenanthrene & 23.4 & 1.004 & 4 & 178 & 176,89 & 20,15 \\
\hline Anthracene & 23.6 & 1.013 & 4 & 178 & 176,89 & 20,15 \\
\hline $\mathrm{C}_{5}$-alkylated naphthalene & 23.9 & 1.026 & 4 & 198 & 183 & variable \\
\hline 2-Methylanthracene & 25.6 & 1.100 & 4 & 192 & 191,96 & 45,10 \\
\hline 4,5-Methylenephenanthrene & 25.7 & 1.103 & 4 & 190 & 189,94 & 90,10 \\
\hline $\mathrm{C}_{1}$-alkylated phenanthrene/anthracene & 25.8 & 1.107 & 4 & 192 & 191,95 & variable \\
\hline 1-Methylphenanthrene & 25.9 & 1.112 & 4 & 192 & 191,94 & 55,5 \\
\hline $\mathrm{C}_{2}$-alkylated phenanthrene/anthracene & 28.0 & 1.202 & 4 & 206 & 191 & variable \\
\hline Fluoranthene & 28.1 & 1.206 & 4 & 202 & 101,203 & 20,15 \\
\hline Pyrene & 28.8 & 1.236 & 4 & 202 & 101,203 & 20,15 \\
\hline $\mathrm{C}_{3}$-alkylated phenanthrene/anthracene & 29.6 & 1.270 & 4 & 220 & 205 & variable \\
\hline Terphenyl- $d_{14}$ & 29.9 & 1.238 & 4 & 244 & 122,245 & 25,20 \\
\hline $\mathrm{C}_{4}$-alkylated phenanthrene/anthracene & 31.0 & 1.330 & 4 & 234 & 219 & variable \\
\hline $\mathrm{C}_{1}$-alkylated fluoranthene/pyrene & 31.0 & 1.330 & 4 & 216 & 215,108 & variable \\
\hline 1-Methylpyrene & 31.1 & 1.335 & 4 & 216 & 215,108 & 70,20 \\
\hline $\mathrm{C}_{2}$-alkylated fluoranthene/pyrene & 32.0 & 1.373 & 4 & 230 & 215 & variable \\
\hline Benz $[a]$ anthracene & 33.4 & .994 & 5 & 228 & 229,226 & 20,25 \\
\hline Chrysene- $d_{12}$ (RR-5) & 33.6 & 1.000 & 5 & 240 & 120,241 & 25,20 \\
\hline Chrysene & 33.7 & 1.003 & 5 & 228 & 229,114 & 20,20 \\
\hline $\mathrm{C}_{3}$-alkylated fluoranthene/pyrene & 34.6 & 1.030 & 5 & 244 & 229 & variable \\
\hline
\end{tabular}


Table 4. Retention times, relative retention times, gas chromatography/mass spectrometry quantitation ions, confirmation ions, and percent relative abundance of confirmation ions for individual polycyclic aromatic hydrocarbons (PAHs) and alkylated PAH homolog groups.-Continued

[Compounds are reported in chromatographic elution order; min, minute; compounds followed by RR are method internal standards and are followed by a designation (RR-1, RR-2,..), which indicates their order as a retention reference; min, minutes; $\mathrm{m} / \mathrm{z}$, mass-to-charge ratio]

\begin{tabular}{|c|c|c|c|c|c|c|}
\hline Compound & $\begin{array}{c}\text { Retention } \\
\text { time } \\
\text { (min) }\end{array}$ & $\begin{array}{c}\text { Relative } \\
\text { retention } \\
\text { time }\end{array}$ & $\begin{array}{l}\text { Retention } \\
\text { reference } \\
\text { compound }\end{array}$ & $\begin{array}{l}\text { Quantitation } \\
\text { ion } \\
(\mathrm{m} / \mathrm{z})\end{array}$ & $\begin{array}{l}\text { Confirmation } \\
\text { ions }(\mathrm{m} / \mathrm{z})\end{array}$ & $\begin{array}{l}\text { Percent relative to } \\
\text { quantitation ion } \\
\text { ab"ndance }\end{array}$ \\
\hline$C_{1}$-alkylated benzo $[a]$ anthracene/chrysene & 35.8 & 1.065 & 5 & 242 & 241,227 & variable \\
\hline $\mathrm{C}_{5}$-alkylated phenanthrene/anthracene & 36.4 & 1.083 & 5 & 248 & 233 & variable \\
\hline $\mathrm{C}_{4}$-alkylated fluoranthene/pyrene & 36.9 & .951 & 6 & 258 & 243 & variable \\
\hline $\mathrm{C}_{2}$-alkylated benzo $[a]$ anthracene/chrysene & 37.3 & 1.110 & 5 & 256 & 241 & variable \\
\hline Benzo $[b]$ fluoranthene & 37.5 & .966 & 6 & 252 & 253,126 & 20,25 \\
\hline Benzo $[k]$ fluoranthene & 37.6 & .969 & 6 & 252 & 253,126 & $2.0,25$ \\
\hline Benzo $[e]$ pyrene- $d_{12}$ & 38.3 & .987 & 6 & 264 & 260,132 & 25,25 \\
\hline Benzo[e]pyrene & 38.4 & .990 & 6 & 252 & 250,126 & 30,20 \\
\hline Benzo $[a]$ pyrene & 38.6 & .995 & 6 & 252 & 250,126 & 25,20 \\
\hline Perylene- $d_{12}$ (RR-6) & 38.8 & 1.000 & 6 & 264 & 260,132 & $\begin{array}{l}2.5,30 \\
2.5,25\end{array}$ \\
\hline Perylene & 38.9 & 1.003 & 6 & 252 & 250,126 & variable \\
\hline $\mathrm{C}_{1}$-alkylated benzopyrene/perylene & 39.8 & 1.026 & 6 & 266 & 251 & variable \\
\hline $\mathrm{C}_{5}$-alkylated fluoranthene/pyrene & 39.8 & 1.026 & 6 & 272 & 257 & variable \\
\hline $\mathrm{C}_{3}$-alkylated benzo $[a]$ anthracene/chrysene & 41.1 & 1.059 & 6 & 270 & 255 & variable \\
\hline $\mathrm{C}_{2}$-alkylated benzopyrene/perylene & 42.0 & 1.082 & 6 & 280 & 265 & \\
\hline Indeno $[1,2,3-c d]$ pyrene & 42.0 & 1.082 & 6 & 276 & 138,137 & $\begin{array}{l}30,20 \\
\text { variable }\end{array}$ \\
\hline $\mathrm{C}_{4}$-alkylated benzo $[a]$ anthracene/chrysene & 42.1 & 1.085 & 6 & 284 & 269 & 30,25 \\
\hline $\operatorname{Dibenz}[a, h]$ anthracene & 42.2 & 1.088 & 6 & 278 & 139,279 & 40,20 \\
\hline Benzo $[g, h, i]$ perylene & 42.7 & 1.101 & 6 & 276 & 138,274 & variable \\
\hline $\mathrm{C}_{3}$-alkylated benzopyrene/perylene & 43.2 & 1.113 & 6 & 294 & 279 & \\
\hline & & & 6 & 298 & & variable \\
\hline $\mathrm{C}_{4}$-alkylated benzopyrene/perylene & 45.0 & $\begin{array}{l}1.105 \\
1.160\end{array}$ & 6 & 308 & $\begin{array}{l}283 \\
293\end{array}$ & $\begin{array}{l}\text { variable } \\
\text { variable }\end{array}$ \\
\hline $\mathrm{C}_{5}$-alkylated benzopyrene/perylene & 45.4 & 1.170 & 6 & 322 & 307 & variable \\
\hline
\end{tabular}

single-component standards to verify retention times and mass spectra of closely eluting or coeluting compounds. Verify retention times following any GC maintenance procedures applied to the capillary columns to improve chromatography.

$$
\text { 8.1.3 Determine retention times for alkylated }
$$

PAH homolog groups. Because authentic standards are not available for many of the substituted PAHs, retention times for these groups are determined by using an alkylated PAH homolog source material (5.9.2). The reference sample is analyzed at about $20 \mathrm{ng} / \mathrm{mL}$.

Extracted ion chromatograms are created using the quantitation and confirmation ions for each alkylated PAH homolog group. The retention times are determined for the first and last isomers for the alkylated PAH homolog group. Quantitation is explained in section 9.4. 8.1.4 Prior to each analytical sequence, assess GC/MS performance by examining peak shape, efficiency of separation for closely eluting compound peirs, and response-factor variation determined for the compounds. Assess these findings prior to the analysis of environmental samples, relative to the performance obtained with a new capillary column, by using freshly prepared CCV (5.10.1) solutions. CCVs are the primary indicator of changes in instrument performance during an analytical sequence and bracket every 10 samples.

\subsection{GC/MS tuning and calibration}

8.2.1 Tune GC/MS prior to analys ${ }^{\text {s }}$ or after any instrument maintenance using automated or other tuning procedures as prescribed by the system manufacturer. Prior to any analysis, verify the GC/MS tune and mass axis calibration by injecting a solution of decafluorotriphenylphosphine (DFTPP). The relative mass fragment abundance and mass assignments need to be within the range of values specified by the U.S. Environmental Protection Agency (1997, p. 265-267). 
8.2.2 Analyze appropriate calibration solutions (5.9.1.1) and determine a best-fit calibration curve using the curve-fitting routines provided by the instrument manufacturer. Carefully inspect the curves to ensure a correlation coefficient $\left(\mathrm{r}^{2}\right)$ of 0.995 or greater and verify that the lowest calibration standard level meets QC criteria. Check the calibration using the third-party check solution (5.10.4), which should result in \pm 25 percent of expected concentrations. If these QC criteria cannot be met, the source of the problem needs to be identified and resolved before a new calibration curve is analyzed and assessed. Instrument maintenance might be necessary or new calibration standards or a TPC solution prepared. After calibration results are determined to be acceptable, assemble samples, set QC samples, mass spectrometer verification solutions, continuing calibration verification solutions, and instrument detection limit solutions into an analytical sequence, and analyze them under conditions identical to those used for the calibration. A typical analytical sequence is listed in table 5 . Use an automated sample injection system to inject $1 \mu \mathrm{L}$ of the appropriate sample extract or standard solution into the GC/MS. Data acquisition conditions for full scan range from 45 to 450 atomic mass units ( $\mathrm{amu}$ ), scanned at a rate of 2.4 scans per second (5-10 scans per peak), with the filament operated at 70 electron volts $(\mathrm{eV})$. Store all data electronically for subsequent qualitative identification, quantitation, and archiving.

\subsection{Qualitative identification}

8.3.1 Criteria and single-component identification. Two criteria are evaluated when establishing a positive compound identification: expected relative retention time and comparative fit of the mass spectrum. The relative retention time (RRT) is the retention time of the compound normalized to the retention time of an internal standard. The internal standard used is one of several perdeuterated polycyclic aromatic hydrocarbons (dPAHIS) added to the sample just prior to analysis. The particular dPAHIS used depends on where in the chromatogram the compound of interest elutes. The formula for determining RRT is

$$
R R T=\frac{T_{c}}{T_{i s}}
$$

where

$$
\begin{gathered}
T_{c}=\text { the retention time (referenced to the start of } \\
\text { the analysis) of the compound of interest, in } \\
\text { minutes; and }
\end{gathered}
$$

\begin{tabular}{|c|c|}
\hline $\begin{array}{l}\text { Analytical } \\
\text { sequence }\end{array}$ & Sample type \\
\hline 1 & $\begin{array}{l}\text { Decafluorotriphenylphosphine mass spectrometer } \\
\text { calibration solution }\end{array}$ \\
\hline 2 & Instrument blank (injection of pure solvent) \\
\hline 3 & Instrument detection level (IDL) solution \\
\hline 4 & Continuing calibration verification (CCV) solution \\
\hline 5 & Set blank \\
\hline 6 & Set PAH spike \\
\hline 7 & Set quality-control reference material sample \\
\hline 8 & Sample 1 \\
\hline 9 & Sample 2 \\
\hline 10 & Sample 3 \\
\hline 11 & Sample 4 \\
\hline 12 & Sample 5 \\
\hline 13 & Sample 6 \\
\hline 14 & Sample 7 \\
\hline 15 & $\mathrm{CCV}$ \\
\hline 16 & Sample 8 \\
\hline 17 & Sample 9 \\
\hline 18 & Sample 10 \\
\hline 19 & Sample 11 \\
\hline 20 & Sample 12 \\
\hline 21 & Sample 13 \\
\hline 22 & $\mathrm{CCV}$ \\
\hline 23 & IDL \\
\hline
\end{tabular}

Table 5. Gas chromatography/mass spectrometry analytical sequence suggested for use in this method.

[PAH, polycyclic aromatic hydrocarbon]

Determine the RRT for each compound by analyzing standard solutions of PAHs and internal standards under identical instrumental conditions as used for samples. Compare RRTs; the match between samples and standards needs to agree within 1 percent. RRTs for PAHs determined in this method are listed in table 4 . The second component for qualitative identification is comparison of library and sample mass spectra. Library mass spectra are derived from authentic compound standards, collected under identical GC/MS cond tions as the sample spectra. The GC/MS operator visually compares library spectra provided by computer routines. In addition, ratios of the integrated abundances of one quantitation ion to two confirmation ions are compared between standards and samples. Peak area ratios of the ions need to agree within \pm 30 percent between standards and samples.

8.3.2 Qualitative identification of the alkylalted PAH homolog groups. Using the approach of Wang and others $(1994,2000)$ and the extracted ion chromatograms as a reference, critically examine peaks within a ratention time window for spectral confirmation and typical alkylated PAH homolog group patterns. Because of the 
variability in ion ratios between isomers for the mulitcomponent groups, there are no rigid criteria. Sum and quantitate the responses for all verified peaks within the retention time window. Note that a characteristic group of peaks defined from the standard analysis is summed to yield a single estimated concentration and it includes the concentrations of the individually identified compounds that are members of the group. For example, concentrations of 1,2-dimethylnaphthalene, 1,6-dimethylnaphthalene, 2,6-dimethylnaphthalene and 2-ethylnaphthalene are included in the reported concentration for $\mathrm{C}_{2}$-alkylated naphthalene. In field samples not all isomers may be present. Figures $2 \mathrm{~A}$ through $2 \mathrm{~F}$ show the complexity of patterns for specified homolog groups.

Figures 2 A through $2 \mathrm{~F}$ show typical patterns for the homolog groups for phenanthrene/anthracene. Figure 2A shows a mass fragmentogram corresponding to the quantitation and monitor ions for the isomeric parent PAHs phenanthrene, 23.46 minutes, and anthracene, 23.65 minutes. Figure $2 \mathrm{~B}$ shows the mass fragmentogram for the five integrated $\mathrm{C}_{1}$-alkylated phenanthrene/ anthracene isomers. Figures $2 \mathrm{C}$ and $2 \mathrm{D}$ show the complex chromatographic pattern of partially resolved components for the $\mathrm{C}_{2}$ - and $\mathrm{C}_{3}$-alkylated phenanthrene/ anthracenes. The peak areas are summed when there is mass spectral agreement for each peak and a reference mass spectrum. The reference spectra are produced from the alklyated PAH homolog retention time source material (5.9.2). Figures $2 \mathrm{E}$ and $2 \mathrm{~F}$ show the retention time windows for the $\mathrm{C}_{4}$ - and $\mathrm{C}_{5}$-alkylated phenanthrene/anthracenes. Although there are peaks in the expected retention time window, no peaks were integrated because of the lack of agreement with the reference mass spectra.

\section{Calculation and Reporting of Results}

The calculation of a final concentration requires multiple equations. A comprehensive discussion of the math is found in Furlong and others (1996).

9.1 Calculate the dry weight of sediment extracted, in $\operatorname{grams}(W s)$ :

$$
W_{s}=W_{u^{\prime}} \times f_{d}
$$

where

$$
\begin{aligned}
& W_{w}=\text { wet weight of sediment, in grams (7.1.6); } \\
& \text { and }
\end{aligned}
$$

\subsection{Calculate the GPC fraction $\left(F_{G P C}\right)$}

where

$$
\begin{aligned}
& F_{G P C}=\text { fraction of the total extract processed } \\
& \text { through the GPC; } \\
& F_{G P C}=\left(W_{1} / W_{2}\right)
\end{aligned}
$$

where

$$
\begin{aligned}
& W_{1}=\text { weight of sample before GPC (7.5.5) minus } \\
& \text { weight of sample after aliquot is collected } \\
& \text { for GPC, in grams (7.5.10); and } \\
& W_{2}=\text { weight of sample before GPC (7.5.5) minus } \\
& \text { tared GPC vial weight, in grams (7.4.1). }
\end{aligned}
$$

\subsection{Determination of single-componert compound concentrations}

The concentration of a compound is calculated after a compound has met qualitative criteria for retention time and mass spectral agreement (see section 8.3.1).

Concentration $(\mu \mathrm{g} / \mathrm{kg})=$

$$
C F r \times\left[V f /\left(W_{s} \times F_{G P C}\right)\right]
$$

where

$$
\begin{aligned}
& C F r=\text { on-column concentration deterrnined by } \\
& V f \quad=\text { final volume of extract, in microliters } \\
& \text { (7.6.5); } \\
& W_{s} \quad=\text { dry weight of sediment extracte } 1 \text {, in grams } \\
& \text { (9.1); and } \\
& F_{G P C}=\text { fraction processed through the GPC (9.2). }
\end{aligned}
$$

Calibration curve-fitting routines are based on the relative response factor (RRF) and are used to obtain a calibration curve for each compound. They are provided by the instrument manufacturer and summarized in Furlong and others (1996). If the calculated cc ncentration of a compound in a sample exceeds the highest concentration point of the calibration curve, dilute the extract to bring the compound response within the range of the calibration curve. If curve-fitting routines (quadratic curves and power curves) are used for calibration, verify that the sample compound response is not outside the working range of the calibration curve.

\subsection{Calculation of multicomponent concentrations \\ 9.4.1 Calculation of alkylated PAHI homolog groups. Each alkylated PAH homolog group ir composed}


of many discernable isomers, many without authentic reference standards. Begin by manually integrating the isomer peak areas based on the appropriate quantitation ion (table 4) present in their expected retention time window range (8.1.3). Using the calibration curves for the compounds selected to represent each homolog group listed in table 6 , calculate the concentration of each alkylated PAH homolog group listed in table 4. Reported concentrations are considered semiquantitative and reported as estimated ("E" coded). If interferences are determined to be present within the integrated isomeric peaks, then manually integrate that portion of the ion chromatogram corresponding to the interference and subtract its peak area from the sum of the peak areas.

Table 6. Relative response factors used for the quantitation of alkylated polycyclic aromatic hydrocarbon homolog series.

$\left[\mathrm{C}_{1}-\mathrm{C}_{5}\right.$, alkylated polycyclic aromatic hydrocarbon homolog series consisting of $\mathrm{C}_{1}, \mathrm{C}_{2}, \mathrm{C}_{3}, \mathrm{C}_{4}, \mathrm{C}_{5}$ groups; $\mathrm{RRF}$, relative response factor]

\begin{tabular}{ll}
\hline \multicolumn{1}{c}{ Homolog series } & $\begin{array}{c}\text { Compound whose RRF is } \\
\text { used for calculations }\end{array}$ \\
\hline $\mathrm{C}_{1}-\mathrm{C}_{5}$ Alkylated naphthalene & $\begin{array}{l}\text { 2,6-Dimethylnaphthalene } \\
\mathrm{C}_{1}-\mathrm{C}_{5} \text { Alkylated phenanthrene/ } \\
\text { anthracene }\end{array}$ \\
$\mathrm{C}_{1}-\mathrm{C}_{5}$ Alkylated fluoranthene/pyrene & 1-Methylpyrene \\
$\mathrm{C}_{1}-\mathrm{C}_{5}$ Alkylated benz $[a]$ anthracene/ \\
chrysene & Benz $[a]$ anthracene \\
$\mathrm{C}_{1}-\mathrm{C}_{5}$ Alkylated benzopyrene/ & Benzo $[a]$ pyrene \\
perylene isomers & \\
\hline
\end{tabular}

9.5 Reporting units - Report compound concentrations for field samples in micrograms per kilogram $(\mu \mathrm{g} / \mathrm{kg})$ dry sediment. Report surrogate data for each sample type as percent recovered. Report data for the set spike and quality-control reference material samples as percent recovered. Compounds quantified in the set blank sample are reported in micrograms per kilogram. Report compound concentrations for field samples to two significant figures.

9.6 Reporting levels-Method detection limits (MDLs) using the procedures outlined by the U.S. Environmental Protection Agency (1997) have been calculated for this method and are discussed further in section 11. The MDL for each compound is used to calculate the minimum reporting levels. Minimum reporting levels have been established at two to five times the calculated MDL. Report qualitatively identified compound concentrations (those PAHs that are identified from relative retention time and MS spectral fit) that are less than the minimum reporting level as estimated ("E" coded) concentrations. Compounds that are not detected are reported as being less than the minimum reporting level. Report qualitatively identified alkylated $\mathrm{PAH}$ homolog groups as estimated ("E" coded) concentrations.

\section{Quality Assurance and Quality Control}

This sediment method adheres to the qualityassurance and quality-control (QA/QC) guidance document (Mark R. Burkhardt and Thomas J. Maloney, U.S. Geological Survey, written commun., 1998) prepared at the NWQL for organic chemistry. It provides a workable procedure for ensuring quality data. Possible scenarios and corrective actions are detailed for each QC sample type in this document. Laboratory reagent blanks and spikes, surrogate standards, and CCVs are used by the analyst to control data quality. Quality-control reference material samples and instrumental checks provide external verification of method performance. They are considered quality-assurance samples.

The laboratory reagent blank (LRB) (see 7.2.2.1) is an analyte- and matrix-free $\left(\mathrm{Na}_{2} \mathrm{SO}_{4}\right)$ sample with minimal analyte interferences. The LRB monitors the entire sample preparation and analytical procedure for possible laboratory contamination. The blank is considered acceptable when a compound is undetected or detected at less than the MRL. Analyte concentrations in the LRB are reported and are not subtracted from the amount detected in an environmental sample. If the concentration of an analyte in the LRB is greater than the MRL, the sample set's data might need to be qualified. If there are interferences that would prevent the analysis of a compound, the source of contamination is determined and eliminated before continuing (Mark R. Burkhardt and Thomas J. Maloney, U.S. Geological Survey, written commun., 1998).

The set laboratory reagent spike (LRS) (see 7.2.2.2) is a matrix-free $\left(\mathrm{Na}_{2} \mathrm{SO}_{4}\right)$ sample fortified with known concentrations of all individual PAH compounds. It is used to monitor method performance recoveries for the set without the effects of sample matrix. The LRS results are compiled for long-term recovery performance used in creating control limits and charts. A series of at least 30 LRS are analyzed and used in the statistical process analysis to create QC criteria updated annually. If the recovery of a compound is not within the criteria, the compound is judged out of control. Before continuing, the source of the problem is identified and resolved. The data for the compounds that fail can be reported as estimated ("E" coded) or at raised reporting levels. 

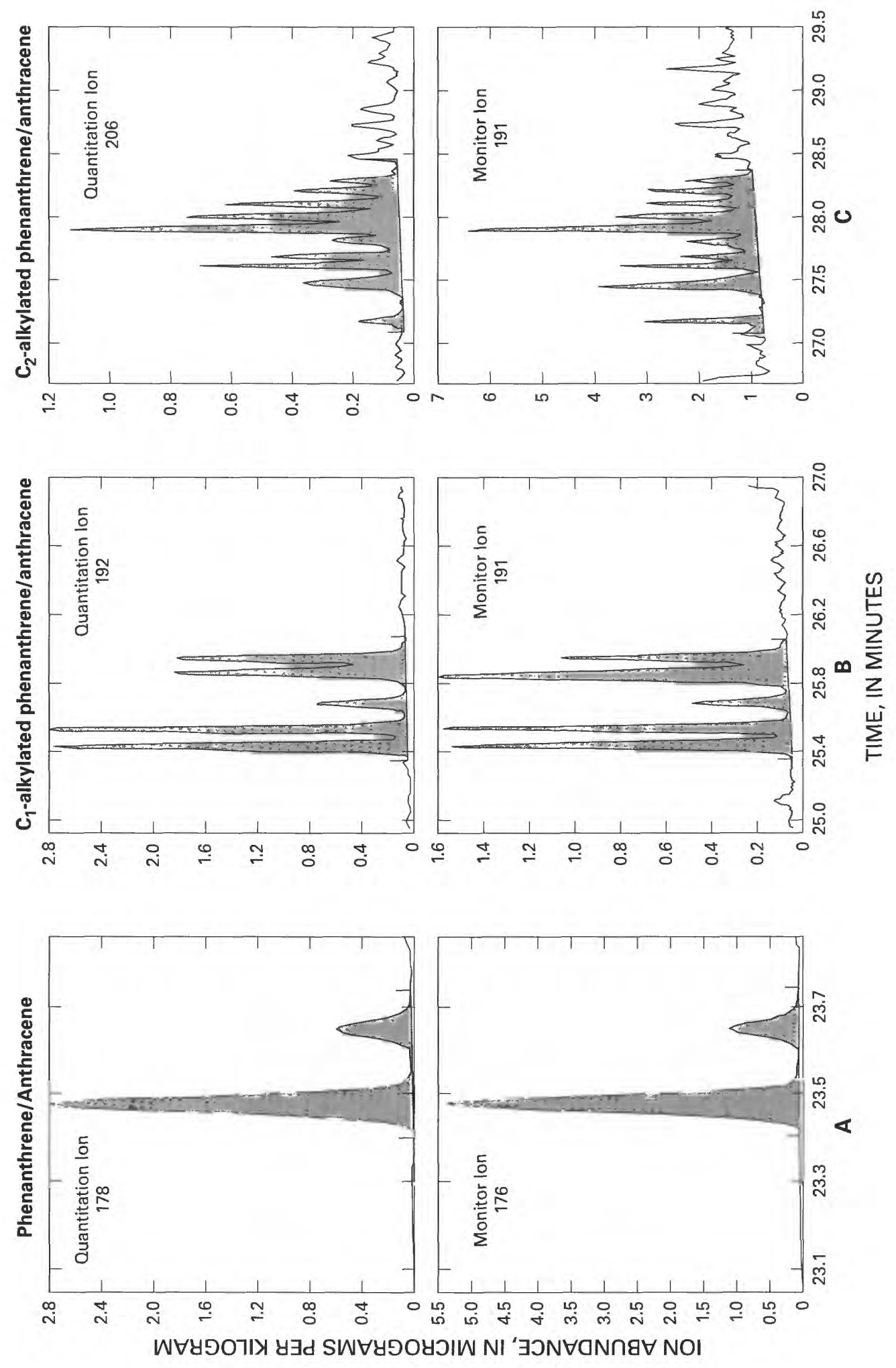

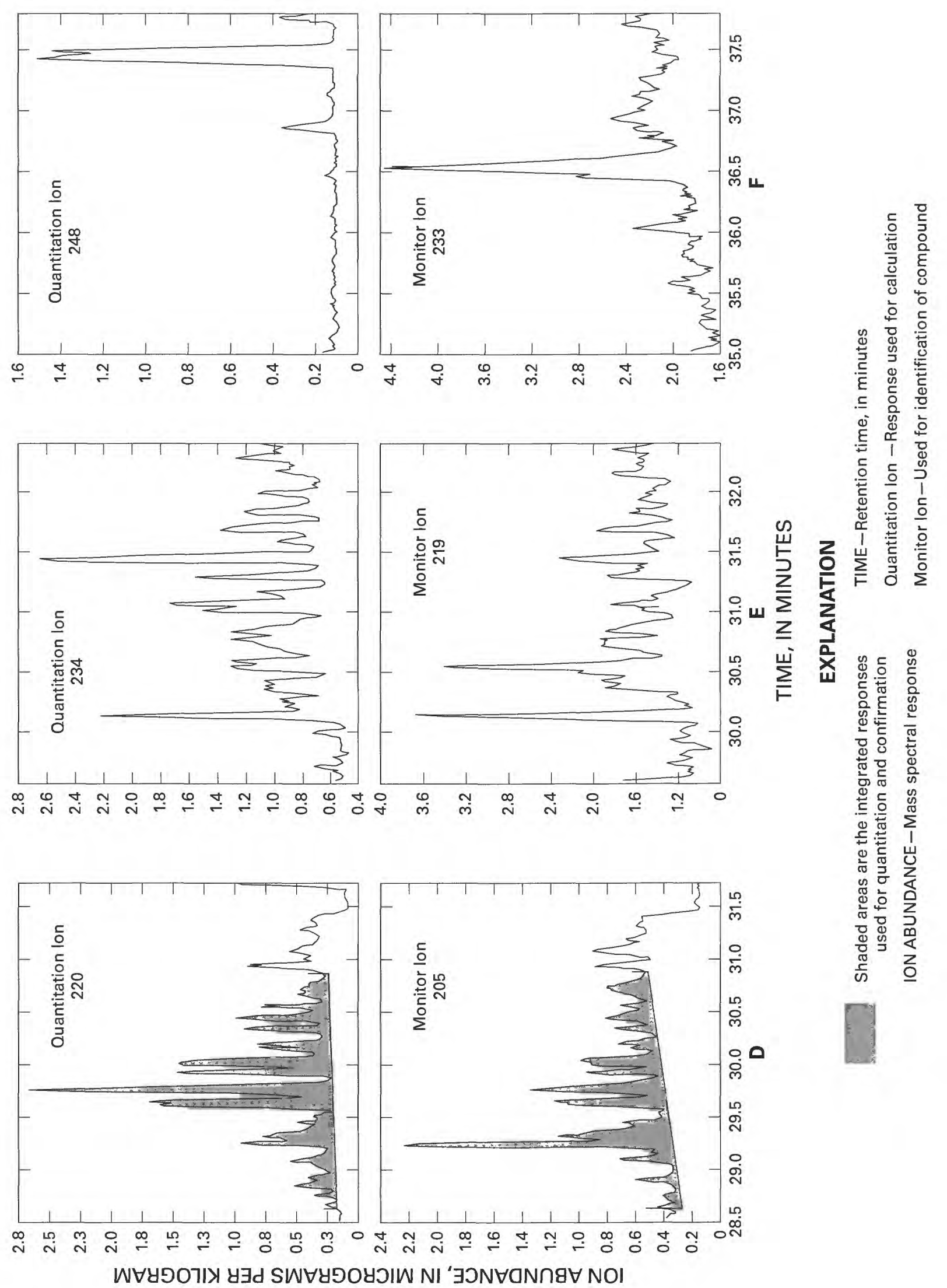

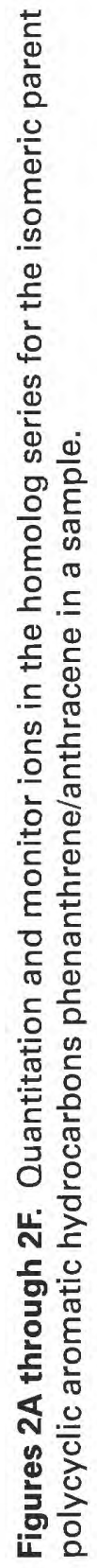


Surrogate standards (5.2.4.1) are compounds similar in physical and chemical properties to the compounds in the method but not expected to be present in the environment. They are added to each environmental and QC sample and used to monitor preparatory steps, matrix effects, and overall method performance. Their recoveries are not used to correct concentrations of the compounds in samples. At least $30 \mathrm{LRBs}$ are used to create QC criteria and are updated annually for each surrogate. The QC criteria are used to evaluate surrogate recoveries in samples. Specific corrective actions are employed if surrogate(s) recoveries fall outside the QC criteria (Mark R. Burkhardt and Thomas J. Maloney, U.S. Geological Survey, written commun., 1998).

CCVs (5.10.1) monitor the instrument's stability in comparison to the calibration curve. They bracket the environmental samples in the analytical sequence. Control limits are established at \pm 25 percent of the expected concentration for each analyte. If a $\mathrm{CCV}$ fails the QC criteria, reanalysis of the affected samples might be required.

Instrumental checks include performance evaluation samples. These are instrument detection limit solutions (5.10.2), third-party check solutions (5.10.4), internal standards (5.7.2) added to the sample extracts, and a solution of DFTPP (5.10.3). The instrument detection limit (IDL) solution (5.10.2) is an aliquot of a low concentration calibration solution $(0.2 \mathrm{ng} / \mu \mathrm{L})$ representing compound concentrations near, but greater than, their respective method detection limit. They bracket the samples in the analytical sequence, and the control limits are established at \pm 25 percent of the expected concentration for each analyte. If an IDL fails the QC criteria, reanalysis of the affected samples might be required. The third-party check solution is made independently from the other standard solutions. Typically it contains all the analytes in the method or at least 1 from every class at a concentration near the midpoint of the calibration curve. It is analyzed after a calibration curve and is expected to fall within \pm 25 percent of the expected value. Internal standards are added for quantitation as well as retention time reference to improve qualitative identification. Their responses are used to assess the quality of the instrumental analysis. DFTPP is analyzed at the beginning of each analytical sequence. It assesses mass spectrometer performance, such as sensitivity and resolution. The relative mass fragment abundance and mass assignments are expected to be within the range of values specified by the U.S. Environmental Protection Agency (1997, p. 265-267).
Quality-control standard reference materials or SRM/CRM (5.2.6) are received from an independent third party to provide objective assessment of methods. Their matrix is a mixture of sediment designed to represent environmental samples. These reference materials typically are certified for a small number of the compounds of interest. These samples are carried through the entire process to monitor performance of sample preparation and the analytical procedure in the presence of a matrix similar to the matrices of the environmental samples. One QC reference material sample is prepared and analyzed with each analytical set. Although the analysis is not controlled on these samples, they provide information about the method long-term recovery performance.

\section{Method Performance}

\section{Polycyclic Aromatic Hydrocarbon Recoveries in Spiked Reagent-Sodium Sulfate and Sediment}

Method performance was determined for $28 \mathrm{PAHs}$ in three matrices at three fortification levels $(4.8,12.0$, and $24.0 \mu \mathrm{g} / \mathrm{kg}$ ). Samples were analyzed using full-scan conditions with an Agilent Technologies 5973 mass selective detector (MSD) GC/MS system. Supplemental data are provided by Furlong and others (1996) using two matrices at three fortification levels $(400,800$, and 2,000 $\mu \mathrm{g} / \mathrm{kg}$ ). The range of fortification concentrations compares with ranges of concentrations in environmental samples.

Matrices chosen to test method performance were: reagent-sodium sulfate (matrix-free); bottom sediment collected from Evergreen Lake, Evergreen, Colorado; and bottom sediment collected near Clear Creek, Colorado. The Evergreen Lake sediment was dredged as part of routine dam maintenance, and the sediment was collected from a mound that had been dredged several weeks prior to collection. The sediment sample is coarse with a substantial sand component. The second sediment type was a sample collected near Clear Creek near Central City, Colorado. This sediment had been size-separated and consisted of particles less than $63 \mu \mathrm{m}$ in diameter. The sediment was light brown, and was received as a dry sample from the donor, whereas the Evergreen Lake sample was collected by NWQL personnel.

\subsection{Bias and precision}

The performance of this method for the extraction, isolation, and determination of the PAHs was evaluated by adding aliquots of standard solutions to seven $25-\mathrm{g}$ dry-weight subsamples of each matrix and processing the fortified samples through the entire method. Three $25-\mathrm{g}$ 
dry-weight unfortified samples from each matrix were processed to determine the background concentrations of any ambient compounds. The separate sets of seven subsamples from each matrix were fortified with 4.8 , 12.0 , and $24.0 \mu \mathrm{g} / \mathrm{kg}$ of each PAH. Final recoveries were adjusted by subtracting the mean background concentrations measured in the three unfortified samples. Laboratory reagent spikes and laboratory reagent blanks were processed with each set.

Bias (percent mean recovery) and precision (percent relative standard deviation) for all matrices are listed in table 7. Background concentrations of the three matrices are listed in table 8 . At the $4.8-\mu \mathrm{g} / \mathrm{kg}$ spiking level in sodium sulfate, the recoveries ranged from 4.6 to 97.0 percent and the percent relative standard deviations (percent RSD) ranged from 5.5 to 170.9. The percent recoveries were low (4.6-43.5 percent) for the lighter compounds with molecular weights of $166 \mathrm{~g} /$ mole or less. The lighter compounds are more volatile and more inclined to loss during the preparatory steps. At the higher spike level of $12.0 \mu \mathrm{g} / \mathrm{kg}$ in sodium sulfate, the percent recoveries ranged from 51.7 to 93.5 percent with RSDs from 3.7 to 16.9 percent. At the spike level of $24.0 \mu \mathrm{g} / \mathrm{kg}$ in sodium sulfate the percent recoveries ranged from 50.4 to 94.5 percent with RSDs from 4.8 to 17.1 percent. The recoveries in the sodium sulfate matrix are lower than the recoveries in the other sediment matrices and likely are caused by the retention of the analytes throughout the procedure by presence of the matrix.

At the $4.8-\mu \mathrm{g} / \mathrm{kg}$ spiking level in the Evergreen Lake sediment the recoveries ranged from 58.6 to 106.8 percent and the percent relative standard deviations (percent RSD) ranged from 3.5 to 123.3 . The recoveries in the Evergreen Lake sediment at the $12.0-\mu \mathrm{g} / \mathrm{kg}$ spiking level ranged from 36.5 to 93.9 percent with RSDs from 13.6 to 92.0 percent. At the $24.0-\mu \mathrm{g} / \mathrm{kg}$ spiking level, recoveries ranged from 49.1 to 138.4 percent with RSDs from 6.1 to 79.1 percent. The RSDs for Evergreen Lake sediment were expectedly high for the $12.0-$ and $24.0-\mu \mathrm{g} / \mathrm{kg}$ spike levels for phenanthrene, fluoranthene, pyrene, benz $[a]$ anthracene, chrysene, benzo $[b]$ fluoranthene, benzo $[k]$ fluoranthene, benzo $[e]$ pyrene, benzo $[a]$ pyrene, perylene, and indeno $[1,2,3-c d]$ pyrene. This high variability probably is caused by the high background contributions varying among spike samples indicated by the large standard deviations for these compounds in the matrix background samples.

At the $4.8-\mu \mathrm{g} / \mathrm{kg}$ spiking level in the Clear Creek sediment, the recoveries ranged from 23.5 to 107.6 percent and the RSDs ranged from 5.6 to 168.5 percent. The recoveries in the Clear Creek sediment at the $12.0-\mu \mathrm{g} / \mathrm{kg}$ spiking level ranged from 40.6 to 102.5 percent with RSDs from 3.8 to 38.8 percent. $A \mathrm{t}$ the $24.0-\mu \mathrm{g} / \mathrm{kg}$ spiking level, recoveries ranged from 47.3 to 99.2 percent with RSDs from 3.2 to 24.2 percent. The RSDs for the Clear Creek sediment improved as the concentration increased, thereby minimizing the effects of variation in background concentrations.

The method surrogates were added to each sample at $20 \mu \mathrm{g} / \mathrm{kg}$ and are listed at the end of table $7 . T^{*} \cdot$ average percent recovery for the three fortification levels was highest in sodium sulfate at 78.1 percent. The average percent recovery was 67.6 percent in Evergreen Lake sediment and 73.7 percent in Clear Creek sediment. Even though sediment matrices provide retention of compounds, they often add to the variability among measured results because of background matrix effects. The highest RSDs are seen in nitrobenzene- $d_{5}$, which range from 11.9 to 32.6 percent likely because of higher volatility at the lower molecular weight ( $128 \mathrm{~g} / \mathrm{mole})$.

\subsection{Bias and precision from Furlong and others} (1996)

Furlong and others (1996) calculated bias and precision data for two sediment matrices. The sediment samples were taken from Evergreen Lake and the Mississippi River. High spike-performance data are listed in tables 9,10 , and 11 and were acquired using the same methodology as the present report.

The analyte list in Furlong and others (19ऽ5) is larger than the list in the present report. To make it easier to read, the analytes of interest were extracted from the original tables. Note that two analytes are missing from Furlong's list that are included in the present report's list: benzo $[e]$ pyrene and perylene. Because they are isomers of benzo $[a]$ pyrene, which is included in both lists, their performance data are comparable.

\subsubsection{Evergreen Lake sediment-The}

Evergreen Lake sediment from Furlong and others (1996) is the same as the matrix used in section 11.1.1 of the present report. Two subsets of seven samples of each analyte were spiked at 800 and $2,000 \mu \mathrm{g} / \mathrm{kg}$. Calculated mean recoveries, standard deviation of mean recovery, and relative standard deviation, in percent, are listed in tables 9 and 10. Final recoveries were adjusted by subtracting the mean concentrations of detected background compounds measured in the three unfortified samples.

The recoveries in the Evergreen Lake sediment at the $800-\mu \mathrm{g} / \mathrm{kg}$ spiking level ranged from 50.3 to 117.3 percent with RSDs from 1.6 to 46.2 percent; at the $2,000-\mu \mathrm{g} / \mathrm{kg}$ spiking level, recoveries ranged from 49.7 to 69.5 percent, with RSDs from 4.0 to 26.8 percent. 
Table 7. Bias and precision data of polycyclic aromatic hydrocarbon spike recoveries for seven replicates using full-scan acquisition with compound concentrations of $4.8,12.0$, and 24.0 micrograms per kilogram in three matrices.

[Percent recovery corrected for ambient environmental concentration. Method detection limits calculated using the data for sodium sulfate results (reagent spikes). $\mu \mathrm{g} / \mathrm{kg}$, micrograms per kilogram; RSD, relative standard deviation; ND, not detected; MDL, method detection limit]

\begin{tabular}{|c|c|c|c|c|c|c|c|c|}
\hline \multirow{2}{*}{ Compound } & \multirow{2}{*}{$\begin{array}{l}\text { Amount } \\
\text { spiked } \\
\text { (pg/kg) }\end{array}$} & \multicolumn{2}{|c|}{ Sodium sulfate } & \multicolumn{2}{|c|}{$\begin{array}{l}\text { Evergreen Lake } \\
\text { sediment }\end{array}$} & \multicolumn{2}{|c|}{$\begin{array}{l}\text { Clear Creek } \\
\text { sediment }\end{array}$} & \multirow{2}{*}{$\underset{(\mu \mathrm{g} / \mathrm{kg})}{\mathrm{MDL}}$} \\
\hline & & $\begin{array}{l}\text { Percent } \\
\text { recovery }{ }^{1}\end{array}$ & $\begin{array}{l}\text { Percent } \\
\text { RSD }\end{array}$ & $\begin{array}{c}\text { Percent } \\
\text { recovery } 1\end{array}$ & $\begin{array}{l}\text { Percent } \\
\text { RSD }\end{array}$ & $\begin{array}{c}\text { Percent } \\
\text { recovery }\end{array}$ & $\begin{array}{l}\text { Percent } \\
\text { RSD }\end{array}$ & \\
\hline \multirow[t]{3}{*}{ Naphthalene } & 4.8 & 4.6 & 170.9 & 60.7 & 9.9 & 23.5 & 117.1 & \\
\hline & 12.0 & 77.0 & 13.7 & 36.5 & 23.3 & 40.6 & 24.6 & 4.0 \\
\hline & 24.0 & 70.7 & 6.1 & 49.1 & 16.6 & 47.3 & 10.1 & \\
\hline \multirow[t]{3}{*}{ 2-Ethylnaphthalene } & 4.8 & 15.2 & 48.7 & 67.3 & 13.7 & 76.4 & 11.9 & \\
\hline & 12.0 & 77.9 & 9.2 & 59.7 & 16.7 & 71.0 & 4.7 & 3.1 \\
\hline & 24.0 & 69.8 & 6.2 & 62.0 & 28.3 & 68.2 & 11.0 & \\
\hline \multirow[t]{3}{*}{ 2,6-Dimethylnaphthalene } & 4.8 & 10.4 & 100.4 & 73.5 & 10.4 & 81.9 & 13.6 & \\
\hline & 12.0 & 78.1 & 10.4 & 57.6 & 19.2 & 79.2 & 8.7 & 3.1 \\
\hline & 24.0 & 70.2 & 6.8 & 67.3 & 11.7 & 75.6 & 8.6 & \\
\hline \multirow[t]{3}{*}{ 1,6-Dimethylnaphthalene } & 4.8 & 10.7 & 73.7 & 77.7 & 10.7 & 76.7 & 15.8 & \\
\hline & 12.0 & 78.0 & 5.2 & 58.9 & 14.6 & 77.4 & 7.3 & 1.5 \\
\hline & 24.0 & 65.1 & 6.5 & 70.0 & 15.1 & 72.0 & 7.7 & \\
\hline \multirow[t]{3}{*}{ Acenaphthylene } & 4.8 & 17.6 & 68.5 & 86.0 & 8.4 & 43.4 & 17.9 & \\
\hline & 12.0 & 75.8 & 9.6 & 55.8 & 16.7 & 63.1 & 12.7 & 2.7 \\
\hline & 24.0 & 71.8 & 9.7 & 63.1 & 9.1 & 67.5 & 6.5 & \\
\hline \multirow[t]{3}{*}{ 1,2-Dimethylnaphthalene } & 4.8 & 20.5 & 50.8 & 69.6 & 5.4 & 78.1 & 8.9 & \\
\hline & 12.0 & 76.4 & 8.9 & 66.1 & 14.4 & 71.7 & 11.7 & 2.6 \\
\hline & 24.0 & 70.1 & 4.8 & 71.6 & 11.9 & 69.9 & 9.6 & \\
\hline \multirow[t]{3}{*}{ Acenapthene } & 4.8 & 30.1 & 20.7 & 77.4 & 11.8 & 91.0 & 25.6 & \\
\hline & 12.0 & 76.1 & 8.3 & 63.5 & 14.5 & 68.8 & 9.5 & 2.4 \\
\hline & 24.0 & 73.0 & 9.0 & 71.4 & 11.5 & 68.3 & 5.0 & \\
\hline \multirow[t]{3}{*}{ 2,3,6-Trimethylnaphthalene } & 4.8 & 39.3 & 12.8 & 80.4 & 9.0 & 84.4 & 10.5 & \\
\hline & 12.0 & 74.9 & 3.7 & 70.4 & 16.2 & 83.1 & 4.8 & 5.1 \\
\hline & 24.0 & 66.4 & 4.8 & 78.5 & 10.3 & 77.4 & 7.7 & \\
\hline \multirow[t]{3}{*}{ 9H-Fluorene } & 4.8 & 43.5 & 14.5 & 87.5 & 3.6 & 97.6 & 18.1 & \\
\hline & 12.0 & 74.8 & 11.9 & 74.6 & 16.3 & 80.5 & 7.4 & 3.4 \\
\hline & 24.0 & 69.8 & 8.6 & 80.3 & 8.6 & 79.5 & 3.8 & \\
\hline \multirow[t]{3}{*}{ 1-Methyl-9H-fluorene } & 4.8 & 52.1 & 28.4 & 106.8 & 7.1 & 103.8 & 5.6 & \\
\hline & 12.0 & 76.9 & 6.9 & 81.0 & 13.6 & 92.1 & 3.8 & 2.0 \\
\hline & 24.0 & 77.3 & 8.3 & 86.6 & 6.1 & 89.6 & 6.9 & \\
\hline \multirow[t]{3}{*}{ Phenanthrene } & 4.8 & 60.1 & 9.3 & 81.2 & 84.9 & 60.1 & 168.5 & \\
\hline & 12.0 & 82.0 & 9.6 & 79.7 & 37.1 & 100.6 & 14.6 & 3.0 \\
\hline & 24.0 & 79.2 & 5.3 & 94.1 & 29.3 & 93.9 & 15.4 & \\
\hline \multirow[t]{3}{*}{ Anthracene } & 4.8 & 57.4 & 16.1 & 76.2 & 16.0 & 86.5 & 33.9 & \\
\hline & 12.0 & 73.3 & 10.2 & 72.1 & 19.9 & 76.7 & 10.0 & 2.8 \\
\hline & 24.0 & 68.3 & 9.2 & 80.1 & 10.6 & 81.7 & 5.6 & \\
\hline
\end{tabular}


Table 7. Bias and precision data of polycyclic aromatic hydrocarbon spike recoveries for seven replicates using full-scan z cquisition with compound concentrations of $4.8,12.0$, and 24.0 micrograms per kilogram in three matrices.-Continued

[Percent recovery corrected for ambient environmental concentration. Method detection limits calculated using the data for sodium sulfate results (reagent spikes). $\mu \mathrm{g} / \mathrm{kg}$, micrograms per kilogram; RSD, relative standard deviation; ND, not detected; MDL, method detection limit]

\begin{tabular}{|c|c|c|c|c|c|c|c|c|}
\hline \multirow{2}{*}{ Compound } & \multirow{2}{*}{$\begin{array}{l}\text { Amount } \\
\text { spiked } \\
\text { ( } \mathrm{gg} / \mathbf{k g} \text { ) }\end{array}$} & \multicolumn{2}{|c|}{ Sodium sulfate } & \multicolumn{2}{|c|}{$\begin{array}{l}\text { Evergreen Lake } \\
\text { sediment }\end{array}$} & \multicolumn{2}{|c|}{$\begin{array}{l}\text { Clear Creek } \\
\text { sediment }\end{array}$} & \multirow{2}{*}{$\underset{(\mu \mathrm{g} / \mathrm{kg})}{\mathrm{MDL}}$} \\
\hline & & $\begin{array}{l}\text { Percent } \\
\text { recovery }{ }^{1}\end{array}$ & $\begin{array}{l}\text { Percent } \\
\text { RSD }\end{array}$ & $\begin{array}{l}\text { Percent } \\
\text { recovery } 1\end{array}$ & $\begin{array}{l}\text { Percent } \\
\text { RSD }\end{array}$ & $\begin{array}{l}\text { Percent } \\
\text { recovery }{ }^{1}\end{array}$ & $\begin{array}{l}\text { Percent } \\
\text { RSD }\end{array}$ & \\
\hline \multirow[t]{3}{*}{ 2-Methylanthracene } & 4.8 & 62.2 & 22.1 & 93.3 & 6.2 & 80.9 & 12.5 & \multirow{3}{*}{1.7} \\
\hline & 12.0 & 72.3 & 6.1 & 69.7 & 17.7 & 93.2 & 5.5 & \\
\hline & 24.0 & 73.3 & 6.1 & 80.8 & 7.5 & 88.5 & 7.8 & \\
\hline \multirow[t]{3}{*}{ 4,5-Methylenephenanthrene } & 4.8 & 67.9 & 10.5 & 95.6 & 3.5 & 85.8 & 23.1 & \multirow{3}{*}{2.7} \\
\hline & 12.0 & 79.4 & 9.0 & 79.4 & 15.7 & 102.5 & 6.6 & \\
\hline & 24.0 & 78.9 & 8.2 & 90.8 & 10.1 & 92.9 & 4.3 & \\
\hline \multirow[t]{3}{*}{ 1-Methylphenanthrene } & 4.8 & 76.2 & 8.5 & 77.7 & 11.8 & 79.5 & 11.0 & \multirow{3}{*}{2.1} \\
\hline & 12.0 & 80.4 & 6.8 & 80.8 & 16.5 & 83.7 & 8.1 & \\
\hline & 24.0 & 79.5 & 6.9 & 91.1 & 7.0 & 85.8 & 4.3 & \\
\hline \multirow[t]{3}{*}{ Fluoranthene } & 4.8 & 87.5 & 14.8 & 88.3 & 123.3 & 87.5 & 157.8 & \multirow{3}{*}{1.3} \\
\hline & 12.0 & 86.9 & 4.0 & 83.9 & 59.9 & 99.4 & 38.8 & \\
\hline & 24.0 & 85.8 & 7.3 & 129.5 & 53.8 & 98.9 & 22.6 & \\
\hline \multirow[t]{3}{*}{ Pyrene } & 4.8 & 79.8 & 8.2 & 79.2 & 96.3 & 80.9 & 148.4 & \multirow{3}{*}{2.8} \\
\hline & 12.0 & 88.3 & 8.3 & 89.3 & 52.4 & 101.2 & 38.0 & \\
\hline & 24.0 & 86.6 & 9.1 & 124.2 & 63.9 & 97.2 & 19.9 & \\
\hline \multirow[t]{3}{*}{ 1-Methylpyrene } & 4.8 & 92.6 & 7.1 & 101.8 & 5.3 & 91.7 & 9.3 & \multirow{3}{*}{3.7} \\
\hline & 12.0 & 86.3 & 11.4 & 92.4 & 14.4 & 101.3 & 4.5 & \\
\hline & 24.0 & 86.8 & 6.2 & 102.0 & 7.9 & 98.5 & 3.2 & \\
\hline \multirow{3}{*}{ Benz $[a]$ anthracene } & 4.8 & 87.2 & 9.4 & 81.3 & 45.3 & 95.8 & 100.1 & \multirow{3}{*}{2.2} \\
\hline & 12.0 & 89.9 & 6.4 & 86.9 & 26.5 & 82.0 & 19.8 & \\
\hline & 24.0 & 94.5 & 9.6 & 125.6 & 52.6 & 88.5 & 12.7 & \\
\hline \multirow[t]{3}{*}{ Chrysene } & 4.8 & 83.6 & 6.0 & 63.0 & 73.8 & 74.7 & 121.2 & \multirow{3}{*}{1.7} \\
\hline & 12.0 & 93.5 & 4.8 & 84.9 & 29.2 & 86.0 & 22.3 & \\
\hline & 24.0 & 91.2 & 6.9 & 130.3 & 61.2 & 88.9 & 13.2 & \\
\hline \multirow[t]{3}{*}{$\operatorname{Benzo}[b]$ fluoranthene } & 4.8 & 97.0 & 7.6 & 80.3 & 44.5 & 64.1 & 118.6 & \multirow{3}{*}{1.6} \\
\hline & 12.0 & 75.5 & 5.7 & 92.6 & 30.1 & 63.7 & 27.6 & \\
\hline & 24.0 & 80.8 & 11.9 & 138.4 & 76.0 & 82.5 & 15.3 & \\
\hline \multirow[t]{3}{*}{ Benzo $[k]$ fluoranthene } & 4.8 & 91.4 & 5.5 & 70.9 & 38.8 & 58.3 & 139.7 & \multirow{3}{*}{3.2} \\
\hline & 12.0 & 90.5 & 9.4 & 80.3 & 26.2 & 101.1 & 15.0 & \\
\hline & 24.0 & 93.0 & 10.3 & 118.3 & 61.5 & 99.2 & 16.4 & \\
\hline Benzo[e]pyrene & 4.8 & 80.1 & 5.8 & 78.5 & 21.1 & 74.0 & 83.1 & \\
\hline & 12.0 & 75.1 & 6.4 & 93.9 & 24.7 & 84.0 & 10.8 & 2.4 \\
\hline & 24.0 & 72.1 & 7.1 & 101.6 & 55.4 & 69.1 & 13.4 & \\
\hline Benzo $[a]$ pyrene & 4.8 & 72.9 & 11.5 & 78.7 & 49.8 & 63.8 & 126.7 & \\
\hline & 12.0 & 77.9 & 6.3 & 84.7 & 28.1 & 73.0 & 31.4 & 1.8 \\
\hline & 24.0 & 73.0 & 4.9 & 131.3 & 79.1 & 80.8 & 16.8 & \\
\hline
\end{tabular}


Table 7. Bias and precision data of polycyclic aromatic hydrocarbon spike recoveries for seven replicates using full-scan acquisition with compound concentrations of 4.8, 12.0, and 24.0 micrograms per kilogram in three matrices. - Continued

[Percent recovery corrected for ambient environmental concentration. Method detection limits calculated using the data for sodium sulfate results (reagent spikes). $\mu \mathrm{g} / \mathrm{kg}$, micrograms per kilogram; RSD, relative standard deviation; ND, not detected: MDL, method detection limit]

\begin{tabular}{|c|c|c|c|c|c|c|c|c|}
\hline \multirow{2}{*}{ Compound } & \multirow{2}{*}{$\begin{array}{c}\text { Amount } \\
\text { spiked } \\
(\mu \mathrm{gg} / \mathrm{kg})\end{array}$} & \multicolumn{2}{|c|}{ Sodium sulfate } & \multicolumn{2}{|c|}{$\begin{array}{l}\text { Evergreen Lake } \\
\text { sediment }\end{array}$} & \multicolumn{2}{|c|}{ Clear Creek sediment } & \multirow{2}{*}{$\begin{array}{c}\text { MDL } \\
(\mu \mathrm{g} / \mathrm{kg})\end{array}$} \\
\hline & & $\begin{array}{l}\text { Percent } \\
\text { recovery }{ }^{1}\end{array}$ & $\begin{array}{l}\text { Percent } \\
\text { RSD }\end{array}$ & $\begin{array}{c}\text { Percent } \\
\text { recovery }\end{array}$ & $\begin{array}{l}\text { Percent } \\
\text { RSD }\end{array}$ & $\begin{array}{c}\text { Percent } \\
\text { recovery }\end{array}$ & $\begin{array}{l}\text { Percent } \\
\text { RSD }\end{array}$ & \\
\hline \multirow[t]{3}{*}{ Perylene } & 4.8 & 67.6 & 12.8 & 72.1 & 17.5 & 81.6 & 38.3 & \\
\hline & 12.0 & 78.0 & 11.0 & 87.5 & 92.0 & 75.7 & 12.0 & 3.1 \\
\hline & 24.0 & 75.6 & 10.8 & 104.9 & 49.3 & 83.8 & 7.6 & \\
\hline \multirow[t]{3}{*}{ Indeno $[1,2,3-c d]$ pyrene } & 4.8 & 81.3 & 12.9 & 89.1 & 39.8 & 67.2 & 105.9 & \\
\hline & 12.0 & 88.8 & 11.4 & 90.3 & 25.7 & 69.9 & 24.4 & 3.8 \\
\hline & 24.0 & 83.4 & 7.0 & 125.1 & 67.8 & 73.0 & 19.7 & \\
\hline \multirow[t]{3}{*}{ Dibenz $[a, h]$ anthracene } & 4.8 & 75.0 & 12.2 & 70.7 & 11.4 & 107.6 & 21.3 & \\
\hline & 12.0 & 88.2 & 7.6 & 93.7 & 17.4 & 101.2 & 5.7 & 2.5 \\
\hline & 24.0 & 92.0 & 8.2 & 103.3 & 15.6 & 84.1 & 5.5 & \\
\hline \multirow[t]{3}{*}{ Benzo $[g, h, i]$ perylene } & 4.8 & 80.1 & 9.4 & 58.6 & 41.6 & 33.7 & 127.4 & \\
\hline & 12.0 & 51.7 & 16.9 & 75.3 & 32.6 & 63.6 & 26.4 & 3.3 \\
\hline & 24.0 & 50.4 & 17.1 & 93.8 & 62.1 & 52.1 & 24.2 & \\
\hline \multicolumn{9}{|c|}{$\begin{array}{l}\text { Method Surrogates } \\
\text { (Add to all samples at } 20 \mu \mathrm{g} / \mathrm{kg} \text { ) }\end{array}$} \\
\hline \multirow[t]{3}{*}{ Nitrobenzene- $d_{5}$} & 4.8 & 67.6 & 11.9 & 61.3 & 12.2 & 67.8 & 12.6 & \\
\hline & 12.0 & 86.8 & 10.7 & 53.3 & 20.9 & 63.3 & 26.4 & \\
\hline & 24.0 & 70.9 & 12.4 & 51.6 & 15.8 & 52.5 & 32.6 & \\
\hline \multirow[t]{3}{*}{ 2-Fluorobiphenyl } & 4.8 & 70.3 & 9.3 & 62.7 & 8.0 & 69.8 & 12.4 & \\
\hline & 12.0 & 71.1 & 5.8 & 58.4 & 15.7 & 60.0 & 4.2 & \\
\hline & 24.0 & 67.1 & 3.3 & 56.7 & 13.1 & 62.9 & 14.3 & \\
\hline \multirow[t]{3}{*}{ Terphenyl- $d_{14}$} & 4.8 & 87.1 & 6.2 & 85.6 & 6.5 & 92.0 & 3.2 & \\
\hline & 12.0 & 90.4 & 6.4 & 89.2 & 12.9 & 97.0 & 6.6 & \\
\hline & 24.0 & 90.8 & 5.8 & 90.4 & 8.7 & 98.4 & 7.0 & \\
\hline
\end{tabular}

${ }^{1}$ Percent recovery corrected for background.

When comparing the percent recoveries for the Evergreen Lake sediment for 12.0, 24.0, 800, and $2,000 \mu \mathrm{g} / \mathrm{kg}$, there are similar recoveries but higher variability at the lower spike levels demonstrated by the higher percent RSDs. This result is caused by the background contributions having a greater effect in variability at the lower concentrations than at the higher concentrations. For example, a background concentration of $11.3 \mu \mathrm{g} / \mathrm{kg}$ for fluoranthene in the Evergreen Lake sediment with a standard deviation of $2.9 \mu \mathrm{g} / \mathrm{kg}$ creates more variability at the $12-\mu \mathrm{g} / \mathrm{kg}$ spiking level than at the $800-\mu \mathrm{g} / \mathrm{kg}$ spiking level. The compound with the lowest percent recovery is naphthalene at $36.5,49.1,50.3$ and 53.7 percent recovered for the four spiking levels. This finding most likely is caused by its lower molecular weight and higher volatility. Overall, the similarities among the four levels indicate the method is consistent over time.

\subsubsection{Mississippi River sediment-}

The matrix was a bottom sediment sample collected from the lower Mississippi River in 1986 and was received dry and size separated of particles less than $63 \mu \mathrm{m}$ in diameter from the donor. A set of seven subsamples was spiked at $400 \mu \mathrm{g} / \mathrm{kg}$; calculated mean recoveries, standard deviation of mean recovery, and relative standard deviation, all in percent, are listed in table 11.

The recoveries in the Mississippi River sediment samples ranged from 27.2 to 104.1 parcent with RSDs from 9.0 to 18.6 percent. 
Table 8. Polycyclic aromatic hydrocarbon matrix background concentrations in full-scan acquisition.

[ $\mu \mathrm{g} / \mathrm{kg}$, micrograms per kilogram. Concentrations are expressed as an equivalent dry weight of $25 \mathrm{grams} ; \mathrm{n}=3$ ]

\begin{tabular}{|c|c|c|c|c|c|c|}
\hline \multirow[b]{2}{*}{ Compound } & \multicolumn{3}{|c|}{ Mean concentration $(\mu \mathrm{g} / \mathrm{kg})$} & \multicolumn{3}{|c|}{ Standard deviation $(\mu \mathrm{g} / \mathrm{r})$} \\
\hline & $\begin{array}{l}\text { Sodium } \\
\text { sulfate }\end{array}$ & $\begin{array}{l}\text { Evergreen } \\
\text { Lake }\end{array}$ & $\begin{array}{l}\text { Clear } \\
\text { Creek }\end{array}$ & $\begin{array}{l}\text { Sodium } \\
\text { sulfate }\end{array}$ & $\begin{array}{c}\text { Evergreen } \\
\text { Lake }\end{array}$ & $\begin{array}{l}\text { Clear } \\
\text { Creek }\end{array}$ \\
\hline Naphthalene & 0 & 0.3 & 5.3 & 0 & 0.6 & 4.0 \\
\hline 2-Ethylnaphthalene & 0 & 0 & 0 & 0 & 0 & 0 \\
\hline 2,6-Dimethylnaphthalene & 0 & 0 & .5 & 0 & 0 & .8 \\
\hline 1,6-Dimethylnaphthalene & 0 & 0 & .9 & 0 & 0 & 1.6 \\
\hline Acenaphthylene & 0 & 0 & 3.5 & 0 & 0 & 1.2 \\
\hline 1,2-Dimethylnaphthalene & 0 & 0 & 0 & 0 & 0 & 0 \\
\hline Acenaphthene & 0 & 0 & 0 & 0 & 0 & 0 \\
\hline 2,3,6-Trimethylnaphthalene & 0 & 0 & 0 & 0 & 0 & 0 \\
\hline 9H-Fluorene & 0 & 0 & 0 & 0 & 0 & 0 \\
\hline 1-Methyl-9H-fluorene & 0 & 0 & .5 & 0 & 0 & .9 \\
\hline Phenanthrene & 0 & 5.8 & 16.1 & 0 & 1.9 & 10.6 \\
\hline Anthracene & 0 & 2.1 & 3.1 & 0 & .2 & .6 \\
\hline 2-Methylanthracene & 0 & .4 & 1.6 & 0 & .6 & .2 \\
\hline 4,5-Methylenephenanthrene & 0 & .4 & 1.5 & 0 & .6 & .2 \\
\hline 1-Methylphenanthrene & 0 & 1.8 & 2.3 & 0 & .3 & .8 \\
\hline Fluoranthene & 0 & 11.3 & 23.1 & 0 & 2.9 & 6.8 \\
\hline Pyrene & 0 & 9.2 & 21.0 & 0 & 2.4 & 6.0 \\
\hline 1-Methylpyrene & 0 & 0 & 1.4 & 0 & .0 & .3 \\
\hline $\operatorname{Benz}[a]$ anthracene & 0 & 4.9 & 9.4 & 0 & .8 & 2.5 \\
\hline Chrysene & 0 & 8.1 & 15.0 & 0 & 1.5 & 2.6 \\
\hline Benzo $[b]$ fluoranthene & 0 & 4.6 & 11.6 & 0 & 1.2 & 1.4 \\
\hline Benzo $[k]$ fluoranthene & 0 & 4.1 & 10.1 & 0 & 1.0 & 1.9 \\
\hline Benzo $[e]$ pyrene & 0 & 3.6 & 8.1 & 0 & .9 & 1.3 \\
\hline Benzo $[a]$ pyrene & 0 & 6.5 & 12.8 & 0 & 1.2 & 1.4 \\
\hline Perylene & 0 & 7.0 & 2.5 & 0 & .2 & .8 \\
\hline Indeno $[1,2,3-c d]$ pyrene & 0 & 3.4 & 9.7 & 0 & 3.0 & 1.7 \\
\hline Dibenzo $[a, h]$ anthracene & 0 & 1.2 & .7 & 0 & 2.1 & 1.2 \\
\hline Benzo $[g, h, i]$ perylene & 0 & 2.9 & 7.6 & 0 & .9 & .9 \\
\hline
\end{tabular}

\subsection{Method detection limits}

The NWQL uses the long-term method detection level procedure (Childress and others, 1999) to determine compound-reporting conventions for water analytical methods. Because of the varied nature of sediment samples, the long-term method detection level procedure has not been implemented for sediment analyses.

Method detection limits (MDLs) were established using procedures outlined by the U.S. Environmental Protection Agency (1997). For this method, the MDL was determined by analyzing a set of seven replicate reagent (sodium sulfate) spike samples fortified at $12.0 \mu \mathrm{g} / \mathrm{kg}$ for PAHs. For the set of seven samples, the sample standard deviation was computed and the MDL calculated from the following formula:

$$
M D L=S \times t(n-1,1-\alpha=0.99)
$$

where

$S=$ standard deviation of replicate analyses, in micrograms per kilogram;

$t_{(n-1,1-\alpha=0.99)}=$ Student's $t$-value for the 99-percent confidence level with $n-1$ degrees of freedom; and

$n=$ number of replicate analyses.

The MDLs were calculated at the $12.0-\mu \mathrm{g} / \mathrm{kg}$ concentration because of the better recoveries and greater precision than at the $4.8-\mu \mathrm{g} / \mathrm{kg}$ spiking concentration. The MDLs range from $1.3 \mu \mathrm{g} / \mathrm{kg}$ for fluoranthene to 5.1 $\mu \mathrm{g} / \mathrm{kg}$ for 2,3,6-trimethylnaphthalene, a lighter compound more inclined to volatile losses. The spiking concentration at $12.0 \mu \mathrm{g} / \mathrm{kg}$ was two to five times the anticipated MDL. The calculated MDL for each compound is listed in table 7. 
Table 9. Recovery of semivolatile organic compounds from Evergreen Lake sediment samples spiked at 800 micrograms pe` kilogram.

$[\mu \mathrm{g} / \mathrm{kg}$, micrograms per kilogram; $\mathrm{n}$, number of determinations used to calculate means and standard deviations; < ERL, less than estimated reporting limit. Method compounds spiked at an equivalent sediment concentration of $800 \mu \mathrm{g} / \mathrm{kg}$. Method surrogates spiked at a concentration of $160 \mu \mathrm{g} / \mathrm{kg}$.]

\begin{tabular}{|c|c|c|c|c|c|c|}
\hline $\begin{array}{c}\text { Compound } \\
\text { (in elution order) }\end{array}$ & $\begin{array}{c}\text { Mean } \\
\text { amount } \\
\text { recovered } \\
(\mu \mathrm{g} / \mathrm{kg})\end{array}$ & $\begin{array}{l}\text { Standard } \\
\text { deviation of } \\
\text { amount } \\
\text { recovered } \\
(\mu \mathrm{g} / \mathrm{kg})\end{array}$ & $\begin{array}{c}\text { Mean } \\
\text { recovery } \\
\text { (percent) }\end{array}$ & $\begin{array}{c}\text { Standard } \\
\text { deviation of } \\
\text { mean } \\
\text { recovery } \\
\text { (percent) }\end{array}$ & $\begin{array}{l}\text { Relative } \\
\text { stantard } \\
\text { deviation } \\
\text { (percent) }\end{array}$ & $n$ \\
\hline Naphthalene & 403 & 186 & 50.3 & 23.3 & 46.2 & 7 \\
\hline 1,6-Dimethylnaphthalene & 567 & 140 & 70.9 & 17.5 & 24.7 & 7 \\
\hline Acenaphthylene & 639 & 122 & 79.9 & 15.3 & 19.2 & 7 \\
\hline 1,2-Dimethylnaphthalene & 620 & 116 & 77.5 & 14.4 & 18.6 & 7 \\
\hline Acenaphthene & 648 & 105 & 81.0 & 13.1 & 16.2 & 7 \\
\hline 2,3,6-Trimethylnaphthalene & 670 & 83 & 83.7 & 10.4 & 12.4 & 7 \\
\hline 2-Methylanthracene & 938 & 41 & 117.3 & 5.1 & 4.4 & 7 \\
\hline 4,5-Methylenephenanthrene & 883 & 41 & 110.3 & 5.1 & 4.6 & 7 \\
\hline 1-Methylphenanthrene & 833 & 38 & 104.1 & 4.8 & 4.6 & 7 \\
\hline Fluoranthene & 862 & 21 & 107.7 & 2.7 & 2.5 & 7 \\
\hline Pyrene & 770 & 21 & 96.3 & 2.6 & 2.7 & 7 \\
\hline 1-Methylpyrene & 775 & 24 & 96.8 & 3.0 & 3.1 & 7 \\
\hline Benz $[a]$ anthracene & 813 & 13 & 101.6 & 1.6 & 1.6 & 7 \\
\hline Chrysene & 779 & 21 & 97.4 & 2.6 & 2.7 & 7 \\
\hline Benzo $[b]$ fluoranthene & 649 & 27 & 81.1 & 3.3 & 4.1 & 7 \\
\hline Benzo $[k]$ fluoranthene & 811 & 59 & 101.3 & 7.4 & 7.3 & 7 \\
\hline Benzo $[a]$ pyrene & 633 & 22 & 79.2 & 2.8 & 3.5 & 7 \\
\hline
\end{tabular}

Minimum reporting levels (MRLs) are assigned to compounds based on a combination of MDL data developed during method validation, observed matrix interference, and the effect of the varied matrices on instrument performance. Results are not censored at the MRL for this method because compounds are determined by mass spectrometry, and, therefore, the method is considered to be information rich (Childress and others, 1999). The MRL for the PAH compounds is $10 \mu \mathrm{g} / \mathrm{kg}$.
The method reporting levels for the alkylated PAH homolog groups are based on the method reporting levels of the compounds selected to represent each gooup (table 6) because of the lack of authentic standards. The MRL is $10 \mu \mathrm{g} / \mathrm{kg}$. They will be permanently reported as estimated ("E" coded). The concentrations of these groups are considered estimates because although the qualitative criteria were met for their detection, their concentrations are based on calibration using compounds that are different from those being determined. 
Table 10. Recovery of semivolatile organic compounds from Evergreen Lake sediment samples spiked at 2,000 micrograms per kilogram.

$[\mu \mathrm{g} / \mathrm{kg}$, micrograms per kilogram; $n$, number of determinations used to calculate means and standard deviations; < ERL, less than estimated repor'ing limit. Method compounds spiked at an equivalent sediment concentration of $2,000 \mu \mathrm{g} / \mathrm{kg}$. Method surrogates spiked at a concentration of $160 \mu \mathrm{g} / \mathrm{kg}$.]

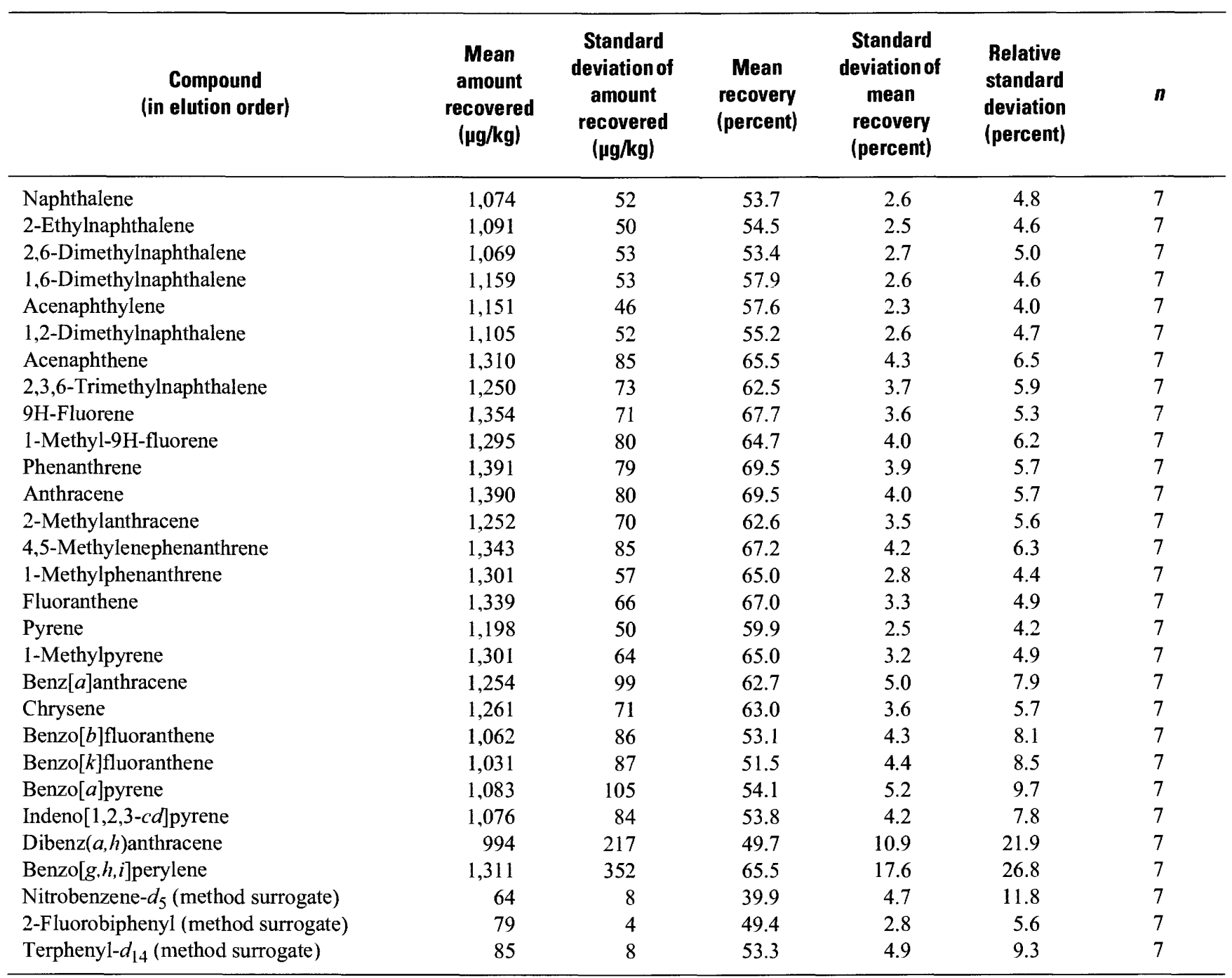

11.4 Performance data using standard reference materials

The SRMs analyzed routinely are $1941 \mathrm{~b}$ and 1944. They are produced by the National Institute of Standards and Technology (NIST) and areused to evaluate analytical methods. They consist of natural sediment and have been certified for specific PAHs as well as other contaminates. Many alkylated PAH homolog groups are present but are not certified. The certified PAHs and uncertified alkylated $\mathrm{PAH}$ homolog groups present and their concentrations are appropriate for this method.

\subsubsection{Standard Reference Material}

$1941 b$ - The NIST SRM $1941 \mathrm{~b}$ is a marine se liment collected at the mouth of Baltimore Harbor in Maryland. A set of seven samples was prepared and anal'zed using the present report's method. Table 12 lists the performance data for the PAHs certified through NIST. These recoveries ranged from 68.2 to 178 percent and RSDs from 0.77 to 9.25 percent. The high recoveries and the low RSDs suggest the method is performing well. Benzo[ $k]$ fluoranthene recovery was 178 percent and dibenz $[a, h]$ anthracene recovery was 156 percent. SRM $1941 \mathrm{~b}$ was certified using slightly different preparation protocols, different extraction solvents, and is lation procedures than were used in this method. 
Table 11. Recovery of semivolatile organic compounds from Mississippi River sediment samples spiked at 400 micrograms per kilogram.

[ $\mu \mathrm{g} / \mathrm{kg}$, micrograms per kilogram; $n$, number of determinations used to calculate mean standard deviations; < ERL, less than estimated reporting limit. Method compounds spiked at an equivalent sediment concentration of $400 \mu \mathrm{g} / \mathrm{kg}$. Method surrogates spiked at a concentration of $160 \mu \mathrm{g} / \mathrm{kg}$.]

\begin{tabular}{|c|c|c|c|c|c|c|}
\hline $\begin{array}{l}\text { Compound } \\
\text { (in elution order) }\end{array}$ & $\begin{array}{c}\text { Mean } \\
\text { amount } \\
\text { recovered } \\
(\mu \mathrm{g} / \mathrm{kg})\end{array}$ & $\begin{array}{c}\text { Standard } \\
\text { deviation of } \\
\text { amount } \\
\text { recovered } \\
(\mu \mathrm{g} / \mathrm{kg})\end{array}$ & $\begin{array}{c}\text { Mean } \\
\text { recovery } \\
\text { (percent) }\end{array}$ & $\begin{array}{c}\text { Standard } \\
\text { deviation of } \\
\text { mean } \\
\text { recovery } \\
\text { (percent) }\end{array}$ & $\begin{array}{l}\text { Relative } \\
\text { standard } \\
\text { deviation } \\
\text { (percent) }\end{array}$ & $n$ \\
\hline Naphthalene & 221 & 39 & 55.3 & 9.8 & 17.7 & 7 \\
\hline 2-Ethylnaphthalene & 109 & 16 & 27.2 & 3.9 & 14.5 & 7 \\
\hline 2.6-Dimethylnaphthalene & 128 & 16 & 32.0 & 4.0 & 12.5 & 7 \\
\hline 1,6-Dimethylnaphthalene & 110 & 17 & 27.5 & 4.3 & 15.6 & 7 \\
\hline Acenaphthylene & 306 & 30 & 76.5 & 7.6 & 10.0 & 7 \\
\hline 1,2-Dimethylnaphthalene & 131 & 14 & 32.9 & 3.4 & 10.3 & 7 \\
\hline Acenaphthene & 316 & 32 & 78.9 & 8.0 & 10.2 & 7 \\
\hline 2,3,6-Trimethylnaphthalene & 122 & 12 & 30.4 & 3.0 & 9.9 & 7 \\
\hline 9H-Fluorene & 325 & 39 & 81.2 & 9.7 & 11.9 & 7 \\
\hline 1-Methyl-9H-fluorene & 118 & 16 & 29.4 & 4.1 & 14.0 & 7 \\
\hline Phenanthrene & 311 & 37 & 77.7 & 9.2 & 11.9 & 7 \\
\hline Anthracene & 302 & 36 & 75.4 & 8.9 & 11.8 & 7 \\
\hline 2-Methylanthracene & 90 & 10 & 22.5 & 2.6 & 11.6 & 7 \\
\hline 4,5-Methylenephenanthrene & 123 & 12 & 30.9 & 3.0 & 9.8 & 7 \\
\hline 1-Methylphenanthrene & 131 & 24 & 32.8 & 6.1 & 18.6 & 7 \\
\hline Fluoranthene & 335 & 43 & 83.8 & 10.7 & 12.8 & 7 \\
\hline Pyrene & 290 & 36 & 72.5 & 9.0 & 12.4 & 7 \\
\hline 1-Methylpyrene & 114 & 10 & 28.4 & 2.6 & 9.0 & 7 \\
\hline Benz $[a]$ anthracene & 302 & 33 & 75.5 & 8.2 & 10.9 & 7 \\
\hline Chrysene & 323 & 42 & 80.8 & 10.4 & 12.9 & 7 \\
\hline Benzo $[b]$ fluoranthene & 300 & 42 & 75.1 & 10.5 & 14.0 & 7 \\
\hline Benzo $[k]$ fluoranthene & 294 & 39 & 73.6 & 9.7 & 13.1 & 7 \\
\hline Benzo $[a]$ pyrene & 297 & 38 & 74.3 & 9.6 & 12.9 & 7 \\
\hline Indeno $[1,2,3-c d]$ pyrene & 314 & 36 & 78.6 & 9.1 & 11.5 & 7 \\
\hline Dibenz $[a, h]$ anthracene & 373 & 50 & 93.4 & 12.5 & 13.4 & 7 \\
\hline Benzo $[g, h, i]$ perylene & 416 & 55 & 104.1 & 13.7 & 13.2 & 7 \\
\hline Nitrobenzene- $d_{5}$ (method surrogate) & 88.4 & 16.2 & 55.3 & 10.1 & 18.3 & 6 \\
\hline 2-Fluorobiphenyl (method surrogate) & 141 & 11 & 88.4 & 6.7 & 7.6 & 7 \\
\hline Terphenyl- $d_{14}$ (method surrogate) & 125 & 15 & 78.0 & 9.4 & 12.1 & 7 \\
\hline
\end{tabular}

Table 13 lists mean concentrations of alkylated PAH homolog groups present, but which are not reported, in the SRM certification documents supplied with SRM 1941b. Many of the alkylated PAH homolog groups were not present, which is common in environmental samples. The RSDs are all less than 7 percent, thus showing good agreement between measurements.

\subsubsection{Standard Reference Material}

1944-The NIST SRM 1944 is a mixture of marine sediment. A set of seven samples was prepared and analyzed using the present report's method. Table 14 lists performance data for the PAHs certified through NIST.
These recoveries ranged from 49.3 to 127 percent and RSDs from 5.53 to 10.5 percent. The high recoveries and the low RSDs suggest the method is performing well.

Table 15 lists mean concentrations of alkylated PAH homolog groups present, but which are rot reported in the SRM certification documents supplied with SRM 1944. The RSDs are all less than 12 percent, thus showing good agreement between measurements. Not all of the alkylated PAH homolog groups were present. 
Table 12. Polycyclic aromatic hydrocarbon concentrations certified by the National Institute of Standards and Technology for Stardard Reference Material 1941b and determined using this method.

$[\mu \mathrm{g} / \mathrm{kg}$, micrograms per kilogram; number of analyses $=7]$

\begin{tabular}{|c|c|c|c|c|}
\hline Compound & $\begin{array}{l}\text { Expected concentration } \\
(\mu \mathrm{g} / \mathrm{kg})\end{array}$ & $\begin{array}{c}\text { Measured mean } \\
\text { concentration }(\mu \mathrm{g} / \mathrm{kg})\end{array}$ & $\begin{array}{l}\text { Recovery } \\
\text { percent) }\end{array}$ & $\begin{array}{l}\text { Relative standard } \\
\text { deviation (percent) }\end{array}$ \\
\hline Anthracene & 184 & 196 & 107 & 2.29 \\
\hline Benz $[a]$ anthracene & 335 & 384 & 115 & 3.53 \\
\hline Benzo $[b]$ fluoranthene & 453 & 476 & 105 & 6.98 \\
\hline Benzo $[k]$ fluoranthene & 225 & 402 & 178 & 3.50 \\
\hline Benzo $[g, h, i]$ perylene & 307 & 209 & 68.2 & 3.46 \\
\hline Benzo $[a]$ pyrene & 358 & 355 & 99.2 & 4.63 \\
\hline Benzo[e]pyrene & 325 & 303 & 93.3 & 3.16 \\
\hline Chrysene & 291 & 363 & 125 & 2.87 \\
\hline Dibenz $[a, h]$ anthracene & 53.0 & 82.6 & 156 & 5.72 \\
\hline Fluoranthene & 651 & 613 & 94.1 & 1.78 \\
\hline 9H-Fluorene & 85.0 & 92.0 & 108 & 4.00 \\
\hline Indeno $[1,2,3-c d]$ pyrene & 341 & 407 & 119 & 9.25 \\
\hline 1-Methylphenanthrene & 73.2 & 81.3 & 111 & 4.23 \\
\hline Naphthalene & 848 & 621 & 73.3 & 282 \\
\hline Perylene & 397 & 347 & 87.4 & 226 \\
\hline Phenanthrene & 406 & 340 & 83.7 & 0.77 \\
\hline Pyrene & 581 & 508 & 87.5 & 1.39 \\
\hline
\end{tabular}

Table 13. Alkylated polycyclic aromatic hydrocarbon homolog group concentrations detected in Standard Reference Material 1941b not reported by the National Institute of Standards and Technology and determined using this method.

$[\mu \mathrm{g} / \mathrm{kg}$, micrograms per kilogram; NR, not reported; -, no data; number of analyses=7]

\begin{tabular}{|c|c|c|c|}
\hline Compound & $\begin{array}{c}\text { Measured mean } \\
\text { concentration }(\mu \mathrm{g} / \mathrm{kg})\end{array}$ & $\begin{array}{c}\text { Standard deviation } \\
(\mu \mathrm{g} / \mathrm{kg})\end{array}$ & $\begin{array}{l}\text { Relative standard } \\
\text { deviation (percent) }\end{array}$ \\
\hline$C_{1}$-alkylated naphthalene & 448 & 18.3 & 4.09 \\
\hline $\mathrm{C}_{2}$-alkylated naphthalene & 478 & 25.0 & 5.22 \\
\hline $\mathrm{C}_{3}$-alkylated naphthalene & 690 & 27.2 & 3.95 \\
\hline $\mathrm{C}_{4}$-alkylated naphthalene & NR & - & - \\
\hline $\mathrm{C}_{5}$-alkylated naphthalene & NR & - & - \\
\hline$C_{1}$-alkylated phenanthrene/anthracene & 456 & 7.06 & 1.55 \\
\hline $\mathrm{C}_{2}$-alkylated phenanthrene/anthracene & 413 & 8.15 & 1.97 \\
\hline $\mathrm{C}_{3}$-alkylated phenanthrene/anthracene & 300 & 14.6 & 4.85 \\
\hline $\mathrm{C}_{4}$-alkylated phenanthrene/anthracene & NR & - & - \\
\hline $\mathrm{C}_{5}$-alkylated phenanthrene/anthracene & NR & - & - \\
\hline $\mathrm{C}_{1}$-alkylated fluoranthene/pyrene & 576 & 13.4 & 2.33 \\
\hline $\mathrm{C}_{2}$-alkylated fluoranthene/pyrene & 427 & 24.2 & 5.68 \\
\hline $\mathrm{C}_{3}$-alkylated fluoranthene/pyrene & NR & - & - \\
\hline $\mathrm{C}_{4}$-alkylated fluoranthene/pyrene & NR & - & - \\
\hline $\mathrm{C}_{5}$-alkylated fluoranthene/pyrene & NR & - & - \\
\hline $\mathrm{C}_{1}$-alkylated benzo $[a]$ anthracene/chrysene & 389 & 27.2 & 6.98 \\
\hline $\mathrm{C}_{2}$-alkylated benzo $[a]$ anthracene/chrysene & NR & - & - \\
\hline $\mathrm{C}_{3}$-alkylated benzo $[a]$ anthracene/chrysene & NR & - & - \\
\hline $\mathrm{C}_{4}$-alkylated benzo $[a]$ anthracene/chrysene & NR & - & - \\
\hline $\mathrm{C}_{5}$-alkylated benzo $[a]$ anthracene/chrysene & NR & - & - \\
\hline$C_{1}$-alkylated benzopyrene/perylene & 409 & 27.6 & 6.75 \\
\hline $\mathrm{C}_{2}$-alkylated benzopyrene/perylene & NR & - & - \\
\hline $\mathrm{C}_{3}$-alkylated benzopyrene/perylene & NR & - & - \\
\hline $\mathrm{C}_{4}$-alkylated benzopyrene/perylene & NR & - & - \\
\hline $\mathrm{C}_{5}$-alkylated benzopyrene/perylene & NR & - & - \\
\hline
\end{tabular}




\section{Determination of Polycyclic Aromatic Hydrocarbon Compounds in Sediment}

Table 14. Polycyclic aromatic hydrocarbon concentrations certified by the National Institute of Standards and Technology for Standard Reference Material 1944 and determined using this method.

$[\mu \mathrm{g} / \mathrm{kg}$, micrograms per kilogram; number of analyses $=7]$

\begin{tabular}{lcccc}
\hline \multicolumn{1}{c}{ Compound } & $\begin{array}{c}\text { Expected } \\
\text { concentration } \\
(\boldsymbol{\mu g} / \mathbf{k g})\end{array}$ & $\begin{array}{c}\text { Measured mean } \\
\text { concentration } \\
(\boldsymbol{\mu g} / \mathbf{k g})\end{array}$ & $\begin{array}{c}\text { Recovery } \\
\text { (percent) }\end{array}$ & $\begin{array}{c}\text { Relative standard } \\
\text { deviation (percent) }\end{array}$ \\
\hline Anthracene & 1,770 & 1,440 & 81.3 & 7.79 \\
Benz[ $a$ ]anthracene & 4,720 & 3,870 & 81.9 & 6.78 \\
Benzo[b]fluoranthene & 3,870 & 3,160 & 81.7 & 8.63 \\
Benzo[k]fluoranthene & 2,300 & 2,920 & 127 & 7.30 \\
Benzo[g,h,i]perylene & 2,840 & 1,680 & 59.2 & 7.05 \\
Benzo[ $a$ ]pyrene & 4,300 & 3,170 & 73.6 & 7.61 \\
Benzo[e]pyrene & 3,280 & 2,480 & 75.6 & 6.67 \\
Chrysene & 4,860 & 4,470 & 92.1 & 7.22 \\
Dibenz[a,h]anthracene & 424 & 347 & 81.8 & 7.38 \\
Fluoranthene & 8,920 & 6,670 & 74.8 & 6.07 \\
Indeno[1,2,3-cd]pyrene & 2,780 & 2,820 & 102 & 6.77 \\
Naphthalene & 1,650 & 820 & 49.3 & 10.5 \\
Perylene & 1,170 & 740 & 63.3 & 7.13 \\
Phenanthrene & 5,270 & 3,970 & 75.3 & 6.36 \\
Pyrene & 9,700 & 6,580 & 67.8 & 5.53 \\
\hline
\end{tabular}

Table 15. Alkylated polycyclic aromatic hydrocarbon homolog group concentrations detected in Standard Reference Material 1944 not reported by the National Institute of Standards and Technology and determined using this method.

[ $\mu \mathrm{g} / \mathrm{kg}$, micrograms per kilogram; NR, not reported; -, no data; number of analyses=7]

\begin{tabular}{|c|c|c|c|}
\hline Compound & $\begin{array}{c}\text { Measured mean } \\
\text { concentration } \\
(\mu \mathrm{g} / \mathrm{kg})\end{array}$ & $\begin{array}{c}\text { Standard } \\
\text { deviation }(\mu \mathrm{g} / \mathbf{k g})\end{array}$ & $\begin{array}{l}\text { Relative standard } \\
\text { deviation } \\
\text { (percent) }\end{array}$ \\
\hline $\mathrm{C}_{1}$-alkylated naphthalene & 1,090 & 131 & 12.0 \\
\hline $\mathrm{C}_{2}$-alkylated naphthalene & 2,630 & 242 & 9.19 \\
\hline $\mathrm{C}_{3}$-alkylated naphthalene & 6,180 & 480 & 7.78 \\
\hline $\mathrm{C}_{4}$-alkylated naphthalene & NR & - & - \\
\hline $\mathrm{C}_{5}$-alkylated naphthalene & NR & - & - \\
\hline $\mathrm{C}_{1}$-alkylated phenanthrene/anthracene & 5,630 & 660 & 11.7 \\
\hline $\mathrm{C}_{2}$-alkylated phenanthrene/anthracene & 6,110 & 373 & 6.11 \\
\hline $\mathrm{C}_{3}$-alkylated phenanthrene/anthracene & 3,330 & 263 & 7.90 \\
\hline $\mathrm{C}_{4}$-alkylated phenanthrene/anthracene & NR & - & - \\
\hline $\mathrm{C}_{5}$-alkylated phenanthrene/anthracene & NR & - & - \\
\hline $\mathrm{C}_{1}$-alkylated fluoranthene/pyrene & 7,930 & 548 & 6.91 \\
\hline $\mathrm{C}_{2}$-alkylated fluoranthene/pyrene & 5,430 & 562 & 10.4 \\
\hline $\mathrm{C}_{3}$-alkylated fluoranthene/pyrene & NR & - & - \\
\hline $\mathrm{C}_{4}$-alkylated fluoranthene/pyrene & NR & - & - \\
\hline $\mathrm{C}_{5}$-alkylated fluoranthene/pyrene & NR & - & - \\
\hline $\mathrm{C}_{1}$-alkylated benzo $[a]$ anthracene/chrysene & 4,570 & 354 & 7.74 \\
\hline $\mathrm{C}_{2}$-alkylated benzo $[a]$ anthracene/chrysene & 1,980 & 157 & 7.96 \\
\hline $\mathrm{C}_{3}$-alkylated benzo $[a]$ anthracene/chrysene & NR & - & - \\
\hline $\mathrm{C}_{4}$-alkylated benzo $[a]$ anthracene/chrysene & NR & - & - \\
\hline $\mathrm{C}_{5}$-alkylated benzo $[a]$ anthracene/chrysene & NR & - & - \\
\hline $\mathrm{C}_{1}$-alkylated benzopyrene/perylene & 4,860 & 473 & 9.73 \\
\hline $\mathrm{C}_{2}$-alkylated benzopyrene/perylene & NR & - & - \\
\hline $\mathrm{C}_{3}$-alkylated benzopyrene/perylene & NR & - & - \\
\hline $\mathrm{C}_{4}$-alkylated benzopyrene/perylene & NR & - & - \\
\hline $\mathrm{C}_{5}$-alkylated benzopyrene/perylene & NR & - & - \\
\hline
\end{tabular}




\section{Summary and Conclusions}

This report presents a method for the determination of 28 polycyclic aromatic hydrocarbon (PAH) compounds and 25 groups of alkylated PAH homologs in sediment using gas chromatography/mass spectrometry. Method improvements include low $(10 \mu \mathrm{g} / \mathrm{kg})$ detection limits and full-scan flexibility. The alkylated PAH homolog groups are reported as estimated in the absence of authentic standards. This method has the ability to determine PAH compounds, organochlorine pesticides, polychlorinated biphenyls, and organophosphate pesticides from the same sample extraction.

Extensive information is given for the preparation of the sediment samples and the analytical design for the detection of these compounds. The preparation includes a Soxhlet extraction, compound isolation using gel-permeation chromatography, and concentration through solvent reduction. Gas chromatography/mass spectrometry is used for the analytical detection and quantitation. Quantitation ions and monitor ions are provided and their use is illustrated with fragmentograms.

Performance data were presented for three matrices for the 28 PAH compounds at three spiking levels. The matrices were reagent sodium sulfate and two bed sediments. The spiking levels $(4.8,12.0$, and $24.0 \mu \mathrm{g} / \mathrm{kg})$ were designed to locate and refine the method detection limit for each PAH. The 4.8- $\mu \mathrm{g} / \mathrm{kg}$ spiking level proved too low, with recoveries for many of the volatile compounds less than 40 percent and with high relative standard deviations greater than 50 percent. A $10-\mu \mathrm{g} / \mathrm{kg}$ minimum reporting level was calculated using the data from the $12-\mu \mathrm{g} / \mathrm{kg}$ spiking level in the reagent sodium sulfate because recoveries were greater than 50 percent and relative standard deviations were less than 20 percent. The recoveries and percent relative standard deviations for the $24-\mu \mathrm{g} / \mathrm{kg}$ spiking level were similar to the $12-\mu \mathrm{g} / \mathrm{kg}$ spiking level for the three matrices. Higher spike levels and environmental data concentrations were provided by Furlong and others (1996) using a method similar to the method described in this report. Using two sediment matrices and the same preparatory procedure, they spiked compounds at three levels: 400,800 and 2,000 $\mu \mathrm{g} / \mathrm{kg}$. The recoveries were similar to the $24-\mu \mathrm{g} / \mathrm{kg}$ spiking level (greater than 50 percent), but the percent relative standard deviations were higher, less than 46.2 percent for the $800-\mu \mathrm{g} / \mathrm{kg}$ spiking level and less than 26.8 percent for the $2,000-\mu \mathrm{g} / \mathrm{kg}$ spiking level.

Standard reference materials provided additional data showing good method precision for the certified compounds and the uncertified alkylated PAH homolog groups. The two standard reference materials were NIST $1941 \mathrm{~b}$ and 1944. The recoveries for the certified compounds in standard reference material $1941 \mathrm{~b}$ ranged from 68.2 to 178 percent with percent relative standard deviations less than 10.0 . The percent relative standard deviations for the detected alkylated $\mathrm{PAH}$ homolog groups were less than 7 percent. The recoveries for the certified compounds in standard reference materials 1944 ranged from 49.3 to 127 percent with percent relative standard deviations less than 10.5. The parcent relative standard deviations for the detected alkylated PAH homolog groups were less than 12.0 percent.

The method described proves a preparatory pronedure and analytical design to detect and quantitate $28 \mathrm{PAH}$ compounds and 25 groups of alkylated PAH homologs in sediment samples.

\section{References Cited}

Childress, C.J.O., Foreman, W.T., Connor, B.F., ard Maloney, T. J., 1999, New reporting procedures based on long-term method detection levels and some consideration: for interpretations of water-quality data provided by the U.S. Geological Survey National Water Quality Laboratory: U.S. Geological Survey Open-File Report 99-193, 19 p.

Fishman, M.J., ed., 1993, Methods of analysis by tl $\odot$ U.S. Geological Survey National Water Quality Laborato*y-Determination of inorganic and organic constituents in water and fluvial sediments: U.S. Geological Survey Open-File Report 93-125, $217 \mathrm{p}$.

Furlong, E.T., Vaught, D.G., Merten, L.M., Forem`n, W.T., and Gates, P.M., 1996, Methods of analysis by th $\because$ U.S. Geological Survey National Water Quality Laborato"y-Determination of semivolatile organic compounds in bottom sediment by solvent extraction, gel permeation chromatographic fractionation, and capillary-column gas chromatography/mass spectrometry: U.S. Geological Survey Open-File Report 95-719, $67 \mathrm{p}$.

Jha, V.K., and Wydoski, D.S., 2003, Methods of analysis by the U.S. Geological Survey National Water Quality Laboratory-Determination of organophosphate pesticides in bottom sediment by gas chromatography with flame photometric detection: U.S. Geological Survey Water-Resources Investigations Report 02-4222, $30 \mathrm{p}$.

Miller, J.C., and Miller, J.N., 1993, Statistics for analytical chemistry ( $3 \mathrm{~d}$ ed.): New York, Ellis Horwood Limited.

Nauss, K.M., 1995, Critical issues in assessing the carcinogenicity of diesel exhaust-A synthesis of current knowledge, in Diesel exhaust: A critical analysis of emission? exposure, and health effects: Cambridge, Mass., Health Effects Institute, p. 11-61. 
Noriega, M.C., Wydoski, D.S., and Foreman, W.T., 2004, Methods of analysis by the U.S. Geological Survey National Water Quality Laboratory-Determination of organochlorine pesticides and polychlorinated biphenyls in bottom and suspended sediment by gas chromatography with electron-capture detection: U.S. Geological Survey

Water-Resources Investigations Report 03-4293, 46 p.

U.S. Environmental Protection Agency, 1997, Guidelines establishing test procedures for the analysis of pollutants (App. B, Part 136, Definition and procedures for the determination of the method detection limit): U.S. Code of Federal Regulations, Title 40, p. 265-267.

Wang, Zhendi, Fingas, Merv, and Li, Ken, 1994, Fractionation of a light crude oil and identification and quantitation of aliphatic, aromatic, and biomarker compounds by GC-FID and GC-MS, Parts I and II: Journal of Chromatographic Science, v. 32, p. 361-382.

Wang, Zhendi, Fingas, Merv, and Sigouin, Lise, 2000, Characterization and source identification of an unknown spilled oil using fingerprinting techniques by GC-MS and GC-FID: LCGC, v. 18, no. 10, p. 1058-1067.

Wershaw, R.L., Fishman, M.J., Grabbe, R.R., and Lowe, L.E., eds., 1987, Methods for the determination of organic substances in water and fluvial sediments: U.S. Geological Survey Techniques of Water-Resources Investigations, book 5, chap. A3, p. 79 and 80. 
Attachment 1

Determination of Polycyclic Aromatic Hydrocarbons in Sediment by Gas Chromatography/Mass Spectrometry Using Selected-Ion Monitoring 


\section{Introduction}

The method described in this report was originally implemented at the NWQL in 1996 as a custom method. This attachment provides an overview of the custom method and differences between it and the method presented in the body of this report. It provides performance data for the parent PAH compounds and the alkylated PAH homolog groups using the custom method. An initial demonstration of capability provided that this method was suitable for the determination of PAH compounds in soil and sediment samples containing at least $5 \mu \mathrm{g} / \mathrm{kg}$.

The custom method is similar to the method presented in the body of the report. The introduction and summary of the custom method is the same as that described in sections 1 and 2 . Because this was a custom method, it did not have a method number. It was given the custom schedule code of 8022 . The interferences are the same as in section 3, and the apparatus and equipment used is the same as in section 4. Section 5 describes reagents and consumable materials also used in the custom method. This custom method used the same safety precautions described in section 6 , the same preparatory plan presented in section 7, and the same method of analysis discussed in section 8 , except it used selected-ion monitoring for the acquisition of data on the mass spectrometer. It used the same method of reporting (section 9) and the same quality-assurance and quality-control practices described in section 10 .

The custom method differed in two aspects from the method described in this report: it used selected-ion monitoring (SIM) in data acquisition, and three additional analytes were included in the analysis. First, it used SIM acquisition instead of full-scan (FS) data acquisition. In 1996, SIM was necessary for minimum reporting levels of $5 \mu \mathrm{g} / \mathrm{kg}$. With the improvement of instrumentation, FS acquisition now rivals SIM for sensitivity with added benefits. In FS acquisition the acquired spectra are more complete, thereby providing greater confidence when comparing sample spectra with reference spectra. This result is especially important for the analysis of alkylated PAH homolog groups. Because authentic standards are not available for many of them, a more complete mass spectra provides greater confidence in detection. Full scan also allows for future analysis of unknowns not initially requested.

The second difference is the original SIM analyte list included phenol, $p$-cresol, and coronene. These three compounds were eliminated from the FS performance data (table 7) because of unacceptable method performance and recoveries of less than 50 percent. They are included, however, in the SIM performance data for historical purposes.

Because the $5 \mu \mathrm{g} / \mathrm{kg}$ reporting level in the SIM method is lower than the FS's reporting level $(10 \mu \mathrm{g} / \mathrm{kg})$, the working solutions for GC/MS PAH calibration standards (5.9.1.1) were prepared at lower con?entrations. They were prepared for the entire suite of individual $\mathrm{PAH}$ compounds listed in table 1 at $0.01,0.02,0.05,0.1,0.2$, 0.5 , and $1.0 \mathrm{ng} / \mu \mathrm{L}$ per component in ethyl acetate using mixed stock solutions, including PAH surrogate solution (section 5.2.4.1) and GPC-PAH surrogate solution (section 5.4.4). Aliquots of the dPAHIS solution (section 5.7.2) were added to each of the calibration solutions to produce individual dPAHIS compound concentrations of $1 \mathrm{ng} / \mu \mathrm{L}$.

It was necessary to create SIM windows for the acquisition method on the GC/MS by using th $\bullet$ peak identifications, retention times, mass-to-charge ratios, and abundances relative to the quantitation ion for PAHs listed in table 4 . The relative ion abundances were not included for the alkylated PAH homolog groups because the ratios are different among isomers. Because authentic standards were not available for many of the individual components in the alkylated PAH homolog goups, retention times for these groups were determired using an alkylated $\mathrm{PAH}$ homolog retention time source material (5.9.2).

OPTIONALLY: An Alberta Sweet Mix Blend, a light crude reference oil, can be used (Wang and others, 1994). The reference sample was analyzed in FS mode at about $5 \mathrm{ng} / \mathrm{mL}$. Extracted ion chromatograms were created using the quantitation and confirmation ions for each alkylated PAH homolog group. The retention times were determined for the first and last isomers. The quantitation and confirmation ions were entered into the SIM windows in the acquisition method that encompassed that time period. Some ions were included in more than one SIM window. SIM windows were constructed, and retention times were updated in the method $u$ sing this procedure. The reference sample was analyzet again using the newly created SIM conditions to ve-ify SIM windows.

This attachment provides method performance information for SIM acquisition of the original analyte list. The performance information includes bias and precision data, calculated MDLs, historical reagent spike data, standard reference material data, and cettified reference material data. The last table (table 24 ) compares SIM and FS acquisition using the statistical F-test. 


\section{Performance Data}

Method performance was determined for polycyclic aromatic hydrocarbons using SIM acquisition. The Agilent Technologies 5973 mass selective detector (MSD) GC/MS system was used. The bias and precision data include calculations for percent recovered and relative standard deviation (RSD) for three spike levels in the three different matrices (table 16). Matrices chosen to test method performance were reagent-sodium sulfate (matrix-free), bottom sediment collected from Evergreen Lake, Evergreen, Colorado, and bottom sediment collected near Clear Creek, Colorado. The matrices are described in section 11 in the main body of the report.

The performance of this method for the extraction, isolation, and analysis of the PAHs was evaluated by adding aliquots of standard solutions to seven subsamples of each matrix and processing the fortified samples through the entire method. Three unfortified samples from each matrix were processed to determine the background concentrations of any ambient compounds. The three separate sets of seven subsamples from each matrix were fortified with $4.8,12.0$, and $24.0 \mu \mathrm{g} / \mathrm{kg}$ of each PAH. Final recoveries were adjusted by subtracting the mean concentrations of detected background compounds measured in the three unfortified samples. Laboratory reagent spikes and laboratory reagent blanks were processed with each set. The alkylated PAH homolog groups were not quantitatively evaluated because of the lack of available standards. Bias and precision data for PAH spike recoveries are listed in table 16. Background concentrations are listed in table 17.

The recoveries in the sodium sulfate in the $4.8-\mu \mathrm{g} / \mathrm{kg}$ spiking level ranged from 12.8 to 83.9 percent and relative standard deviations (RSD) from 1.8 to 74.8 percent. Compounds with molecular weights of $166 \mathrm{~g} / \mathrm{mole}$ and less had recoveries ranging from 12.8 to 39.0 percent. The lighter compounds are more volatile and more inclined to loss during the preparatory steps, thus explaining the lower recoveries. At the higher spike level of $12.0 \mu \mathrm{g} / \mathrm{kg}$ in sodium sulfate, the recoveries ranged from 8.3 to 93.1 percent with RSDs from 3.8 to 23.7 percent. At the spike level of $24.0 \mu \mathrm{g} / \mathrm{kg}$ in sodium sulfate, the recoveries ranged from 9.0 to 100.5 percent with RSDs from 6.3 to 29.5 percent.

The recoveries in the Evergreen Lake sediment in the $4.8-\mu \mathrm{g} / \mathrm{kg}$ spiking level ranged from 14.4 to 91.8 percent and RSDs from 4.0 to 124.8 percent. The recoveries at the $12.0-\mu \mathrm{g} / \mathrm{kg}$ spiking level ranged from 16.7 to 87.6 percent with RSDs from 12.1 to 115.4 percent. The recoveries for the $24.0-\mu \mathrm{g} / \mathrm{kg}$ spiking level ranged from 11.1 to 97.0 percent with RSDs from 4.7 to 39.2 percent. The RSDs for Evergreen Lake sediment were expectedly high for the $12.0-\mu \mathrm{g} / \mathrm{kg}$ spiking level for phenanthrene, fluoranthene, pyrene, benz $[a]$ anthracene, chrysene, benzo $[b]$ fluoranthene, benzo $[k]$ fluoranthene, benzo[e]pyrene, benzo[ $a]$ pyrene, perylene, indeno $[1,2,3-c d]$ pyrene, and benzo[ $g, h, i]$ perylene. This high variability is probably caused by the high background concentration in some spike sampes. These statistics include phenol, $p$-cresol, and coroner because they were included in the analyte list when this was a custom method.

The recoveries in the Clear Creek sediment in the $4.8-\mu \mathrm{g} / \mathrm{kg}$ spiking level ranged from 11.0 to 99.6 percent with RSDs from 8.3 to 176.8 percent. The recoveries at the $12.0-\mu \mathrm{g} / \mathrm{kg}$ spiking level ranged from 21.8 to 107.4 percent with RSDs from 5.4 to 164.0 percent. P.ecoveries at the $24.0-\mu \mathrm{g} / \mathrm{kg}$ spiking level ranged from 22.7 to 110.3 percent with RSDs from 4.5 to 38.0 percent. The RSDs for the Clear Creek sediment improved as the consentration increased, thus minimizing the effects of background concentrations. The highest RSDs are associated with the compounds with the highest background concentrations. An example is fluoranthene. It has a matrix barkground concentration of $24.0 \mu \mathrm{g} / \mathrm{kg}$ with a relative standard deviation of 7.1 percent.

\section{Method Detection Limits}

The NWQL uses the long-term method detection level procedure (Childress and others, 1999) to determine compound-reporting conventions for water analytical methods. Owing to the varied nature of sediment samples, the long-term method detection level procedure has not been implemented for sediment analyses.

Method detection limits (MDLs) were established by using procedures outlined by the U.S. Environmental Protection Agency (1997). For this method, the MDL was determined by analyzing a set of seven replicate reagent (sodium sulfate) spike samples fortified at $12.0 \mu \mathrm{g} / \mathrm{kg}$ for PAHs. For the set of seven samples, the sample standard deviation was computed and the MDL calculated from the following formula:

$$
M D L=S \times t(n-1,1-\alpha=0.99)
$$

where

$S=$ standard deviation of replicate analyses, in micrograms per kilogram;

$t_{(n-1,1-\alpha=0.99)}=$ Student's $t$-value for the 99-percent confidence level with $n-1$ deg ees of freedom; and

$n=$ number of replicate analyses. 
Table 16. Bias and precision data of polycyclic aromatic hydrocarbon spike recoveries for seven replicates using selected-ion monitoring acquisition with compound concentrations of 4.8, 12.0, and 24.0 micrograms per kilogram in three matrices. Percent recovery corrected for ambient environmental concentration. Method detection limits calculated using the data for sodium sulfate rerults (reagent spikes).

[ $\mu \mathrm{g} / \mathrm{kg}$, micrograms per kilogram; RSD, relative standard deviation; NR, not reported; MDL, method detection limit]

\begin{tabular}{|c|c|c|c|c|c|c|c|c|}
\hline \multirow{2}{*}{ Compound } & \multirow{2}{*}{$\begin{array}{l}\text { Amount } \\
\text { spiked } \\
(\mu g / k g)\end{array}$} & \multicolumn{2}{|c|}{ Sodium sulfate } & \multicolumn{2}{|c|}{$\begin{array}{c}\text { Evergreen Lake } \\
\text { sediment }\end{array}$} & \multicolumn{2}{|c|}{$\begin{array}{l}\text { Clear Creek } \\
\text { sediment }\end{array}$} & \multirow{2}{*}{$\underset{(\mu \mathrm{g} / \mathrm{kg})}{\mathrm{MDL}}$} \\
\hline & & $\begin{array}{l}\text { Percent } \\
\text { recovery }\end{array}$ & RSD & $\begin{array}{l}\text { Percent } \\
\text { recovery }{ }^{1}\end{array}$ & $\begin{array}{l}\text { Percent } \\
\text { RSD }\end{array}$ & $\begin{array}{c}\text { Percent } \\
\text { Recovery }\end{array}$ & $\begin{array}{l}\text { Percent } \\
\text { RSD }\end{array}$ & \\
\hline \multirow[t]{3}{*}{ Phenol } & 4.8 & 30.4 & 74.8 & 38.9 & 8.2 & 41.0 & 18.1 & \\
\hline & 12.0 & 24.4 & 12.3 & NR & NR & 20.2 & 85.5 & 1.1 \\
\hline & 24.0 & 36.5 & 16.5 & 18.1 & 38.6 & 20.9 & 21.8 & \\
\hline \multirow[t]{3}{*}{$p$-Cresol } & 4.8 & 21.7 & 14.7 & 61.7 & 18.0 & 70.8 & 14.7 & \\
\hline & 12.0 & 33.3 & 20.7 & 50.6 & 24.1 & 61.1 & 19.2 & 2.6 \\
\hline & 24.0 & 32.4 & 29.5 & 63.1 & 17.4 & 73.0 & 8.4 & \\
\hline \multirow[t]{3}{*}{ Naphthalene } & 4.8 & 12.8 & 18.7 & 45.7 & 11.4 & 24.7 & 77.6 & \\
\hline & 12.0 & 79.0 & 4.7 & 39.7 & 22.6 & 40.0 & 31.8 & 1.4 \\
\hline & 24.0 & 73.6 & 6.4 & 51.8 & 14.8 & 49.0 & 14.3 & \\
\hline \multirow[t]{3}{*}{ 2-Ethylnaphthalene } & 4.8 & 17.9 & 21.5 & 60.7 & 7.1 & 69.7 & 8.3 & \\
\hline & 12.0 & 76.4 & 4.7 & 55.6 & 17.4 & 68.6 & 10.7 & 1.4 \\
\hline & 24.0 & 72.0 & 6.7 & 65.9 & 10.9 & 71.4 & 6.4 & \\
\hline \multirow[t]{3}{*}{ 2,6-Dimethylnaphthalene } & 4.8 & 20.0 & 21.8 & 64.5 & 6.3 & 68.8 & 9.0 & \\
\hline & 12.0 & 75.0 & 4.4 & 52.4 & 21.0 & 63.9 & 11.6 & 1.3 \\
\hline & 24.0 & 70.7 & 7.2 & 63.1 & 11.5 & 69.5 & 5.2 & \\
\hline \multirow[t]{3}{*}{ 1,6-Dimethylnaphthalene } & 4.8 & 23.3 & 20.4 & 65.6 & 9.1 & 45.8 & 26.2 & \\
\hline & 12.0 & 75.0 & 3.8 & 54.9 & 15.2 & 64.3 & 10.6 & 1.1 \\
\hline & 24.0 & 71.5 & 7.3 & 63.8 & 10.6 & 73.0 & 5.4 & \\
\hline \multirow[t]{3}{*}{ Acenaphthylene } & 4.8 & 20.0 & 23.2 & 69.0 & 5.1 & 61.1 & 14.5 & \\
\hline & 12.0 & 73.8 & 4.7 & 50.7 & 14.6 & 60.6 & 17.4 & 1.3 \\
\hline & 24.0 & 68.6 & 6.9 & 60.3 & 11.5 & 67.7 & 6.4 & \\
\hline \multirow[t]{3}{*}{ 1,2-Dimethylnaphthalene } & 4.8 & 24.8 & 22.4 & 65.3 & 6.2 & 72.4 & 12.0 & \\
\hline & 12.0 & 75.8 & 4.7 & 58.9 & 14.5 & 67.7 & 7.1 & 1.4 \\
\hline & 24.0 & 72.0 & 6.9 & 68.8 & 10.2 & 72.7 & 5.1 & \\
\hline \multirow[t]{3}{*}{ Acenapthene } & 4.8 & 19.9 & 32.0 & 63.8 & 6.3 & 77.7 & 34.8 & \\
\hline & 12.0 & 77.4 & 5.1 & 59.4 & 13.9 & 61.1 & 9.3 & 1.5 \\
\hline & 24.0 & 72.4 & 6.4 & 67.8 & 11.6 & 66.9 & 5.7 & \\
\hline \multirow[t]{3}{*}{ 2,3,6-Trimethylnaphthalene } & 4.8 & 42.3 & 14.4 & 75.9 & 5.2 & 77.4 & 8.6 & \\
\hline & 12.0 & 72.9 & 4.3 & 68.8 & 14.6 & 78.5 & 7.5 & 1.2 \\
\hline & 24.0 & 69.1 & 7.9 & 79.0 & 8.0 & 83.1 & 4.5 & \\
\hline \multirow[t]{3}{*}{ 9H-Fluorene } & 4.8 & 39.0 & 15.0 & 72.2 & 7.0 & 75.9 & 18.8 & \\
\hline & 12.0 & 74.6 & 4.9 & 66.0 & 14.7 & 67.0 & 7.0 & 1.4 \\
\hline & 24.0 & 69.5 & 7.1 & 76.3 & 9.8 & 76.1 & 5.1 & \\
\hline \multirow[t]{3}{*}{ 1-Methyl-9H-fluorene } & 4.8 & 58.0 & 8.1 & 76.6 & 5.2 & 24.3 & 34.7 & \\
\hline & 12.0 & 75.2 & 5.3 & 78.8 & 12.1 & 86.1 & 5.4 & 1.5 \\
\hline & 24.0 & 70.8 & 7.4 & 86.7 & 5.8 & 89.0 & 5.2 & \\
\hline
\end{tabular}


Table 16. Bias and precision data of polycyclic aromatic hydrocarbon spike recoveries for seven replicates using selected-ion monitoring acquisition with compound concentrations of 4.8, 12.0, and 24.0 micrograms per kilogram in three matrices. Percent recovery corrected for ambient environmental concentration. Method detection limits calculated using the data for sodium sulfate results (reagent spikes).-Continued

[ $\mu \mathrm{g} / \mathrm{kg}$, micrograms per kilogram; RSD, relative standard deviation; NR, not reported; MDL, method detection limit]

\begin{tabular}{|c|c|c|c|c|c|c|c|c|}
\hline \multirow{2}{*}{ Compound } & \multirow{2}{*}{$\begin{array}{l}\text { Amount } \\
\text { spiked } \\
(\mu g / k g)\end{array}$} & \multicolumn{2}{|c|}{ Sodium sulfate } & \multicolumn{2}{|c|}{$\begin{array}{c}\text { Evergreen Lake } \\
\text { sediment }\end{array}$} & \multicolumn{2}{|c|}{ Clear Creek sediment } & \multirow{2}{*}{$\underset{(\mu \mathrm{g} / \mathrm{kg})}{\mathrm{MDL}}$} \\
\hline & & $\begin{array}{l}\text { Percent } \\
\text { recovery }{ }^{1}\end{array}$ & $\begin{array}{l}\text { Percent } \\
\text { RSD }\end{array}$ & $\begin{array}{l}\text { Percent } \\
\text { recovery1 }\end{array}$ & $\begin{array}{l}\text { Percent } \\
\text { RSD }\end{array}$ & $\begin{array}{l}\text { Percent } \\
\text { recovery1 }\end{array}$ & $\begin{array}{l}\text { Percent } \\
\text { RSD }\end{array}$ & \\
\hline \multirow[t]{3}{*}{ Phenanthrene } & 4.8 & 64.3 & 8.7 & 82.8 & 81.3 & 53.8 & 176.8 & \\
\hline & 12.0 & 80.7 & 6.3 & 75.3 & 33.9 & 19.4 & 79.3 & 1.9 \\
\hline & 24.0 & 76.9 & 6.3 & 90.6 & 30.2 & 55.2 & 27.7 & \\
\hline \multirow[t]{3}{*}{ Anthracene } & 4.8 & 58.9 & 11.3 & 78.6 & 14.4 & 84.4 & 39.5 & \\
\hline & 12.0 & 71.1 & 7.2 & 65.4 & 17.1 & 68.8 & 9.8 & 1.9 \\
\hline & 24.0 & 69.2 & 6.6 & 76.1 & 10.6 & 78.6 & 7.0 & \\
\hline \multirow[t]{3}{*}{ 2-Methylanthracene } & 4.8 & 58.3 & 12.4 & 82.0 & 4.6 & 87.8 & 9.2 & \\
\hline & 12.0 & 69.5 & 5.8 & 64.4 & 15.9 & 85.5 & 6.2 & 1.5 \\
\hline & 24.0 & 67.5 & 7.5 & 73.5 & 6.2 & 89.2 & 4.5 & \\
\hline \multirow[t]{3}{*}{ 4,5-Methylenephenanthrene } & 4.8 & 69.9 & 6.2 & 80.3 & 9.9 & 88.9 & 18.4 & \\
\hline & 12.0 & 77.0 & 4.9 & 75.0 & 15.5 & 80.6 & 6.3 & 1.4 \\
\hline & 24.0 & 75.4 & 6.9 & 84.1 & 6.7 & 84.9 & 5.2 & \\
\hline \multirow[t]{3}{*}{ 1-Methylphenanthrene } & 4.8 & 72.3 & 5.9 & 78.4 & 4.0 & 74.7 & 12.9 & \\
\hline & 12.0 & 78.7 & 5.2 & 72.2 & 17.6 & 75.2 & 6.4 & 1.5 \\
\hline & 24.0 & 77.6 & 7.0 & 82.8 & 5.7 & 84.6 & 4.6 & \\
\hline \multirow[t]{3}{*}{ Fluoranthene } & 4.8 & 78.6 & 5.7 & 87.5 & 124.8 & 90.3 & 163.4 & \\
\hline & 12.0 & 82.9 & 7.6 & 71.4 & 65.7 & 21.8 & 164.0 & 2.4 \\
\hline & 24.0 & 83.6 & 6.6 & 94.9 & 31.8 & 58.5 & 38.0 & \\
\hline \multirow[t]{3}{*}{ Pyrene } & 4.8 & 78.6 & 5.7 & 85.7 & 102.2 & 81.9 & 148.7 & \\
\hline & 12.0 & 83.1 & 5.4 & 77.1 & 54.5 & 30.9 & 113.2 & 1.7 \\
\hline & 24.0 & 82.9 & 6.8 & 97.0 & 27.9 & 62.5 & 31.4 & \\
\hline \multirow[t]{3}{*}{ 1-Methylpyrene } & 4.8 & 79.5 & 4.1 & 91.8 & 4.5 & 95.5 & 9.6 & \\
\hline & 12.0 & 82.1 & 5.2 & 71.1 & 18.1 & 83.8 & 6.7 & 1.6 \\
\hline & 24.0 & 81.2 & 7.8 & 85.0 & 5.5 & 92.2 & 4.9 & \\
\hline \multirow[t]{3}{*}{ Benz $[a]$ anthracene } & 4.8 & 82.1 & 5.0 & 90.1 & 43.7 & 98.6 & 107.4 & \\
\hline & 12.0 & 87.5 & 4.7 & 80.4 & 27.8 & 68.0 & 29.4 & 1.6 \\
\hline & 24.0 & 87.3 & 7.7 & 91.6 & 13.7 & 83.8 & 13.4 & \\
\hline \multirow[t]{3}{*}{ Chrysene } & 4.8 & 83.9 & 5.9 & 43.7 & 93.4 & 73.6 & 119.1 & \\
\hline & 12.0 & 91.1 & 5.2 & 72.9 & 37.8 & 36.7 & 47.0 & 1.8 \\
\hline & 24.0 & 91.3 & 6.9 & 88.1 & 13.7 & 63.5 & 20.3 & \\
\hline \multirow[t]{3}{*}{ Benzo $[b]$ fluoranthene } & 4.8 & 81.3 & 3.3 & 75.4 & 40.1 & 69.0 & 106.5 & \\
\hline & 12.0 & 88.3 & 5.5 & 87.6 & 27.7 & 69.0 & 26.4 & 1.8 \\
\hline & 24.0 & 88.0 & 9.5 & 96.7 & 12.6 & 80.3 & 14.4 & \\
\hline \multirow[t]{3}{*}{ Benzo $[k]$ fluoranthene } & 4.8 & 79.8 & 4.5 & 62.6 & 46.4 & 58.1 & 120.1 & \\
\hline & 12.0 & 93.1 & 6.2 & 83.1 & 27.6 & 63.0 & 20.3 & 2.2 \\
\hline & 24.0 & 93.7 & 6.8 & 90.7 & 13.1 & 76.3 & 16.9 & \\
\hline
\end{tabular}


Table 16. Bias and precision data of polycyclic aromatic hydrocarbon spike recoveries for seven replicates using selected-ion monitoring acquisition with compound concentrations of 4.8, 12.0, and 24.0 micrograms per kilogram in three matrices. Percent recovery corrected for ambient environmental concentration. Method detection limits calculated using the data for sodium sulfate results (reagent spikes).-Continued

[ $\mu \mathrm{g} / \mathrm{kg}$, micrograms per kilogram; RSD, relative standard deviation; NR, not reported; MDL, method detection limit]

\begin{tabular}{|c|c|c|c|c|c|c|c|c|}
\hline \multirow{2}{*}{ Compound } & \multirow{2}{*}{$\begin{array}{l}\text { Amount } \\
\text { spiked } \\
\text { ( } \mu \mathrm{g} / \mathrm{kg})\end{array}$} & \multicolumn{2}{|c|}{ Sodium sulfate } & \multicolumn{2}{|c|}{$\begin{array}{l}\text { Evergreen Lake } \\
\text { sediment }\end{array}$} & \multicolumn{2}{|c|}{$\begin{array}{l}\text { Clear Creek } \\
\text { sediment }\end{array}$} & \multirow{2}{*}{$\underset{(\mu \mathrm{gD} / \mathrm{kg}}{\mathrm{MDL}}$} \\
\hline & & $\begin{array}{c}\text { Percent } \\
\text { recovery }\end{array}$ & $\begin{array}{l}\text { Percent } \\
\text { RSD }\end{array}$ & $\begin{array}{c}\text { Percent } \\
\text { Recovery }{ }^{1}\end{array}$ & $\begin{array}{l}\text { Percent } \\
\text { RSD }\end{array}$ & $\begin{array}{l}\text { Percent } \\
\text { recovery }\end{array}$ & $\begin{array}{l}\text { Perc?nt } \\
\text { RS }\end{array}$ & \\
\hline \multirow[t]{3}{*}{ Benzo[e]pyrene } & 4.8 & 77.2 & 1.8 & 73.8 & 29.4 & 71.5 & 73.0 & \\
\hline & 12.0 & 81.3 & 6.0 & 75.7 & 23.6 & 73.3 & 15.6 & 2.4 \\
\hline & 24.0 & 80.4 & 7.5 & 83.7 & 9.5 & 69.5 & 12.6 & \\
\hline \multirow[t]{3}{*}{ Benzo $[a]$ pyrene } & 4.8 & 68.8 & 8.2 & 78.9 & 49.0 & 75.5 & 123.5 & \\
\hline & 12.0 & 90.8 & 5.4 & 86.3 & 27.8 & 76.3 & 25.0 & 1.9 \\
\hline & 24.0 & 100.5 & 7.6 & 91.4 & 14.2 & 84.0 & 16.5 & \\
\hline \multirow[t]{3}{*}{ Perylene } & 4.8 & 69.5 & 7.7 & 74.1 & 14.3 & 76.4 & 323 & \\
\hline & 12.0 & 76.4 & 6.4 & 71.5 & 115.4 & 73.6 & 8.9 & 1.8 \\
\hline & 24.0 & 75.9 & 8.2 & 88.4 & 39.2 & 76.4 & 83 & \\
\hline \multirow[t]{3}{*}{ Indeno $[1,2,3-c d]$ pyrene } & 4.8 & 77.1 & 5.8 & 76.8 & 43.1 & 70.5 & 99.6 & \\
\hline & 12.0 & 90.8 & 8.8 & 74.0 & 27.9 & 92.3 & 20.3 & 3.0 \\
\hline & 24.0 & 89.2 & 7.8 & 78.0 & 10.0 & 105.6 & 13.8 & \\
\hline \multirow[t]{3}{*}{ Dibenz $[a, h]$ anthracene } & 4.8 & 65.5 & 5.5 & 72.6 & 9.6 & 78.8 & 26.1 & \\
\hline & 12.0 & 92.0 & 6.9 & 74.0 & 17.0 & 107.4 & 9.2 & 2.4 \\
\hline & 24.0 & 92.0 & 7.3 & 78.4 & 4.7 & 110.3 & 4.8 & \\
\hline \multirow[t]{3}{*}{ Benzo $[g, h, i]$ perylene } & 4.8 & 72.6 & 3.9 & 47.9 & 44.4 & 34.1 & 113.2 & \\
\hline & 12.0 & 53.5 & 12.4 & 55.6 & 36.0 & 63.3 & 26.8 & 2.5 \\
\hline & 24.0 & 54.3 & 18.5 & 55.9 & 12.4 & 63.0 & 23.7 & \\
\hline \multirow[t]{3}{*}{ Coronene } & 4.8 & 36.8 & 3.9 & 14.4 & 25.2 & 11.0 & 44.5 & \\
\hline & 12.0 & 8.3 & 23.7 & 16.7 & 42.3 & 38.3 & 31.4 & 0.7 \\
\hline & 24.0 & 9.0 & 20.9 & 11.1 & 13.1 & 22.7 & 20.2 & \\
\hline \multicolumn{9}{|c|}{$\begin{array}{l}\text { Method Surrogates } \\
\text { (Add to all samaples at } 20 \mu \mathrm{g} / \mathrm{kg} \text { ) }\end{array}$} \\
\hline \multirow{3}{*}{ Nitrobenzene- $d_{5}$} & 4.8 & 63.9 & 7.3 & 56.6 & 7.2 & 69.2 & 13.2 & \\
\hline & 12.0 & 69.7 & 8.4 & 57.8 & 7.4 & 44.6 & 24.8 & \\
\hline & 24.0 & 73.1 & 8.8 & 61.5 & 21.1 & 47.8 & 20.9 & \\
\hline \multirow[t]{3}{*}{ 2-Fluorobiphenyl } & 4.8 & 68.6 & 4.6 & 60.6 & 6.4 & 69.6 & 6.6 & \\
\hline & 12.0 & 73.3 & 5.1 & 58.9 & 8.9 & 60.4 & 9.5 & \\
\hline & 24.0 & 68.8 & 6.2 & 58.7 & 13.6 & 64.6 & 14.8 & \\
\hline \multirow[t]{3}{*}{ Terphenyl- $d_{14}$} & 4.8 & 91.1 & 4.3 & 91.7 & 6.4 & 98.8 & 2.9 & \\
\hline & 12.0 & 84.7 & 2.5 & 90.0 & 11.3 & 101.4 & 4.4 & \\
\hline & 24.0 & 83.5 & 6.4 & 92.4 & 9.3 & 106.7 & 7.8 & \\
\hline
\end{tabular}

${ }^{1}$ Percent recovery corrected for background. 
Table 17. Polycyclic aromatic hydrocarbon matrix background concentrations in selected-ion monitoring.

$[\mu \mathrm{g} / \mathrm{kg}$, micrograms per kilogram. Concentrations are expressed as an equivalent dry weight of 25 grams; number of analyses $=3$ ]

\begin{tabular}{|c|c|c|c|c|c|c|}
\hline \multirow{2}{*}{ Compound } & \multicolumn{3}{|c|}{ Mean amount ( $\mu \mathrm{g} / \mathrm{kg})$} & \multicolumn{3}{|c|}{ Standard deviation $(\mu \mathrm{g} / \mathrm{kg})$} \\
\hline & $\begin{array}{l}\text { Sodium } \\
\text { sulfate }\end{array}$ & $\begin{array}{c}\text { Evergreen } \\
\text { Lake }\end{array}$ & $\begin{array}{l}\text { Clear } \\
\text { Creek }\end{array}$ & $\begin{array}{l}\text { Sodium } \\
\text { sulfate }\end{array}$ & $\begin{array}{c}\text { Evergreen } \\
\text { Lake }\end{array}$ & $\begin{array}{l}\text { Clear } \\
\text { Creek }\end{array}$ \\
\hline Phenol & 0.8 & 2.7 & 3.5 & 0.3 & 0.4 & 0.6 \\
\hline$p$-Cresol & .3 & 2.2 & 3.4 & .5 & .3 & 6 \\
\hline Naphthalene & 0 & 1.0 & 5.5 & 0 & .2 & 3.9 \\
\hline 2-Ethylnaphthalene & 0 & .5 & .8 & 0 & 0 & .2 \\
\hline 2,6-Dimethylnaphthalene & 0 & .9 & 1.4 & 0 & .1 & .4 \\
\hline 1,6-Dimethylnaphthalene & 0 & .9 & 2.8 & 0 & .2 & 1.0 \\
\hline Acenaphthylene & 0 & 1.6 & 3.5 & 0 & .1 & 2.1 \\
\hline 1,2-Dimethylnaphthalene & 0 & .6 & .8 & 0 & 0 & .3 \\
\hline Acenaphthene & 0 & .5 & .5 & 0 & .1 & .1 \\
\hline 2,3,6-Trimethylnaphthalene & 0 & .5 & 1.0 & 0 & .4 & .2 \\
\hline 9H-Fluorene & 0 & 6 & .7 & 0 & .1 & .1 \\
\hline 1-Methyl-9H-fluorene & 0 & 1.6 & 4.3 & 0 & .1 & 5.3 \\
\hline Phenanthrene & 0 & 5.6 & 15.9 & 0 & 1.8 & 11.0 \\
\hline Anthracene & 0 & 2.1 & 3.3 & 0 & .2 & .4 \\
\hline 2-Methylanthracene & 0 & 1.3 & 1.7 & 0 & .1 & .2 \\
\hline 4,5-Methylenephenanthrene & 0 & 1.3 & 1.7 & 0 & .3 & .3 \\
\hline 1-Methylphenanthrene & 0 & 2.1 & 2.8 & 0 & .2 & .8 \\
\hline Fluoranthene & 0 & 11.7 & 24.0 & 0 & 3.1 & 7.1 \\
\hline Pyrene & 0 & 9.9 & 22.4 & 0 & 2.6 & 6.4 \\
\hline 1-Methylpyrene & 0 & 1.1 & 2.0 & 0 & .1 & .3 \\
\hline Benz $[a]$ anthracene & 0 & 5.6 & 10.4 & 0 & 1.0 & 2.9 \\
\hline Chrysene & 0 & 8.1 & 14.1 & 0 & 1.4 & 2.8 \\
\hline Benzo $[b]$ fluoranthene & 0 & 5.1 & 11.2 & 0 & 1.1 & 2.0 \\
\hline Benzo $[k]$ fluoranthene & 0 & 4.2 & 9.7 & 0 & 1.0 & 1.9 \\
\hline Benzo[e]pyrene & 0 & 3.5 & 7.8 & 0 & .8 & 1.2 \\
\hline Benzo $[a]$ pyrene & 0 & 6.0 & 12.3 & 0 & 1.4 & 2.3 \\
\hline Perylene & 0 & 6.9 & 3.2 & 0 & .3 & .7 \\
\hline Indeno $[1,2,3-c d]$ pyrene & 0 & 4.4 & 10.6 & 0 & 1.1 & 1.6 \\
\hline Dibenz $[a, h]$ anthracene & 0 & 4.3 & 1.9 & 0 & 5.9 & .3 \\
\hline Benzo[g,h,i]perylene & 0 & 2.7 & 7.0 & 0 & .8 & .9 \\
\hline Coronene & 0 & 0.1 & 1.0 & 0 & .1 & .1 \\
\hline
\end{tabular}

The MDLs were calculated at the $12.0-\mu \mathrm{g} / \mathrm{kg}$ spiking level because of the improved recoveries and greater precision than at the $4.8-\mu \mathrm{g} / \mathrm{kg}$ spiking level. The spiking concentration at $12.0 \mu \mathrm{g} / \mathrm{kg}$ was two to five times the anticipated MDL. The MDLs range from $1.1 \mu \mathrm{g} / \mathrm{kg}$ for 1,6-dimethylnaphthalene to $3.0 \mu \mathrm{g} / \mathrm{kg}$ for indeno[1,2,3-cd]pyrene. The calculated MDL for each compound is listed in table 16 .

Minimum reporting levels (MRLs) originally were assigned to compounds on the basis of demonstration of capability data developed during method validation, observed matrix interference, and the effect of the varied matrices on instrument performance. Results were not censored at the MRL for this method because compounds are determined by mass spectrometry; therefore, the method is considered to be "information rich" (Childress and others, 1999). The MRL for all compound determined by SIM was $5 \mu \mathrm{g} / \mathrm{kg}$.)

\section{Long-Term Laboratory Reagent Spike Result-}

This method initially was designed for custom work at the National Water Quality Laboratory beginning in 1996, and method spikes were extracted in reasent sodium sulfate and fortified at $24.0 \mu \mathrm{g} / \mathrm{kg}$. The mean, standard deviation, and percent relative standard deviation are listed in table 18 for the year 2000. Mean recoveries range from 22.18 to 94.86 percent vith RSDs from 10.80 to 61.31 percent. Excellent performance was demonstrated for PAHs with molecular weights between 
Table 18. Polycyclic aromatic hydrocarbon method spike recoveries using selected-ion monitoring at a concentration of 24 micrograms per kilogram for the year 2000 .

$[\mu \mathrm{g} / \mathrm{kg}$, micrograms per kilogram; $n$, number; percent relative standard deviation (mean/standard deviation) $\mathrm{x} 100]$

\begin{tabular}{|c|c|c|c|}
\hline \multirow[b]{2}{*}{ Compound } & \multicolumn{3}{|c|}{ Method spike recoveries ( $n=18)$} \\
\hline & $\begin{array}{c}\text { Mean } \\
\text { percent } \\
\text { recovery }\end{array}$ & $\begin{array}{l}\text { Standard } \\
\text { deviation }\end{array}$ & $\begin{array}{l}\text { Percent } \\
\text { relative } \\
\text { standard } \\
\text { deviation }\end{array}$ \\
\hline Phenol & 49.33 & 17.11 & 34.69 \\
\hline$p$-Cresol & 34.68 & 21.26 & 61.31 \\
\hline Naphthalene & 73.79 & 14.18 & 19.22 \\
\hline 2-Ethylnaphthalene & 71.98 & 13.72 & 19.07 \\
\hline 2,6-Dimethylnaphthalene & 70.84 & 14.54 & 20.53 \\
\hline 1,6-Dimethylnaphthalene & 71.46 & 14.62 & 20.45 \\
\hline Acenaphthene & 67.15 & 12.67 & 18.87 \\
\hline 1,2-Dimethylnaphthalene & 71.55 & 14.16 & 19.80 \\
\hline Acenaphthene & 72.42 & 13.65 & 18.85 \\
\hline 2,3,6-Trimethylnaphthalene & 72.28 & 15.44 & 21.36 \\
\hline 9H-Fluorene & 73.37 & 13.82 & 18.83 \\
\hline 1-Methyl-9H-fluorene & 76.08 & 13.63 & 17.91 \\
\hline Phenanthrene & 78.34 & 13.15 & 16.78 \\
\hline Anthracene & 71.62 & 12.25 & 17.10 \\
\hline 2-Methylanthracene & 71.60 & 12.76 & 17.82 \\
\hline 4,5-Methylenephenanthrene & 81.20 & 11.43 & 14.08 \\
\hline 1-Methylphenanthrene & 81.41 & 12.23 & 15.03 \\
\hline Fluoranthene & 89.47 & 11.13 & 12.44 \\
\hline Pyrene & 89.15 & 11.32 & 12.70 \\
\hline 1-Methylpyrene & 90.00 & 9.72 & 10.80 \\
\hline Benz $[a]$ anthracene & 88.71 & 12.21 & 13.77 \\
\hline Chrysene & 89.23 & 13.79 & 15.45 \\
\hline Benzo $[b]$ fluoranthene & 94.56 & 14.88 & 15.73 \\
\hline Benzo $[k]$ fluoranthene & 94.86 & 18.11 & 19.09 \\
\hline Benzo $[e]$ pyrene & 87.35 & 14.73 & 16.87 \\
\hline Benzo $[a]$ pyrene & 79.42 & 13.87 & 17.46 \\
\hline Perylene & 71.60 & 12.08 & 16.87 \\
\hline Indeno $[1,2,3-c d]$ Pyrene & 89.36 & 14.96 & 16.74 \\
\hline Dibenz $[a, h]$ Anthracene & 93.66 & 16.46 & 17.58 \\
\hline Benzo $[g, h, i]$ Perylene & 67.48 & 11.24 & 16.66 \\
\hline Coronene & 22.18 & 7.59 & 34.23 \\
\hline
\end{tabular}

178 and $252 \mathrm{~g} /$ mole. Recoveries were greater than 70 percent with RSDs less than 20 percent.

The spike recoveries in the sodium-sulfate matrix fortified at $24 \mu \mathrm{g} / \mathrm{kg}$ completed in 2002 (see table 16) and the spike recoveries in 2000 listed in table 18 are comparable and indicate that the method's performance is consistent over time. The differences are seen in the RSDs. The RSDs are two to three times lower in 2002, thereby suggesting improved method precision. This could be accounted for by greater efficiency in sample preparation and analysis along with improved instrumentation.
The exceptions are phenol, benzo[g,h,i]p rylene, and coronene. They had higher recoveries in the year 2000 . These compounds are problematic, often displaying erratic performance at the GPC step during th ? sample preparation (section 7.5). The data in table 18 were compiled throughout 2000 , thus minimizing variation over time, whereas the $24-\mu \mathrm{g} / \mathrm{kg}$ spike data in 2002 were compiled from a single GPC sequence.

\section{Quality-Control Reference Material Data}

Performance data are included for three quality-control reference material samples: SRM 1941b, SRM 1944, and CRM 354. The SRMs are produced by the National Institute of Standards and Technolozy (NIST) and are used to evaluate analytical methods. They consist of natural sediment and have been certified for specific PAHs as well as other contaminates. Many alkylated PAH homolog groups are present in the samples but are not certified. The certified PAHs and uncertified alkylated PAH homolog groups present and their concentrations are appropriate for this method. CRM 354 is a reference material certified through Environmental Resources Associates in Denver, Colorado. It has been certified for specific PAHs. No alkylated PAH homolog group data are included.

The NIST SRM $1941 \mathrm{~b}$ is a marine sediment. Seven samples were prepared and analyzed using SI 1 . Table 19 lists the performance data for the PAHs certified through NIST. These recoveries ranged from 53.8 to 246 percent with RSDs from 0.92 to 5.76 percent. The high recoveries and the low RSDs suggest the method is perfo ${ }^{\text {ming well. }}$ No method performance acceptance criteria were provided in the SRM certification documents supplied with SRM $1941 \mathrm{~b}$.

Table 20 lists mean concentrations, standard deviations, and relative standard deviations for the alkylated PAH homolog groups present, but which are not reported in the SRM certification documents. Many of the groups were not present, which is often th $\%$ case for environmental samples. The RSDs are all les? than 16 percent thus showing good agreement between measurements except for $\mathrm{C}_{4}$-alkylated napthalene with a RSD of 48.0 percent.

SRM 1944-The NIST SRM 1944 is a mixture marine sediment. Seven samples were prepared and analyzed using SIM. Table 21 lists performance data for the PAHs certified through NIST. These recoveries ranged from 47.2 to 145 percent with RSDs fom 5.79 to 26.2 percent. The high recoveries and the low RSDs suggest the method is performing well. 
Table 19. Polycyclic aromatic hydrocarbon concentrations certified by the National Institute of Standards and Technology for Standard Reference Material 1941b and determined using selected-ion monitoring.

$[\mu \mathrm{g} / \mathrm{kg}$, micrograms per kilogram; number of analyses $=7$ ]

\begin{tabular}{|c|c|c|c|c|}
\hline Compound & $\begin{array}{l}\text { Expected concentration } \\
(\mu \mathrm{\mu g} / \mathrm{kg})\end{array}$ & $\begin{array}{c}\text { Measured mean } \\
\text { concentration }(\mu \mathrm{g} / \mathrm{kg})\end{array}$ & $\begin{array}{l}\text { Recovery } \\
\text { (percent) }\end{array}$ & $\begin{array}{c}\text { Relative stinndard } \\
\text { deviation (percent) }\end{array}$ \\
\hline Anthracene & 184 & 241 & 131 & 2.05 \\
\hline Benz $[a]$ anthracene & 335 & 371 & 111 & 2.79 \\
\hline Benzo $[b]$ fluoranthene & 453 & 459 & 101 & 4.50 \\
\hline Benzo $[k]$ fluoranthene & 225 & 411 & 183 & 5.76 \\
\hline Benzo[g,h,i]perylene & 307 & 165 & 53.8 & 3.10 \\
\hline Benzo $[a]$ pyrene & 358 & 398 & 78.5 & 4.67 \\
\hline Benzo[e]pyrene & 325 & 268 & 82.6 & 2.84 \\
\hline Chrysene & 291 & 351 & 120 & 2.34 \\
\hline Dibenz $[a, h]$ anthracene & 53.0 & 131 & 246 & 4.51 \\
\hline Fluoranthene & 651 & 658 & 101 & 1.77 \\
\hline 9H-Fluorene & 85.0 & 105 & 124 & 2.96 \\
\hline Indeno $[1,2,3-c d]$ pyrene & 341 & 349 & 102 & 4.14 \\
\hline 1-Methylphenanthrene & 73.2 & 125 & 171 & 2.29 \\
\hline Naphthalene & 848 & 622 & 73.9 & 3.17 \\
\hline Perylene & 397 & 354 & 89.2 & 3.27 \\
\hline Phenanthrene & 406 & 359 & 88.5 & .92 \\
\hline Pyrene & 581 & 545 & 93.8 & 1.91 \\
\hline
\end{tabular}

Table 20. Alkylated polycyclic aromatic hydrocarbon homolog groups detected in Standard Reference Material 1941b not reported by the National Institute of Standards and Technology and determined using selective-ion monitoring. $[\mu \mathrm{g} / \mathrm{kg}$, micrograms per kilogram; NR, not reported; -, no data; number of analyses=7]

\begin{tabular}{|c|c|c|c|}
\hline Compound & $\begin{array}{c}\text { Measured mean } \\
\text { concentration }(\mu \mathrm{g} / \mathrm{kg})\end{array}$ & $\begin{array}{c}\text { Standard deviation } \\
\quad(\mu \mathrm{g} / \mathrm{kg})\end{array}$ & $\begin{array}{c}\text { Relative standard } \\
\text { deviation (percent) }\end{array}$ \\
\hline $\mathrm{C}_{1}$-alkylated naphthalene & 464 & 13.8 & 2.97 \\
\hline $\mathrm{C}_{2}$-alkylated naphthalene & 450 & 44.1 & 9.80 \\
\hline $\mathrm{C}_{3}$-alkylated naphthalene & 750 & 52.8 & 7.04 \\
\hline $\mathrm{C}_{4}$-alkylated naphthalene & 197 & 94.0 & 48.0 \\
\hline $\mathrm{C}_{5}$-alkylated naphthalene & NR & - & - \\
\hline$C_{1}$-alkylated phenanthrene/anthracene & 540 & 6.8 & 1.25 \\
\hline $\mathrm{C}_{2}$-alkylated phenanthrene/anthracene & 429 & 16.2 & 3.78 \\
\hline $\mathrm{C}_{3}$-alkylated phenanthrene/anthracene & 3.5 & 16.2 & 5.29 \\
\hline $\mathrm{C}_{4}$-alkylated phenanthrene/anthracene & 128 & 20.0 & 16.0 \\
\hline $\mathrm{C}_{5}$-alkylated phenanthrene/anthracene & NR & - & - \\
\hline $\mathrm{C}_{1}$-alkylated fluoranthene/pyrene & 622 & 27.8 & 4.47 \\
\hline $\mathrm{C}_{2}$-alkylated fluoranthene/pyrene & 123 & 19.6 & 16.0 \\
\hline $\mathrm{C}_{3}$-alkylated fluoranthene/pyrene & NR & - & - \\
\hline $\mathrm{C}_{4}$-alkylated fluoranthene/pyrene & NR & - & - \\
\hline $\mathrm{C}_{5}$-alkylated fluoranthene/pyrene & NR & - & - \\
\hline $\mathrm{C}_{1}$-alkylated benzo $[a]$ anthracene/chrysene & 307 & 13.6 & 4.41 \\
\hline $\mathrm{C}_{2}$-alkylated benzo $[a]$ anthracene/chrysene & 185 & 19.6 & 16.0 \\
\hline $\mathrm{C}_{3}$-alkylated benzo $[a]$ anthracene/chrysene & NR & - & - \\
\hline $\mathrm{C}_{4}$-alkylated benzo $[a]$ anthracene/chrysene & NR & - & - \\
\hline $\mathrm{C}_{5}$-alkylated benzo $[a]$ anthracene/chrysene & NR & - & - \\
\hline$C_{1}$-alkylated benzopyrene/perylene & 386 & 27.0 & 7.00 \\
\hline $\mathrm{C}_{2}$-alkylated benzopyrene/perylene & NR & - & - \\
\hline $\mathrm{C}_{3}$-alkylated benzopyrene/perylene & NR & - & - \\
\hline $\mathrm{C}_{4}$-alkylated benzopyrene/perylene & NR & - & - \\
\hline $\mathrm{C}_{5}$-alkylated benzopyrene/perylene & NR & - & - \\
\hline
\end{tabular}


Table 21. Polycyclic aromatic hydrocarbon concentrations certified by the National Institute of Standards and Technology for St`ndard Reference Material 1944 and determined using selective-ion monitoring.

$[\mu \mathrm{g} / \mathrm{kg}$, micrograms per kilogram; number of analyses $=7]$

\begin{tabular}{|c|c|c|c|c|}
\hline Compound & $\begin{array}{c}\text { Expected } \\
\text { concentration } \\
(\mu \mathrm{g} / \mathrm{kg})\end{array}$ & $\begin{array}{c}\text { Measured } \\
\text { mean concentration } \\
(\boldsymbol{\mu g} / \mathbf{k g})\end{array}$ & $\begin{array}{l}\text { Recovery } \\
\text { (percent) }\end{array}$ & $\begin{array}{l}\text { Relative standard } \\
\text { deviation } \\
\text { (persent) }\end{array}$ \\
\hline Anthracene & 1,770 & 1,890 & 107 & 7.60 \\
\hline Benz $[a]$ anthracene & 4,720 & 4,180 & 88.6 & 6.01 \\
\hline Benzo $[b]$ fluoranthene & 3,870 & 2,900 & 74.9 & 9.27 \\
\hline Benzo $[k]$ fluoranthene & 2,300 & 2,810 & 122 & 5.79 \\
\hline Benzo $[g, h, i]$ perylene & 2,840 & 1,340 & 47.2 & 6.08 \\
\hline Benzo $[a]$ pyrene & 4,300 & 3,210 & 74.8 & 7.31 \\
\hline Benzo[e]pyrene & 3,280 & 1,940 & 59.2 & 6.14 \\
\hline Chrysene & 4,860 & 3,980 & 81.9 & 6.75 \\
\hline Dibenz $[a, h]$ anthracene & 424 & 614 & 145 & 26.2 \\
\hline Fluoranthene & 8,920 & 7,290 & 81.7 & 6.30 \\
\hline Indeno $[1,2,3-c d]$ pyrene & 2,780 & 2,440 & 87.9 & 6.48 \\
\hline Naphthalene & 1,650 & 830 & 49.8 & 10.3 \\
\hline Perylene & 1,170 & 697 & 59.6 & 6.64 \\
\hline Phenanthrene & 5,270 & 4,160 & 78.9 & 6.00 \\
\hline Pyrene & 9,700 & 7,070 & 72.9 & 6.29 \\
\hline
\end{tabular}

Table 22 lists mean concentrations of alkylated PAH homolog groups present, but which are not reported in the SRM certification documents supplied with SRM 1944. The RSDs are all less than 17.7 percent, thereby showing good agreement between measurements. Many of the alkylated PAH homolog groups were not present.

CRM 354-CRM 354 is a reference material certified through Environmental Resources Associates in Denver, Colorado. Its soil characterization contained about 91.4 percent sand, 4.4 percent silt, and 4.3 percent clay.

A certified SRM/CRM sample was prepared and analyzed with each set of environmental samples. Results for Certified Reference Material (CRM) 354 analyzed are listed in table 23 for 2001 . It can be seen that, with the exception of anthracene, all results fell within the acceptance limits of the CRM. Mean recovered anthracene concentrations were slightly higher than the range of acceptance limits, which are statistically derived. Given that the spiked concentration of anthracene is more than three times the high limit of acceptance, this result suggests that for anthracene, this method performs better than the method or methods used to determine acceptance limits for the CRM. The mean PAH concentrations measured in the CRM by this method were greater than the midpoint of the acceptance limits.

\section{Comparing selected-ion monitoring (SIM) and} full-scan ion monitoring (FS) acquisition using the F-test-Until recently (2002), achieving a $5-\mu \mathrm{g} / \mathrm{kg}$ laboratory reporting level was possible only under SIM conditions. Improvements in GC/MS instrumentation, such as the Agilent Technologies 5973 MSD, can provide comparable reporting levels between SIM ard FS.

Lower method detection levels by about a factor of two can be achieved using SIM analysis (table 16) as opposed to full-scan monitoring (table 7). SIM scans on average only 20 to 30 ions during a specified time interval. It can eliminate or reduce many background interferences because many interfering ions are not monitored. Conversely, potential interferences might be missed that contribute to false positive identification.

There are benefits when using full-scan data acquisition. First, there is greater confidence in the qualitative identification of compounds because the mass spectrometer scans across the range of 45 to 450 atomic mass units (amu), which results in more spectral information than the few ions monitored uncer SIM conditions. Because of the greater number of ions monitored for each compound, there is greater confidence in compound identification. In this method with the lack of standard material for many of the isomers in the alkylated PAH homolog groups, the additioral detection of fragment ions results in greater confidencs in their detection. Secondly, FS data allow for investigation 
Table 22. Alkylated polycyclic aromatic hydrocarbon homolog groups detected in Standard Reference Material 1944 not reported b' the National Institute of Standards and Technology and determined using selective-ion monitoring.

$[\mu \mathrm{g} / \mathrm{kg}$, micrograms per kilogram; NR, not reported; -, no data; number of analyses $=7]$

\begin{tabular}{|c|c|c|c|}
\hline Compound & $\begin{array}{c}\text { Measured } \\
\text { mean concentration } \\
(\mu \mathrm{g} / \mathrm{kg})\end{array}$ & $\begin{array}{c}\text { Standard deviation } \\
(\mu \mathrm{g} / \mathrm{kg})\end{array}$ & $\begin{array}{l}\text { Relative standard } \\
\text { deviation (percent) }\end{array}$ \\
\hline $\mathrm{C}_{1}$-alkylated naphthalene & 1,300 & 130 & 10.0 \\
\hline $\mathrm{C}_{2}$-alkylated naphthalene & 2,780 & 299 & 10.7 \\
\hline$C_{3}$-alkylated naphthalene & 7,111 & 754 & 10.6 \\
\hline $\mathrm{C}_{4}$-alkylated naphthalene & 4,790 & 670 & 14.0 \\
\hline $\mathrm{C}_{5}$-alkylated naphthalene & $\mathrm{NR}$ & - & - \\
\hline $\mathrm{C}_{1}$-alkylated phenanthrene/anthracene & 8,220 & 506 & 6.15 \\
\hline $\mathrm{C}_{2}$-alkylated phenanthrene/anthracene & 7,260 & 595 & 8.19 \\
\hline $\mathrm{C}_{3}$-alkylated phenanthrene/anthracene & 5,104 & 423 & 8.29 \\
\hline $\mathrm{C}_{4}$-alkylated phenanthrene/anthracene & 1,100 & 194 & 17.7 \\
\hline $\mathrm{C}_{5}$-alkylated phenanthrene/anthracene & NR & - & - \\
\hline $\mathrm{C}_{1}$-alkylated fluoranthene/pyrene & 9.350 & 766 & 8.20 \\
\hline $\mathrm{C}_{2}$-alkylated fluoranthene/pyrene & 3,400 & 369 & 10.9 \\
\hline$C_{3}$-alkylated fluoranthene/pyrene & NR & - & - \\
\hline $\mathrm{C}_{4}$-alkylated fluoranthene/pyrene & NR & - & - \\
\hline $\mathrm{C}_{5}$-alkylated fluoranthene/pyrene & NR & - & - \\
\hline $\mathrm{C}_{1}$-alkylated benz $[a]$ anthracene/chrysene & 4,110 & 324 & 7.90 \\
\hline $\mathrm{C}_{2}$-alkylated benz $[a]$ anthracene/chrysene & 2,150 & 183 & 8.50 \\
\hline $\mathrm{C}_{3}$-alkylated benz $[a]$ anthracene/chrysene & NR & - & - \\
\hline $\mathrm{C}_{4}$-alkylated benz $[a]$ anthracene/chrysene & NR & - & - \\
\hline $\mathrm{C}_{5}$-alkylated benz $[a]$ anthracene/chrysene & NR & - & - \\
\hline $\mathrm{C}_{1}$-alkylated benzopyrene/perylene & 4,400 & 282 & 6.40 \\
\hline $\mathrm{C}_{2}$-alkylated benzopyrene/perylene & NR & - & - \\
\hline $\mathrm{C}_{3}$-alkylated benzopyrene/perylene & NR & - & - \\
\hline $\mathrm{C}_{4}$-alkylated benzopyrene/perylene & NR & - & - \\
\hline $\mathrm{C}_{5}$-alkylated benzopyrene/perylene & NR & - & - \\
\hline
\end{tabular}

Table 23. Polycyclic aromatic hydrocarbon concentrations detected in Certified Reference Material 354 using selected-ion monitoring for year 2001.

$[\mu \mathrm{g} / \mathrm{kg}$, micrograms per kilogram; number of analyses $=8]$

\begin{tabular}{|c|c|c|c|c|c|}
\hline Spike compound & $\begin{array}{l}\text { Concentration } \\
\text { spiked } \\
(\mu \mathrm{g} / \mathrm{kg})\end{array}$ & $\begin{array}{c}\text { Mean } \\
\text { concentration } \\
\text { recovered }(\mu \mathrm{g} / \mathrm{kg})\end{array}$ & $\begin{array}{c}\text { Performance } \\
\text { acceptance limits } \\
(\mu \mathrm{g} / \mathrm{kg})\end{array}$ & $\begin{array}{r}\text { Standard } \\
\text { deviation } \\
(\mu \mathrm{g} / \mathbf{k g})\end{array}$ & $\begin{array}{c}\text { Relative standard } \\
\text { deviation } \\
\text { (percent) }\end{array}$ \\
\hline Anthracene & 4,440 & 1,525 & $799-1,368$ & 156 & 10.20 \\
\hline Benzo $[k]$ fluoranthene & 5,170 & 3,690 & $2,171-4,601$ & 359 & 9.73 \\
\hline Chrysene & 1,660 & 1,284 & $681-1,494$ & 116 & 9.05 \\
\hline Fluoranthene & 11,500 & 8,061 & $3,795-10,350$ & 922 & 11.40 \\
\hline Naphthalene & 9,770 & 4,054 & $1,466-9,282$ & 816 & 20.10 \\
\hline Phenanthrene & 6,150 & 4,112 & $2,398-5,781$ & 493 & 12.00 \\
\hline Pyrene & 6,580 & 4,321 & $2,106-5,922$ & 375 & 8.68 \\
\hline
\end{tabular}


of compounds not specifically determined by the method (nonselected compounds). Nonselected compounds can be identified tentatively using computerized comparison of mass spectra with large reference mass-spectral libraries publicly available from USEPA or NIST. Such computerized nonselected searches can be a valuable tool in the search for potential emerging contaminants, a capability not possible with SIM data.

In general, SIM analysis relative to FS analysis provides lower (about 2 times) detection capability and improved quantitation at low concentrations. Because the calculation of the MDL is based on the method variability, the F-test was applied to determine whether there were statistically significant differences in the precision between SIM and FS acquisition (table 24). The data of sodium sulfate matrix spikes fortified at $12.0 \mu \mathrm{g} / \mathrm{kg}$ were used in a two-tailed F-test. The critical value of $F$, based on 6 degrees of freedom, is 5.820 at the 5-percent probability level (Miller and Miller, 1993).
At a 95-percent confidence level, the variances differ significantly for naphthalene, 2,6-dimethylnaphthalene, and $9 \mathrm{H}$-fluorene. In these three cases, the FS variance is larger than its SIM counterpart, demonstratirg higher variability in FS acquisition. The variability is greater in full-scan acquisition because of the greater background signal, lowering the signal-to-noise ratio and making data integration more difficult.

In FS and SIM, as the spike level increases $(24 \mu \mathrm{g} / \mathrm{kg})$ the response increases, thus resulting in a larger signal-to-noise ratio. Appropriate peak integration becomes more obvious and variations in peal integration are smaller, which improves precision. At higher spike levels, the integration of the peak has greater uniformity between SIM and FS. This results in generally lower percent relative standard deviations than at lower spike concentrations and greater variability.

Table 24. Statistics for selected-ion monitoring and full-scan acquisition data fortified at 12.0 micrograms per kilogram. Confidence interval $(P=0.05)$; F-test: 2-tailed, critical value $=5.820$

[Compounds designated with an $\left(^{*}\right)$ differ significantly between the two methods; SIM, selected-ion monitoring; number of analyses=7]

\begin{tabular}{|c|c|c|c|}
\hline Compound & Variance SIM & Variance full scan & F-test \\
\hline Naphthalene & 0.198 & 1.610 & $* 8.125$ \\
\hline 2-Ethylnaphthalene & .186 & .746 & 4.018 \\
\hline 2,6-Dimethylnaphthalene & .160 & .956 & *5.973 \\
\hline 1,6-Dimethylnaphthalene & .117 & .236 & 2.024 \\
\hline Acenaphthylene & .173 & .757 & 4.377 \\
\hline 1,2-Dimethylnaphthalene & .187 & .672 & 3.602 \\
\hline Acenapthene & .228 & .579 & 2.539 \\
\hline 2,3,6-Trimethylnaphthalene & .143 & .110 & 1.299 \\
\hline 9H-Fluorene & .193 & 1.146 & *5.941 \\
\hline 1-Methyl-9H-fluorene & .232 & .409 & 1.760 \\
\hline Phenanthrene & .368 & .886 & 2.408 \\
\hline Anthracene & .376 & .807 & 2.147 \\
\hline 2-Methylanthracene & .236 & .282 & 1.196 \\
\hline 4,5-Methylenephenanthrene & .203 & .739 & 3.643 \\
\hline 1-Methylphenanthrene & .240 & .426 & 1.779 \\
\hline Fluoranthene & .573 & .176 & 3.260 \\
\hline Pyrene & .289 & .767 & 2.652 \\
\hline 1-Methylpyrene & .266 & 1.383 & 5.195 \\
\hline Benz $[a]$ anthracene & .247 & .478 & 1.938 \\
\hline Chrysene & .329 & .288 & 1.142 \\
\hline Benzo $[b]$ fluoranthene & .337 & .263 & 1.281 \\
\hline Benzo $[k]$ fluoranthene & .476 & 1.036 & 2.178 \\
\hline Benzo[e]pyrene & .606 & .585 & 1.036 \\
\hline Benzo $[a]$ pyrene & .347 & .343 & 1.011 \\
\hline Perylene & .318 & .987 & 3.102 \\
\hline Indeno $[1,2,3-c d]$ pyrene & .917 & 1.473 & 1.607 \\
\hline Dibenz $[a, h]$ anthracene & .576 & .645 & 1.119 \\
\hline Benzo $[g, h, i]$ perylene & .631 & 1.100 & 1.742 \\
\hline
\end{tabular}




\section{Conclusions}

The custom method described in this attachment was originally implemented in 1996. It used the same methodology as the method in the body of this report except for two differences. The custom method used SIM data acquistion and included phenol, $p$-cresol, and coronene in its analyte list. Selected-ion monitoring originally was used to reach a $5-\mu \mathrm{g} / \mathrm{kg}$ reporting level. Full scan can now report at $10 \mu \mathrm{g} / \mathrm{kg}$ with the added benefits of greater confidence in detection of compounds and future analysis.

Performance data were presented for three spike levels in three different matrices. MDLs were calculated. Standard reference material and certified reference material data provided additional performance data for the polycyclic aromatic hydrocarbons and precision data for the alkylated PAH homolog groups. A statistical F-test was used to compare the precision between full-scan data acquisition and selected-ion monitoring data acquisition. Variation between the two types of analysis was not significantly different except for three compounds: naphthalene, 2,6-dimethylnaphthalene, and 9H-fluorene. 



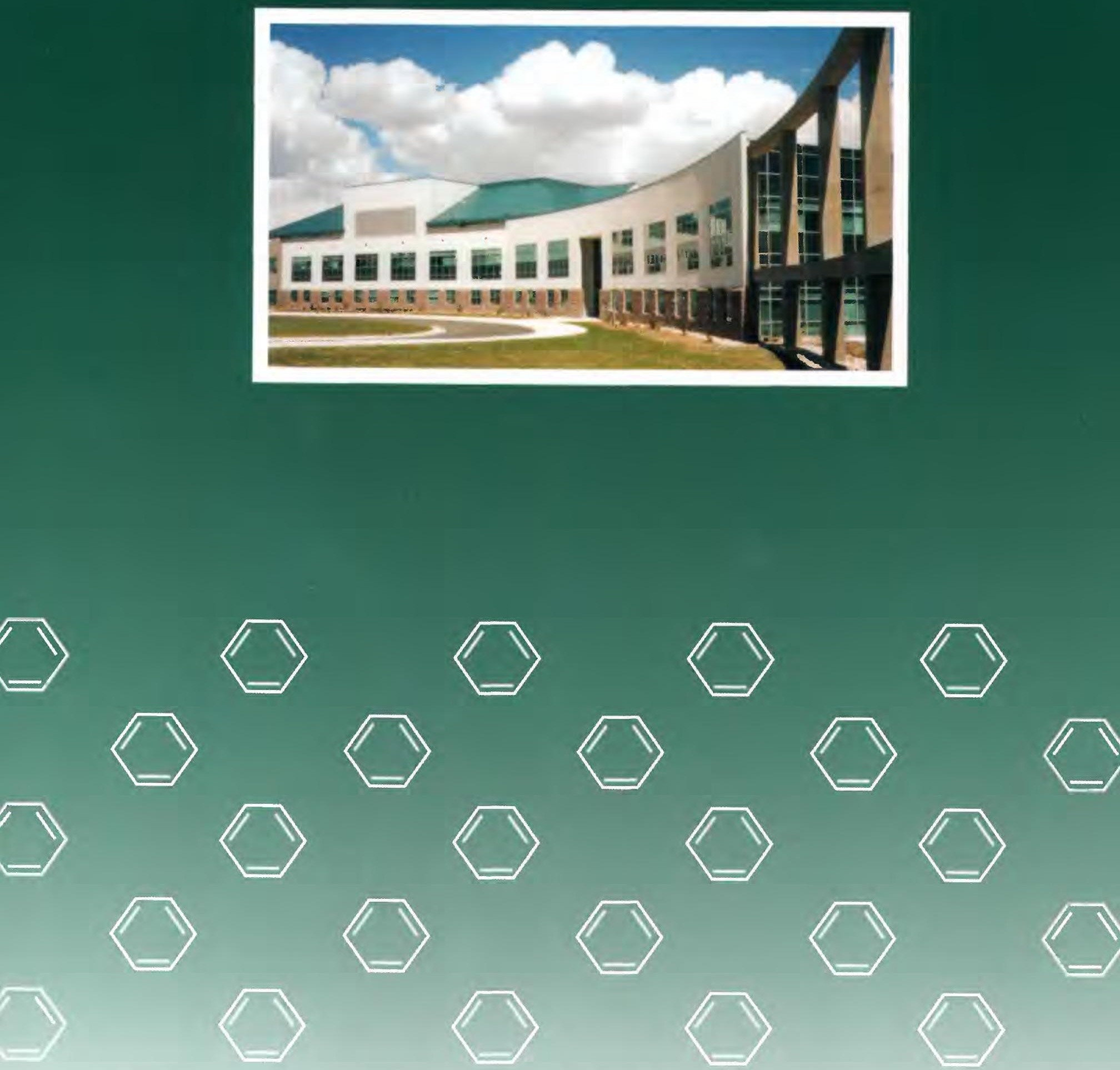

(8) Printed on recycled paper

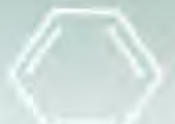

